NBSIR 75-910

\title{
The Role of Chemical Kinetics in Energy Conservation
}

H. M. Rosenstock

D. Garvin

J. T. Herron

W. Tsang

Institute for Materials Research

National Bureau of Standards

Washington, D. C. 20234

October 1975

Final

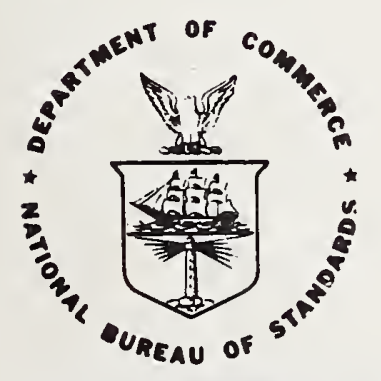

U S. DEPARTMENT OF COMMERCE

QC NATIONAL BUREAU OF STANDARDS

100

.456

$\# 75.910$

1975 


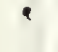


NBSIR 75.910

THE ROLE OF CHEMICAL KINETICS IN ENERGY CONSERVATION

H. M. Rosenstock

D. Garvin

J. T. Herron

W. Tsang

Institute for Materials Research

National Bureau of Standards

Washington, D. C. 20234

October 1975

Final

U.S. DEPARTMENT OF COMMERCE, Rogers C.B. Morton, Secretary James A. Baker, III, Under Secretary

Dr. Betsy Ancker-Johnson. Assistant Secretary for Science and Technology

NATIONAL BUREAU OF STANDARDS. Ernest Ambler, Acting Director 
i 
Executive Summary

Objectives of the Study

Findings

Recommendations

1. Combustion Modeling and Data Needs 1

1.1 Introduction 1

1.2 The Role of Modeling in this R\&D Area 3

1.3 Kinetics and Thermochemical Data Needs 4 References to Section $1 \quad 8$

2. What is Combustion? 9

2.1 The Hydrogen-Oxygen Flame 9

2.2 The Methane Oxygen Flame 10

2.3 A General Combustion Scheme 14

2.4 Relation to Industrial Processes 19

References to Section 2

3. Pyrolysis and Hydrogen Atom Chemistry 21

3.1 Mechanism 21

3.2 State of the Rate Data 23

References of Section $3 \quad 28$

4. Oxidation Processes 30

4.1 Reactions of Atomic Oxygen 30

4.2 Reactions of Hydroxyl Radicals 40

4.3 Reactions of Hydrocarbon Free Radicals with Atomic and Molecular Oxygen 40

References of Section 4

5. Pollutant-Forming Reactions 50

5.1 Formation of Nitric Oxide in Combustion 50

5.2 Formation of Nitric Oxide from Fue1 Nitrogen 51

5.3 Formation of Oxides of Sulfur from Fuel

Sulfur 51

References to Section 5 
6. Resources for Combustion Kinetics Data Base:

Evaluated Data and Prediction Schemes 54

6.1 Introduction $\quad 54$

6.2 Major Data Compilations and Evaluations

Pertinent to Combustion Chemistry 56

6.3 The Prediction of Reaction Rate Data-General 57

6.4 Specific Methods for Estimating Rate Data 62

6.5 Evaluation of Experimental Rate Data for Use at High Temperatures 78

6.6 Summary 83

References to Section $6 \quad 84$

7. Recommendations for an Approach 90

7.1 Introduction $\quad 90$

7.2 Construction of a Combustion Kinetics Data Base $\quad 92$

7.3 Pyrolysis and Hydrogen Atom Chemistry 95

7.4 Oxidation Processes 103

7.5 Pollutant Forming Processes 110

7.6 Scale and Scope of the Recommended Program 110

Appendix - Organizations Carrying on Combustion Modeling

Attachments - 1. I. Glassman and W. A. Sirignano

"Summary Report of the Workshop on Energy

Related Combustion Research"

2. A. K. Oppenheim and F. J. Weinberg

"Combustion R\&D - Key to Our Energy Future" 


\section{OBJECTIVES}

Combustion is the primary means for transforming chemically stored energy into useful forms. A major part of a strategy for energy conservation is the improvement of performance of combustion based processes and devices. Present day advanced design techniques make major use of mathematical modeling of the devices and processes. These models require substantial amounts of chemical data as input. The use of these modeling techniques will play a major role in the R\&D process in the near future.

It is the purpose of this study to:

1. Define the needs for chemical data by the user community of equipment designers and chemical modelers, with special emphasis on chemical kinetics.

2. Assess the quality, completeness and usefulness of the existing body of chemical data pertinent to this user group.

3. Formulate a plan for developing a carefully evaluated, extensive, and consistent body of chemical kinetics data, i.e. a kinetics data base, that will provide input information appropriate to the needs of present-day and future combustion equipment and process modeling.

\section{FINDINGS}

\section{Modeling}

Mathematical modeling of various combustion processes and combustion devices is a very active field. Twenty-eight organizations have so far been identified that are active in this field. They include government, non-profit, academic and industrial laboratories. The systems modeled include flames, turbines, engines, rockets and chemical reactors.

\section{Data Needs}

Among the most important input data required for these models are information on the detailed chemical mechanisms and the rates of the individual molecular processes comprising the chemical mechanisms. The data required must be appropriate to the high temperatures generally encountered in these systems. The chemical kinetics data required can be categorized in four classes:
a. Pyrolytic processes
b. Hydrogen atom reactions
c. Oxidative processes
d. Pollutant-forming processes 
This body of kinetics data will be widely applicable to a diversity of specific models.

In addition to this chemical information, data are required on pertinent thermochemical and transport processes.

\section{State of the Present-Day Data Base}

Although many resources are available, there does not exist at present an adequate, publicly available data base for combustion modeling. Many of the existing data have not been compiled and evaluated. Most of the pertinent data is only valid for low temperature processes and cannot be simply extrapolated to the high temperature region of combustion processes. And, last, there are large gaps in the available information, particularly in the area of hydrogen atom reactions and hydroyl radical reactions.

\section{Improvement of the Data Base}

In the near future the quality of the present data base can be significantly improved by a systematic program of kinetics data compilation, evaluation and dissemination. However, numerous information gaps will remain.

In order to provide the substantial amount of additional needed information, an extensive experimental program must be undertaken as well. Experimental techniques are available for accurate measurement of all classes of reactions of importance here. One technique, the shock tube technique, is directly applicable to the temperature range of importance. Two other techniques, kinetics-mass spectrometry and flash-photolysis resonance fluorescence, require modification to carry out studies in the appropriate temperature range.

Numerous empirical and semi-empirical schemes are available for estimating rate constants for a number of the types of pertinent chemical reactions. The reliability of the schemes is often good enough to fill some of the gaps provisionally, and to serve as a screening tool for deciding which reactions must be accurately measured. The entire group of estimation schemes needs more careful evaluation and testing, using an appropriate data base.

\section{RECOMMENDATIONS}

It is recommended that a program be initiated, consisting of three paralle1 activities.

1. An activity of data compilation, estimation, evaluation and dissemination, leading to periodic publication of an improved data base.

2. An activity of accurate experimental measurement of mechanisms and rates of selected pyrolysis and hydrogen atom reactions. 
3. An activity of accurate experimental measurement of selected oxidation processes.

4. An activity of experimental measurements directed at elucidating the mechanisms and rates of formation of oxides of nitrogen and sulfur in combustion.

The data activity would ensure the effective utilization of all experimental data forthcoming from other laboratories.

The experimental activities would provide information not only for filling important gaps but also key information for improving the usefulness of selected estimation schemes, thus minimizing the need for additional measurements.

An effective level of effort for the above program would require 510 man years per year for a period of 3-5 years. 

The Role of Chemical Kinetics in

Energy Conservation

1. Combustion Modeling and Data Needs

$1.1 \quad$ Introduction

Many strategies and approaches to energy conservation have

been and are being developed. The approach proposed here is a program to systematically develop an accurate, comprehensive and consistent body

of kinetic and thermochemical data pertinent to the quantitative description, control, and engineering development of devices and processes based on the combustion and pyrolysis of fossil fuel.

This approach is based on the following premises:

(a) A significant energy saving will result from improvements in the efficiency of high temperature devices required for transportation and heating.

(b) The improvement in these devices and engineering development of alternative devices must be carried on in such a way as to meet present and future restrictions on pollutant emissions.

(c) It is likely that the restrictions on emissions will pose more and more acute problems as dirtier and more complex fuels are employed. In fact, the safe and efficient use of dirty fuels is largely equivalent in effect to energy conservation.

(d) The entire process of research and development in this area is becoming more and more strongly dependent on mathematical modeling of the complex physical and chemical phenomena occurring in these devices.

(e) There is, in consequence, an urgent need for an appropriate kinetics and thermochemistry data base to provide essential input information for these models. 
(f) This single body of data can serve simultaneously in support of a great variety of engineering developments and for similar developmental activities carried on in varfous establishments, such a single body of information will vastly improve the reliability and comparability of various modeling approaches.

1.1.1 Transportation and Heating

One of the major points of emphasis today is the effort to improve the fuel economy of automobiles while at the same time retaining performance and meeting pollutant emission restrictions. To this end, active research and development efforts are underway ranging from minor modifications of the existing engines to evaluation and development of other engine concepts including stratified charge, rotary engines, turbines, variable displacement, improved performance sensing and control, etc. An essential element in this $R$ and $D$ process is the measurement, quantitative description and control of the combustion process in such a manner as to meet most economically the sometimes conflicting requirements of efficiency, performance, emission control and noise (Oppenheim and Weinberg, 1974; Glassman and Sirignano, 1974). It has been pointed out that each one-percent increase in automobile engine combustion efficiency leads to an annual saving of about 14.5 million barrels of oil per year. An analogous problem area is the improvement of the efficiency of combustors such as are employed in furnaces, steam generators and heating systems. About $22 \%$ of the nation's energy consumption is for space heating, almost all of it supplied by gas and oil (Hottel and Howard, 1971). This class of devices is now being subjected to detailed mathematical analysis in which much of the same physical chemistry information is required (Palmer and Beer, 1974). 


\subsubsection{Future Emission Restrictions}

The continuation of restrictions on pollutant emissions is generally accepted. Details are given by Hottel and Howard (1971).

\subsubsection{Dirty Fuels}

One environmental problem caused by dirty fuels is $\mathrm{SO}_{2}$ pollution associated with use of high sulfur coal or petroleum products. A second is the generation of nitrogen oxide pollutants from combustion of organic nitrogen compounds which are very likely to be present in, for example, shale oil. In addition, there is presently a question concerning the formation of so-called "prompt nitrogen oxide" at unexpectedly early times in the combustion process. The mechanism of formation is sti11 not understood.

\subsection{The Role of Modeling in this $R$ and $D$ Area}

Mathematical modeling is not new. It is one and the same as the quantitative considerations that have been employed by process designers and design engineers for decades. The thing that is new is that mathematical and computer capabilities have reached a stage of development such that real processes and real systems are now beginning to be quantitatively described in terms of the real physical and chemical processes that are going on (Cornelius and Agnew, 1972). It is now possible to describe or simulate real systems with a degree of faithfulness that makes these models an essential complement to, and to an ever increasing extent, a substitute for costly experimental pilot studies. Simply stated, modeling is not a curlosity. It is a very cost effective tool. Examples of real systems which are being modeled include chemical reactors, jet engines, stratified charge engines, combustors, flames, 
etc. (Spalding, 1972; Me1lor, 1972; Edelman, Fortune and Weilerstein, 1972). Modeling studies are being carried out in many organizations in the private sector, in the public sector, and in universities. In the universities the work is often done in engineering departments.

A partial list of organizations carrying out modeling activities pertinent to this energy utilization problem is given in the appendix. 1.3 Kinetics and Thermochemical Data Needs

Any meaningful model of a reacting chemical system must incorporate appropriate kinetic and thermochemical data for the species and reactions, and, in addition, the transport properties of the species, a description of the flow conditions and flow flelds, and a statement of the boundary conditions. Considerable advances have been made in the computer solution of realistic flow problems of at least a prototype character, and data and estimation schemes exist for pertinent transport properties. We turn now to the chemistry.

Many models of combustion processes treat the multiplicity of detailed chemical events in a global phenomenological fashion. This is partly a matter of computational convenience and partly a matter of ignorance. The detailed mechanism of, say, isooctane combustion is not yet known. Even the oxidation mechanism of methane to $\mathrm{CO}_{2}$ and $\mathrm{H}_{2} \mathrm{O}$ is not fully worked out. Reaction schemes including up to several dozen steps have been proposed and utilized with varying degrees of success. The point we wish to make is that for any carbon-containing combustion system from methane on up the detailed sequences and loops of reactions remain to be firmly established. The apparent complexity 
of this situation need not, however, lead to grim pessissism for the following reasons. When viewed at the level of the elementary processes, many combustion situations involving a diversity of hydrocarbon fuels will proceed in large part through the same set of chemical reactions. Information on mechanisms, energetics and rates of elementary processes will have a transfer value to many combustion situations, and the same information is completely applicable to the elucidation of the mechanistic schemes as well. It is thus to be expected that the value and range of applicability of the elementary process information will increase rapidly with time. Lastly, the earlier sketch of modeling has been given in terms of description of engineering prototype systems. There is also a significant area of experimentation and modeling of semi-complex chemical reactors such as pyrolyzers and oxidizers. These devices are not intended to serve as engineering prototypes but rather as tools to develop phenomenological data. Here, too, the modeling of these semi-complex phenomena in terms of the actual chemical processes is essential in assessing the range of applicability of the phenomenological data to new engineering situations. In fact studies in this area will be essential to validating the correctness of the complex reaction schemes and the associated thermochemical and rate information.

It is evident from the above that the thermochemical and kinetics data needs cannot be completely specified at this time. The needs depend on the details of the exact mechanisms, and the elucidation of the exact mechanism is aided by the available data. We remark further that a mechanism states not only which reactions occur, but also which reactions do not occur and, in a more qualitative way, which reactions 
dominate the chemical picture and which are side issues. And the side issues assume a central importance when one is concerned with pollutant emissions.

As for the kinetics data, at this point we note that the classes of processes that must be considered include thermal decomposition reactions of fuel molecules and their reactive intermediate products, the reaction of all these with oxygen atoms and molecules and with hydrogen atoms and hydroxyl radicals. Also, in considering pollution aspects the rates of processes leading to the formation of oxides of nitrogen and sulfur will have to be considered.

We now turn to the thermochemical data. In order to describe the energy transport of the real (or semi-complex) system it is necessary to have available the enthalpies of the species involved. Since the unstable reactive intermediates are present only in small concentrations they affect this picture only through their reaction rates and mechanisms. However, the reactive species enthalpies and free energies are of crucial short term importance for the kinetics aspect of this problem.

As will be discussed below, the body of available reaction rate data is at present very incomplete both in regard to specific elementary processes and to applicable temperature range. Tables of reactive species enthalpies and free energies are very useful to establish rapidly preliminary estimates of specific reaction rates. They are also of considerable use in delineating the complex reaction schemes and providing some guidance as to which rates need more accurate experimental definition. Needless to say, they are also extremely useful in deciding which reaction rates are negligibly small, i.e. they serve a screening function. A second and important use of reactive species thermochemical 
data is to provide equilibrium constant data. These are used to compute rates of a particular reaction where only the rate of the reverse process is known. This is a frequent occurrence. Although the data are scattered and not fully evaluated there appears to be no urgent need for a comprehensive compilation at the moment. This situation may change in the future. In the following sections we will outline the current state of the information in these areas, along with an assessment of rate constant estimation schemes. Finally, we will outline the data, data estimation, measurement and measurement technique development needs appropriate to this problem area and suggest a possible program for meeting these needs. 
Cornelius, W., and Agnew, W. G., editors, "Emission From Cont1nuous Combustion Systems," (Plenum Press, 1972)

Edelman, R. B., Fortune, O., and Weilerstein, G., "Some Observations on Flows Described by Coupled Mixing and Kinetics," in "Emission From Continuous Combustion Systems," W. Cornelius and W. G. Agnew, editors (Plenum Press, 1972)

Glassman, I., and Sirignano, W. A., Summary Report of the Workshop on Energy-Related Basic Combustion Research," Rept. \#1177, Energy-Related General Research Office, Research Directorate, National Science Foundation, Guggenheim Labs., Dept. Aerospace and Mechanical Sciences, Princeton University, Princeton, NJ (1974)

Hotte1, H. C., and Howard, J. B., "New Energy Technology -Some Facts and Assessments," (MIT Press, 1971)

Melior, A. M., "Current Kinetic Modeling Techniques for Continuous Flow Combustors," in "Emission From Continuous Combustion Systems," W. Cornelius and W. G. Agnew, editors (Plenum Press, 1972)

Oppenheim, A. K., and Weinberg, F.J., "Combustion R \& D Key to Our Energy Future," Astronautics Aero. 12, 22 (1974)

Palmer, H. B., and Béer, J.M., "Combustion Technology: Some Modern Developments," (Academic Press, 1974)

Spalding, D. B., "Mathematical Models of Continuous Combustion," in "Emission From Continuous Combustion Systems,"

W. Cornelius and W. G. Agnew, editors (Plenum Press, 1972) 


\subsection{The Hydrogen-Oxygen Flame}

From the standpoint of generating usable thermal energy by means of oxidation of a fuel the very simplest example is the oxidation of hydrogen. There are fifteen elementary reactions which must be considered to account for the properties of the hydrogen-oxygen flame containing excess hydrogen. These are listed below along with their heats of reaction. When two moles of hydrogen react with one mole of oxygen to produce two moles of water, there are $485 \mathrm{~kJ} / \mathrm{mol}$ of energy released. The rate at which a flame will propagate is determined primarily by the rate at which this energy can be released. In a rich hydrogenoxygen flame the predominant radicals are hydrogen atoms. Reactions 1 , 2, and 3 are important radical generating steps. Although they do not release heat to the flame they provide a major channel for the consumption of hydrogen and oxygen. For an atmospheric pressure flame, the most important heat releasing reactions are 10 followed by 11,14 , and 15 . Even though 10 is a three-body combination reaction it is very fast simply because oxygen is at a much higher concentration throughout most of the flame zone than that of any other radical. While 11 and 14 , which rapidly consume the $\mathrm{HO}_{2}$ produced by 10 also generate radicals, reaction 15 removes radicals from the flame. The other important radical destroying reaction is 7 which also releases a large amount of energy. The key reactions in the system are therefore 1, 2, and 3, which produce radicals but which release little energy, reactions 10,11 , and 14 which also produce radicals but in addition release energy, and finally reactions 15 and 7 which release energy but destroy radicals. 


\begin{tabular}{|c|c|c|}
\hline 1. & $\mathrm{H}_{2}+\mathrm{OH}=\mathrm{H}_{2} \mathrm{O}+\mathrm{H}$ & $\begin{array}{l}\Delta \mathrm{H}(298 \mathrm{~K}) \\
-63 \mathrm{~kJ} / \mathrm{mol}\end{array}$ \\
\hline 2. & $\mathrm{H}+\mathrm{O}_{2}=\mathrm{OH}+\mathrm{O}$ & 71.0 \\
\hline 3. & $\mathrm{H}_{2}+\mathrm{O}=\mathrm{OH}+\mathrm{H}$ & 8.24 \\
\hline 4. & $\mathrm{H}_{2} \mathrm{O}+\mathrm{O}=\mathrm{OH}+\mathrm{OH}$ & 71.5 \\
\hline 5. & $\mathrm{H}+\mathrm{OH}+\mathrm{M}=\mathrm{H}_{2} \mathrm{O}+\mathrm{M}$ & -498 \\
\hline 6. & $0+0+M=O_{2}+M$ & -494 \\
\hline 7. & $\mathrm{H}+\mathrm{H}+\mathrm{M}=\mathrm{H}_{2}+\mathrm{M}$ & -435 \\
\hline 8. & $\mathrm{O}+\mathrm{H}+\mathrm{M}=\mathrm{OH}+\mathrm{M}$ & -427 \\
\hline 9. & $\mathrm{H}_{2}+\mathrm{O}_{2}=\mathrm{OH}+\mathrm{OH}$ & 79.1 \\
\hline 10 & $\mathrm{H}+\mathrm{O}_{2}+\mathrm{M}=\mathrm{HO}_{2}+\mathrm{M}$ & -197 \\
\hline 11. & $\mathrm{HO}_{2}+\mathrm{H}=\mathrm{OH}+\mathrm{OH}$ & -159 \\
\hline 12. & $\mathrm{HO}_{2}+\mathrm{O}=\mathrm{OH}+\mathrm{O}_{2}$ & -230 \\
\hline 13. & $\mathrm{HO}_{2}+\mathrm{OH}=\mathrm{H}_{2} \mathrm{O}+\mathrm{O}_{2}$ & -301 \\
\hline 14. & $\mathrm{HO}_{2}+\mathrm{H}=\mathrm{H}_{2} \mathrm{C}+\mathrm{O}$ & -230 \\
\hline 15. & $\mathrm{HO}_{2}+\mathrm{H}=\mathrm{H}_{2}+\mathrm{O}_{2}$ & -238 \\
\hline
\end{tabular}

Using these it has been possible to model quantitatively this flame; to compute temperature profiles, radical concentration profiles, the energy flux, and the flame speed; and to gain an understanding of the key processes and cycles through which the flame may be inhibited.

\subsection{The Methane-Oxygen Flame}

The next most simple flame is the methane-oxygen flame. The following reactions are typical of the sets used in various models of this flame. From a chemical point of view it is highly unlikely that more than about one half of these are really significant in any given mode1. And it is probable that some other reactions will have to be added in order to arrive at a complete description of a specific combustion situation of this system. It should be noted that this set includes the reactions of the hydrogen-oxygen flame. 

1. $\mathrm{CH}+\mathrm{CHO} \rightarrow \mathrm{CH}_{2}+\mathrm{CO}$
2. $\mathrm{CH}+\mathrm{CH}_{2} \mathrm{O} \rightarrow \mathrm{CH}_{2}+\mathrm{CHO}$
3. $\mathrm{CH}+\mathrm{CH}_{3} \rightarrow \mathrm{CH}_{2}+\mathrm{CH}_{2}$
4. $\mathrm{CH}+\mathrm{CH}_{4} \rightarrow \mathrm{CH}_{2}+\mathrm{CH}_{3}$
5. $\mathrm{CH}+\mathrm{CO}_{2} \rightarrow \mathrm{CHO}+\mathrm{CO}$
6. $\mathrm{CH}+\mathrm{H}+\mathrm{M} \rightleftarrows \mathrm{CH}_{2}+\mathrm{M}$
7. $\mathrm{CH}+\mathrm{OH} \rightarrow \mathrm{CHO}+\mathrm{H}$
8. $\mathrm{CH}+\mathrm{OH} \rightarrow \mathrm{CH}_{2}+\mathrm{O}$
9. $\mathrm{CH}+\mathrm{OH} \rightarrow \mathrm{CO}+\mathrm{H}_{2}$
10. $\mathrm{CH}+\mathrm{HO}_{2} \rightarrow \mathrm{CHO}+\mathrm{OH}$
11. $\mathrm{CH}+\mathrm{HO}_{2} \rightarrow \mathrm{CH}_{2}+\mathrm{O}_{2}$
12. $\mathrm{CH}+\mathrm{H}_{2} \rightarrow \mathrm{CH}_{2}+\mathrm{H}$
13. $\mathrm{CH}+\mathrm{H}_{2} \mathrm{O} \rightarrow \mathrm{CH}_{2}+\mathrm{OH}$
14. $\mathrm{CH}+\mathrm{O} \rightarrow \mathrm{CO}+\mathrm{H}$
15. $\mathrm{CH}+\mathrm{O}+\mathrm{M} \rightarrow \mathrm{CHO}+\mathrm{M}$
16. $\mathrm{CH}+\mathrm{O}_{2} \rightarrow \mathrm{CHO}+\mathrm{O}$
17. $\mathrm{CH}+\mathrm{O}_{2} \rightarrow \mathrm{CO}+\mathrm{OH}$
18. $\mathrm{CHO}+\mathrm{M} \rightarrow \mathrm{CO}+\mathrm{H}+\mathrm{M}$
19. $\mathrm{CHO}+\mathrm{CHO} \rightarrow \mathrm{CH}_{2} \mathrm{O}+\mathrm{CO}$
20. $\mathrm{CHO}+\mathrm{CH}_{2} \rightarrow \mathrm{CH}_{3}+\mathrm{CO}$
21. $\mathrm{CHO}+\mathrm{CH}_{3} \rightarrow \mathrm{CH}_{2}+\mathrm{CH}_{2} \mathrm{O}$
22. $\mathrm{CHO}+\mathrm{CH}_{3} \rightarrow \mathrm{CH}_{4}+\mathrm{CO}$
23. $\mathrm{CHO}+\mathrm{CH}_{4} \rightarrow \mathrm{CH}_{2} \mathrm{O}+\mathrm{CH}_{3}$ 
24. $\mathrm{CHO}+\mathrm{H} \rightarrow \mathrm{CH}_{2}+\mathrm{O}$

25. $\mathrm{CHO}+\mathrm{H}+\mathrm{M} \rightarrow \mathrm{CH}_{2} \mathrm{O}+\mathrm{M}$

26. $\mathrm{CHO}+\mathrm{H} \rightarrow \mathrm{CO}+\mathrm{H}_{2}$

27. $\mathrm{CHO}+\mathrm{OH} \rightarrow \mathrm{CH}_{2} \mathrm{O}+\mathrm{O}$

28. $\mathrm{CHO}+\mathrm{OH} \rightarrow \mathrm{CO}+\mathrm{H}_{2} \mathrm{O}$

29. $\mathrm{CHO}+\mathrm{H}_{2} \rightarrow \mathrm{CH}_{2} \mathrm{O}+\mathrm{H}$

30. $\mathrm{CHO}+\mathrm{H}_{2} \mathrm{O} \rightarrow \mathrm{CH}_{2} \mathrm{O}+\mathrm{OH}$

31. $\mathrm{CHO}+\mathrm{O} \rightarrow \mathrm{CO}+\mathrm{OH}$

32. $\mathrm{CH}_{2}+\mathrm{CH}_{4} \rightarrow \mathrm{CH}_{3}+\mathrm{CH}_{3}$

33. $\mathrm{CH}_{2}+\mathrm{OH} \rightarrow \mathrm{CH}_{3}+\mathrm{O}$

34. $\mathrm{CH}_{2}+\mathrm{H}_{2} \rightarrow \mathrm{CH}_{3}+\mathrm{H}$

35. $\mathrm{CH}_{2}+\mathrm{H}_{2} \mathrm{O} \rightarrow \mathrm{CH}_{3}+\mathrm{OH}$

36. $\mathrm{CH}_{2}+\mathrm{O}_{2} \rightarrow \mathrm{CH}_{2} \mathrm{O}+\mathrm{O}$

37. $\mathrm{CH}_{2} \mathrm{O}+\mathrm{H} \rightarrow \mathrm{CH}_{3}+\mathrm{O}$

38. $\mathrm{CH}_{2} \mathrm{O}+\mathrm{H}+\mathrm{M} \rightarrow \mathrm{CH}_{3} \mathrm{O}+\mathrm{M}$

39. $\mathrm{CH}_{2} \mathrm{O}+\mathrm{OH} \rightarrow \mathrm{CH}_{3}+\mathrm{O}_{2}$

40. $\mathrm{CH}_{3}+\mathrm{H}+\mathrm{M} \rightarrow \mathrm{CH}_{4}+\mathrm{M}$

41. $\mathrm{CH}_{3}+\mathrm{OH} \rightarrow \mathrm{CH}_{4}+\mathrm{O}$

42. $\mathrm{CH}_{3}+\mathrm{HO}_{2} \rightarrow \mathrm{CH}_{4}+\mathrm{O}_{2}$

43. $\mathrm{CH}_{3}+\mathrm{H}_{2} \rightarrow \mathrm{CH}_{4}+\mathrm{H}$

44. $\mathrm{CH}_{3}+\mathrm{H}_{2} \mathrm{O} \rightarrow \mathrm{CH}_{4}+\mathrm{OH}$

45. $\mathrm{CH}_{3}+\mathrm{O}_{2} \rightarrow \mathrm{CH}_{3} \mathrm{O}+\mathrm{O}$

46. $\mathrm{CH}_{4}+\mathrm{OH} \rightarrow \mathrm{CH}_{3}+\mathrm{H}_{2} \mathrm{O}$

47. $\mathrm{CH}_{4}+\mathrm{O} \rightarrow \mathrm{CH}_{3}+\mathrm{OH}$

48. $\mathrm{CH}_{4}+\mathrm{H} \rightarrow \mathrm{CH}_{3}+\mathrm{H}_{2}$

49. $\mathrm{CH}_{4}+\mathrm{HO}_{2} \rightarrow \mathrm{CH}_{3}+\mathrm{H}_{2} \mathrm{O}_{2}$

50. $\mathrm{CH}_{4}+\mathrm{O}_{2} \rightarrow \mathrm{CH}_{3}+\mathrm{HO}_{2}$ 
51. $\mathrm{CO}+\mathrm{OH} \rightarrow \mathrm{CO}_{2}+\mathrm{H}$

52. $\mathrm{CO}+\mathrm{HO}_{2} \rightarrow \mathrm{CO}_{2}+\mathrm{OH}$

53. $\mathrm{CO}+\mathrm{H}_{2} \mathrm{O} \rightarrow \mathrm{CO}_{2}+\mathrm{H}_{2}$

54. $\mathrm{CO}+\mathrm{O}+\mathrm{M} \rightarrow \mathrm{CO}_{2}+\mathrm{M}$

55. $\mathrm{CO}+\mathrm{O}_{2} \rightarrow \mathrm{CO}_{2}+\mathrm{O}$

56. $\mathrm{H}+\mathrm{H}+\mathrm{M} \rightarrow \mathrm{H}_{2}+\mathrm{M}$

57. $\mathrm{H}+\mathrm{OH} \rightarrow \mathrm{H}_{2}+\mathrm{O}$

58. $\mathrm{OH}+\mathrm{H}+\mathrm{M} \rightarrow \mathrm{H}_{2} \mathrm{O}+\mathrm{M}$

59. $\mathrm{H}+\mathrm{HO}_{2} \rightarrow \mathrm{OH}+\mathrm{OH}$

60. $\mathrm{H}+\mathrm{HO}_{2} \rightarrow \mathrm{H}_{2}+\mathrm{O}_{2}$

61. $\mathrm{H}+\mathrm{HO}_{2} \rightarrow \mathrm{H}_{2} \mathrm{O}+\mathrm{O}$

62. $\mathrm{H}+\mathrm{H}_{2} \mathrm{O} \rightarrow \mathrm{OH}+\mathrm{H}_{2}$

63. $\mathrm{H}+\mathrm{O}+\mathrm{M} \rightarrow \mathrm{OH}+\mathrm{M}$

64. $\mathrm{H}+\mathrm{O}_{2} \rightarrow \mathrm{OH}+\mathrm{O}$

65. $\mathrm{H}+\mathrm{O}_{2}+\mathrm{M} \rightarrow \mathrm{HO}_{2}+\mathrm{M}$

66. $\mathrm{OH}+\mathrm{OH} \rightarrow \mathrm{H}_{2}+\mathrm{O}_{2}$

67. $\mathrm{OH}+\mathrm{OH} \rightarrow \mathrm{H}_{2} \mathrm{O}+\mathrm{O}$

68. $\mathrm{OH}+\mathrm{HO}_{2} \rightarrow \mathrm{H}_{2} \mathrm{O}+\mathrm{O}_{2}$

69. $\mathrm{OH}+\mathrm{O}+\mathrm{M} \rightarrow \mathrm{HO}_{2}+\mathrm{M}$

70. $\mathrm{OH}+\mathrm{O}_{2} \rightarrow \mathrm{HO}_{2}+\mathrm{O}$

71. $\mathrm{O}+\mathrm{O}+\mathrm{M} \rightarrow \mathrm{O}_{2}+\mathrm{M}$

72. $\mathrm{H}_{2}+\mathrm{OH} \rightarrow \mathrm{H}_{2} \mathrm{O}+\mathrm{H}$

73. $\mathrm{H}_{2}+\mathrm{O} \rightarrow \mathrm{OH}+\mathrm{H}$

74. $\mathrm{H}_{2} \mathrm{O}+\mathrm{O} \rightarrow \mathrm{OH}+\mathrm{OH}$

75. $\mathrm{H}_{2}+\mathrm{O}_{2} \rightarrow \mathrm{OH}+\mathrm{OH}$

76. $\mathrm{HO}_{2}+\mathrm{O} \rightarrow \mathrm{OH}+\mathrm{O}_{2}$ 


\subsection{A General Combustion Scheme}

We arrive at a general scheme by noting that more complex

fuels introduce more thermal decomposition reactions and subsequent reactions of the radicals produced with the oxidizers. The scheme illustrated in figure 2.1 shows the chemistry leading to the formation of $\mathrm{CO}$. The cyclic nature of the combustion process should be noted. In particular, each cycle of the process has the effect of reducing the length of the hydrocarbon chain of the fuel molecule. Ultimately carbon monoxide is formed.

The great number of individual reactants has made necessary their grouping into four major categories, hydrocarbons hydrocarbon radicals, oxygenated organics and oxygenated organics radicals. Furthermore the even larger number of possible reaction paths dictates the consideration of classes of reactions. These include, abstraction, addition, decomposition, combination disproportionation and isomerization. We note that the necessity of considering reactant and reaction classes at this early stage of the discussion suggests that the only visible strategy at establishing the required data base must.follow the course of carrying out of a selected number of key experiments and then the development of correlational and prediction schemes so as to render such data applicable to all systems of interest. 
ABSTRACTION (1) (2)

Hydrocarbons

Oxygenated Organics

$$
+\left\{\begin{array}{l}
\mathrm{RO}_{2} \\
\mathrm{RO} \cdot \\
\mathrm{HO}_{2} \\
\mathrm{R} \cdot \\
\mathrm{OH}^{\circ} \\
\mathrm{O} \cdot \\
\mathrm{H} \cdot \\
\mathrm{O}_{2}
\end{array}\right\} \rightarrow\left\{\begin{array}{l}
\mathrm{RO}_{2} \mathrm{H} \\
\mathrm{ROH} \\
\mathrm{HO}_{2} \mathrm{H} \\
\mathrm{RH} \\
\mathrm{H}_{2} \mathrm{O} \\
\mathrm{OH} \\
\mathrm{H}_{2} \\
\mathrm{HO}_{2}
\end{array}\right\}+\text { radicals }
$$

ADDITION (1)

Hydrocarbons

(unsaturated)

$+\left\{\begin{array}{l}\mathrm{R} \cdot \\ \mathrm{H} \cdot\end{array}\right\} \rightarrow$

Hydrocarbon radicals

ADDITION (2)

Hydrocarbons

(unsaturated)

$+0 \cdot \rightarrow \quad$ epoxide

ADDITION (3) (4)

Hydrocarbons
(unsaturated)
$\begin{aligned} & \text { Oxygenated Organics } \\ & \text { (unsaturated) }\end{aligned}$




$$
\begin{aligned}
\mathrm{R}_{1} \cdot+\mathrm{R}_{2} \cdot \longrightarrow & \mathrm{R}_{1} \mathrm{R}_{2} \\
& \mathrm{R}_{1} \mathrm{H}+\text { olefin }
\end{aligned}
$$

Hydrocarbon

Radicals

COMBINATION AND DISPROPORTIONATION (2)

$$
\begin{aligned}
\mathrm{R}_{1}(0) \cdot+\mathrm{R}_{2} \cdot \longrightarrow & \mathrm{R}_{1}(0) \mathrm{R}_{2} \\
& \mathrm{R}_{1}(0) \mathrm{H}=\text { olefin } \\
& \mathrm{R}_{2} \mathrm{H}+\text { Unsaturated Oxygenated Hydrocarbon }
\end{aligned}
$$

Oxygenated Organic Radicals $\rightarrow$ Oxygenated Organics

Organic Radicals

Oxygenated Organics + Hydrocarbon

COMBINATION AND DISPROPORTIONATION (3)
$R_{1}(0) \cdot+R_{2}(0) \cdot$
$\rightarrow \quad R_{1}(0) R_{2}(0)$
$\mathrm{R}_{1}(0) H+$ Unsaturated Oxygenated Hydrocarbon
Oxygenated Organic Radicals $\rightarrow$ Oxygenated Organics

DECOMPOSITION (1)
$\mathrm{R}_{1} \mathrm{R}_{2}$
$\rightarrow \quad \mathrm{R}_{1} \cdot+\mathrm{R}_{2} \cdot$
Hydrocarbon
Hydrocarbon Radicals

DECOMPOSITION (2)

R. (Hydrocarbon Radical) $\rightarrow$ olefins + Hydrocarbon Radical 
DECOMPOSITION (3)
$\mathrm{R}_{1} \mathrm{R}_{2}(0)$
$\rightarrow \quad R_{1}+R_{2}(0)$.
$R_{1}(0) R_{2}(0)$
$\rightarrow \mathrm{R}_{1}(0) \cdot+\mathrm{R}_{2}(0) \cdot$

Oxygenated Organics

Hydrocarbon, Oxygenated Organic Radicals

DECOMPOSITION (4)

$R_{2}(0) \cdot$

Oxygenated Organic

Radicals $\rightarrow \quad \mathrm{R}_{1} \mathrm{R}_{2}(0)+\mathrm{R}_{3}$.

$\rightarrow$ Oxygenated Hydrocarbon + Organic Radical

$\mathrm{R}_{2}(0) \cdot+$ olefins

Oxygenated

Organic Radicals

\section{ISOMERIZATION (1) (2)}

$\mathrm{R} \cdot$

$R(0) \cdot$

Radicals
R.'

$\rightarrow$

$R(0) \cdot$

Radicals (from H-shift and cyclization)

MOLECULAR DECOMPOSITION

$\mathrm{R}_{1} \mathrm{R}_{2}$

$\rightarrow$ Unsaturate + Unsaturate

Unsaturated

Compound 
The discussion above has been given in terms of combustion

only. The data base as envisioned here is obviously applicable to a wide range of industrial pyrolytic processes. These processes are undergoing rapid development to adjust to new feedstock and product requirements imposed by our energy and petroleum situation. For example, total U.S. production of ethylene in 1974 was 23.6 billion pounds (Ponder, 1974). At a unit price of $7 \mathrm{c} / 1 \mathrm{~b}$., this is a contribution of $\$ 1.6$ billions to the U.S. economy. Furthermore the coproducts of the ethylene production process such as propylene and butadiene also make significant contributions. All these compounds are important feedstocks for the chemical industry. Their costs influence the costs of an enormous variety of consumer products.

Substantially all the ethylene and significant quantities of the propylene and butadiene are currently produced through the thermal decomposition of light paraffins (ethane, propane and butane) or naphtha (higher moleculer weight paraffins, including cyclic compounds and aromatics) (Woodhouse et al., 1974). However, the shortage of natural gas and uncertainty with respect to the availability of naphtha has led to the consideration or in some cases the use of heavier fractions such as gas oil or vacuum distillates. In addition, the general increase in the price of all feedstocks makes imperative the optimization of all such processes. Important constraints are thus set on the design and operation of these plants. It is true that the chemical industry does have a vast store of experience and empirical data which can be brought to bear on this problem. However, the availability of kinetic data for a realistic model should prove to be invaluable as a guide for the extension and application of the existing results. Two recent symposia of the American Chemical Society have addressed this general problem. 


\section{REFERENCES TO SECTION 2}

Ponder, T. C., "U.S. Olefins through 1980," Hydrocarbon Processing 53, 104 (1974)

Woodhouse, G., Samols, D., and Newman, J., "The Economics and Technology of Large Ethylene Projects," Chem. Engr. 81, 73 (1974) 


\section{Mechanism}

The pyrolytic decomposition of hydrocarbons proceed for the most part via formation of free radicals. (Leathard and Purnel1, 1970). There are a limited number of hydrocarbons which decompose via molecular mechanisms. In general these can be identified on the basis of a few simple rules. For the others it is possible to visualize the decomposition process in terms of the formation, decomposition, isomerization, transfer, addition and combination processes involving the approprlate free radicals.

(a) Formation of free radicals: (Kerr, 1973; O'Neal and Benson, 1973; Benson and O'Nea1, 1970; Leathard and Purne11, 1970; Frey and Walsh, 1969). The initiating reactions in the chain decomposition of hydrocarbons must involve bond breaking reactions. Carbon-carbon bond $\left(\mathrm{R}_{1} \mathrm{CH}_{2}-\mathrm{CH}_{2} \mathrm{R}_{2}\right)$ splits will in general be favored over carbonhydrogen $\left(\mathrm{R}_{1} \mathrm{R}_{2} \mathrm{R}_{3} \mathrm{C}-\mathrm{H}\right)$ cleavage. The most labile of the former are those joining radicals which possess some degree of resonance stabilization $\left(\mathrm{R}_{1} \mathrm{CH}=\mathrm{CHCH}_{2}-\mathrm{CH}_{2} \mathrm{R}_{2}\right)$. In a second category are the highly substituted paraffinic $\mathrm{C}-\mathrm{C}$ bonds, $\left(\mathrm{R}_{1} \mathrm{R}_{2} \mathrm{R}_{3} \mathrm{C}-\mathrm{CR}_{1} \mathrm{R}_{2} \mathrm{R}_{3}\right)$ followed by those without substitution. Similar considerations apply to carbon-hydrogen bonds. The strongest are the carbon-carbon bonds adjacent to multiple bonds $\left(\mathrm{R}_{1} \mathrm{CH}=\mathrm{CH}-\mathrm{R}_{2}\right)$ and the multiple bonds $\left(\mathrm{R}_{1} \mathrm{CH}=\mathrm{CHR}_{2}\right)$ themselves. These need be considered only in very high temperature situations.

\section{(b) Decomposition of free radica1s: (Kerr, 1973; Kerr and} Trotman-Dickinson, 1964; Kerr and Lloyd, 1968; Kerr and Parsonage, 1972). The hydrocarbon radicals created as a result of bond splits can also be classified in order of their thermal stability. Starting with the least stable, there are first those alkyl radicals with $\mathrm{C}-\mathrm{C}$ bonds 
once removed from the free electron $\left(\mathrm{R}_{1} \mathrm{CH}_{2}-\mathrm{CH}_{2} \mathrm{CH}_{2}{ }^{\circ}\right)$. Cleavage reactions of these $\mathrm{C}-\mathrm{C}$ bonds have very low activation energies. Molecules undergoing these reactions have lifetimes at $1000 \mathrm{~K}$ of $1 \mathrm{\mu sec}$ or less. Thus except at low temperatures or under conditions where concentrations of reactive species are unusually large this will be the main reaction path. In the cases where there is no $\mathrm{B} \mathrm{C}-\mathrm{C}$ bond $\left(\left(\mathrm{CH}_{3}\right)_{3} \mathrm{C}^{\cdot}\right)$ cleavage of the analogous $\mathrm{C}-\mathrm{H}$ bond can occur. Here activation energies are of the order of 40-60 $\mathrm{kJ} / \mathrm{mol}$ higher. Thus such radicals have longer lifetimes with regard to decomposition and a greater tendency to undergo other reactions. Resonance stabilized radicals are less labile. (Tsang, 1973) They are however, not particularly reactive except with respect to combination. This distinguishes them from small radicals such as $\mathrm{H}, \mathrm{CH}_{3}, \mathrm{CH}_{2}$, etc. which do not decompose but are also very reactive.

(c) Isomerization of free radicals: (Kerr, 1973; Leathard and Purne11, 1973). Large organic radicals isomerize by 1,4 and 1,5 hydrogen atom transfer $\left(\mathrm{RCHCH}_{2} \mathrm{CH}_{2} \mathrm{CH}_{3} \rightarrow \mathrm{RCH}_{2} \mathrm{CH}_{2} \mathrm{CH}_{2} \mathrm{CH}_{2} \cdot ; \mathrm{RCH}\left(\mathrm{CH}_{2}\right)_{3} \rightarrow\right.$ $\left.\mathrm{R}\left(\mathrm{CH}_{2}\right)_{4} \mathrm{CH}_{2}{ }^{\circ}\right)$. There have been reports of 1,2 and 1,3 hydrogen shifts, but it is suspected that these arise from misinterpretation of experimental data. Unsaturated radicals can also undergo cyclization reactions. As before preference appears to be for reaction paths which involve 5 or 6 membered cyclic transition states.

(d) Transfer and addition processes: (Kerr, 1973; Kerr and Parsonage, 1972; Trotman-Dickinson and Milne, 1967; Kerr and TrotmanDickinson, 1964). Free radicals can abstract hydrogen atoms from stable compounds or add to unsaturates. The general order of reactivity is $\mathrm{H}-$ atoms, alkyl radicals and resonance stabilized radicals. With respect to abstraction by methyl and ethyl at low temperatures, the relative rates are tert $-\mathrm{H}>\mathrm{sec}-\mathrm{H}>$ primary $-\mathrm{H}>$ methane. This is probably also the case for hydrogen-atoms. Hydrogen atom addition to unsaturates leads to vibrationally excited radicals. This means that at sufficiently 
low pressures the newly formed radicals will decompose at a rate faster than the thermal rate.

(e) Combination and disproportionation of radicals: (Kerr, 1973; O'Neal and Benson, 1973; Benson and O'Neal, 1970). These represent the termination steps in hydrocarbon decomposition. Rate constants are characteristically large. The most rapid are the reaction of $\mathrm{H}$ atoms with organic radicals. Radical-radical reactions are somewhat slower. Most recent studies suggest that highly substituted alkyl radicals may have rates of combination lower than hitherto expected. There are empirical correlations relating disproportionation and combination rates.

From the above discussion it is clear that we have a very good mechanistic picture of how large hydrocarbons decompose into smaller olefins. There remain however large gaps in our knowledge with respect to the formation of soot or carbon in these systems. That is, at some stage polymerization and dehydrogenation must occur. Unfortunately at the present time there is no convincing explanation for the processes which precipitate these reactions.

\subsection{State of the Rate Data}

3.2.1 Bond-Breaking Reactions: Work at NBS using a single-pulse shock tube technique has resulted in the collection of a large volume of data on these processes (Tsang, 1969, 1972). Furthermore correlations and extrapolation techniques have been developed and the results have been corroborated from independent studies. The overall situation is satisfactory. The required rate data exist or can be generated as the need arises. One area which does need some immediate attention is the rate and mechanism of decomposition of 5 and 6 membered cyclic alkanes. These are important components in naphtha and the higher boiling oils. It should be noted that these rate data are of broader significance 
than merely their immediate application to chain initiation. Thus if

the thermal properties of organic radicals are known, then an application of the principle of detailed balancing yields the appropriate rate of combination, i.e. chain termination. Furthermore the activation energy is directly relatable to the enthalpies of the radicals (Benson and O'Nea1, 1970; O'Neal and Benson, 1973). These form the basis for extrapolation and estimation schemes for the determination of the rates of a variety of other processes. There is a need for a general review of the subject. Earlier reviews are obsolete.

\subsubsection{Radical Decomposition: Practically all of the existing data} are from studies on alkyl radical decomposition (Kerr, 1973; Kerr and Trotman-Dickinson, 1964). The principal methods used to determine the rates for these processes are:

(1) Direct Studies: These yield thermal rates. Radicals are generated from the photolysis of a variety of precursors (aldehydes, ketones, azo compounds), from the photosensitized decomposition of paraffins, or from the radical sensitized decomposition of aldehydes and paraffins, and the rate of decomposition is compared with the rate of combination.

(2) Chemical Activation Studies: (Spicer and Rabinovitch, 1970). These yield lifetimes of vibrationally excited alkyl radicals. Aside from their own intrinsic importance rate parameters for the thermal reaction can be derived on the basis of the thermochemistry and calculations using the Rice-Ramsperger-Kassel-Marcus theory of unimolecular reactions.

(3) Detailed Balance: (Kerr and Parsonage, 1972). There exists a large volume of data on the addition of methyl radicals to olefins (see below). Combining this with the thermochemistry permits calculation of the decomposition rate. 
The overall quality of these data is uncertain since there appear to be considerable discrepancies. On the other hand at the higher temperatures this may be immaterial since rates must be extremely fast. What is needed is a set of very accurate numbers for the branching ratios in the cases where there are multiple reaction paths. Some of the data may be extractable from the chemical activation experiments. With regard to resonance stabilized radicals there is a single pulse shock tube study of the decomposition of isobutenyl radical (Tsang, 1973). This indicates that although it is more stable than alkyl radicals its rate of decomposition is appreciable at temperatures in excess of $1000 \mathrm{~K}$. Thus at high temperatures the rate of decomposition of such radicals must play an important role in the overall kinetics. Clearly there is a need for more data on such systems and for other unsaturated radicals such as those with the free electron adjacent to the multiple bonds.

3.2.3 Isomerization of Free Radicals: Data on such processes are limited and may not be of high accuracy. The methods used are similar to those described in Section 3.2.2. The overall rate is fast and it is suspected that the key factor is not the absolute rate but the competition between isomerization and decomposition. More data are needed.

3.2.4 Transfer and Addition Reactions: There exists a vast store of kinetic data on hydrogen atom transfer and addition reactions of methyl radicals with hydrocarbon molecules (Kerr, 1973). Data on other alkyl radicals are somewhat more limited but this may not be of serious consequence except at the lowest temperatures since their short lifetimes preclude their taking part in subsequent reactions. Practically all of these data are determined relative to the recombination rate. This is not a serious problem and in some cases may be an asset since in many physical situations this ratio is the important quantity. More serious is the fact that all of the data are taken at or close to room temperature. Thus for use at 
combustion or pyrolysis temperatures extensive extrapolations are required. In recent pyrolysis experiments $\left(\sim 800^{\circ} \mathrm{K}\right)$ (Leathard and Purnel1, 1970) activation energies for abstraction by methyl have turned out to be considerably higher than the low temperature (455 K) numbers. Straightforward Arrhenius extrapolation appears to be unjustified. With respect to $\mathrm{H}-$ atoms there are satisfactory numbers for $\mathrm{H}$ addition to unsaturated compounds at room temperature. For higher temperature the question of a proper extrapolation procedure becomes important again. With respect to abstraction there is a review of the data on $\mathrm{H}+\mathrm{CH}_{4}$ (Walker, 1968). For all other systems there is little worthwhile data. It is suspected that in any realistic model the relative rates of hydrogen atom reactions are of crucial importance. This is because they are very fast and the hydrogen atoms will not have an opportunity to recombine. Thus in a combustion system, for example, the choice is between $\mathrm{H}+\mathrm{O}_{2} \rightarrow \mathrm{HO}_{2}$ and $\mathrm{H}+\mathrm{O}_{2} \rightarrow \mathrm{OH}+\mathrm{O}$ (which ultimately produce water), or reaction with the hydrocarbon substrate leading to pyrolysis, or an endothermic reaction. 3.2.5 Combustion and Disproportionation Reactions: There are extensive measurements of methyl radical combination at room temperature. At the present time there is a spread of a factor of 2 in the available results (Kerr, 1973). The recent determinations are by kinetic spectroscopy (Bass and Laufer, 1973) while the earlier ones are by the rotating sector technique. The sector technique has also been used to measure the rate of combination of methyl, ethyl, isopropyl and t-butyl radicals (Kerr and Trotman-Dickinson, 1964). A11 investigations were carried out at room temperature. The measurements on the three large alkyl radicals all yielded numbers close to the collision rate. These numbers are now regarded with suspicion because rate constants calculated 
from those for bond breaking reactions of the appropriate alkane are on order of magnitude or more smaller (Tsang, 1969). This conclusion is supported by measurements on the rates of combination of these radicals as compared with those of methyl radicals (Hiatt and Benson, 1972). Nevertheless there remain many unexplained effects. The real need is for direct measurements of radical combination rates at a variety of temperatures.

The brief survey given above demonstrates that despite the gaps there is a considerable volume of data available for use. Unfortunately they have not been acquired with the present application in mind. In general there has been no attempt at acquiring data in a systematic manner; thus it is difficult to devise correlations or extrapolations. Particularly striking is the absence of high temperature data. However this is not due to any intrinsic problems with the measurement technique, and a systematic program for the accumulation of the needed data can be expected to yield all the desired results. 
Bass, A. M., and Laufer, A. H., "The Methyl Radical Combination Rate Constant as Determined by Kinetic Spectroscopy," Intern. J. Chem. Kinet. 5, 1053 (1973)

Benson, S. W., and O'Neal, H. E., "Kinetic Data on Gas Phase Unimolecular Reactions," U.S. National Bureau of Standards, NSRDS-NBS-21 (1970) U.S. Government Printing office, Washington, DC 20402

Frey, H. M., and Walsh, R. W., "The Thermal Unimolecular Reactions of Hydrocarbons," Chem. Reviews 69, 103 (1969)

Hiatt, R., and Benson, S. W., "Rate Constants for Alkyl Radical Recombination. I. Isopropyl Radicals," Intern. J. Chem. Kinet. 4 , 151 (1972)

Kerr, J.A., "Rate Processes in the Gas Phase," in "Free Radicals," J. Kochi, editor (John Wiley and Sons, New York, 1973) 1

Kerr, J.A., and Parsonage, M. J., "Evaluated Kinetic Data on Gas Phase Addition Reactions," (Butterworths, 1972)

Kerr, J.A., and Lloyd, A. C., "Decomposition Reaction of Radicals," Quaterly Review 22, 549 (1968)

Kerr, J.A., and Trotman-Dickenson, A. F., "The Reactions of Alkyl Radicals," in "Progress in Reaction Kinetics, Volume 1," (Pergamon Press, Oxford, 1964)

Leathard, D. A., and Purnell, J.H., "Paraffin Pyrolysis," Ann. Rev. Phys. Chem. 21, 197 (1970)

O'Neal, H. E., and Benson, S. W., "Thermochemistry of Free Radicals," in "Free Radicals," J. Kochi, editor, volume 2 (John Wiley and Sons, New York, 1973) 275

Spicer, L. D., and Rabinovitch, B. S., "Elementary Gas Reactions," Ann. Rev. Phys. Chem. 21, 197 (1970) 
Trotman-Dickenson, A. F., and Milne, G. S., "Tables of Gas

Phase BImolecular Reactions," U.S. National kureau of Standards

NSRDS-NBS-9) (1967) U.S. Government Printing; offlce,

Washington, DC 20402

Tsang, W., "Thermal Decomposition of 3,4-Dimethylpentene-1 2,2,3-Trimethylpentane, 3,3-Dimethylpentane and Isobutylbenzene in a Single Pulse Shock Tube," Intern. J. Chem. Kinet. I, 245 (1969)

Tsang, W., "Thermal Deocmposition of 3,4-Dimethylhexane, 2,2,3-Trimethylpentane-tert-Butylcyclohexane and Related Eydrocarbons," J. Phys. Chem. 16, 143 (1972)

Tsang, W., "Pyrolysis of 2,4-Dimethylhexene-l and the stability of Isobutenyl Radicals," Intern. J. Chem. Kinet. 5, 929 (1973)

Walker, R. W., "Activation Fnergies of the Reversible Reaction between Hydrogen Atoms and Methane t:o Give Hydrogen and Methyl Radicals," J. Chem. Soc., 2391 (1968) 
In the oxidation of hydrocarbons and their $0, N$, and $S$ derivatives the primary step is either direct attack by a free radical species or pyrolysis followed by subsequent reaction of primary products (stable or free radical in nature)

1. $\mathrm{RH}+\mathrm{O}, \mathrm{H}, \mathrm{OH}, \mathrm{HO}_{2},---\rightarrow \mathrm{R}+\mathrm{OH}, \mathrm{H}_{2}, \mathrm{H}_{2} \mathrm{O}, \mathrm{H}_{2} \mathrm{O}_{2},---$

2. $R H+M \rightarrow$ Radicals, olefins, ---, $+M$

3. $\mathrm{R}+\mathrm{O}_{2}, \mathrm{O}, \mathrm{OH},---\rightarrow$ Radicals, olefins, ---

This section is concerned with discrete elements of reactions (1) and (3). The class of reactions represented by (2) has been discussed in section 3.

4.1 Reactions of atomic oxygen

The reactions of atomic oxygen with hydrocarbons and their derivatives have been systematically studied at NBS over the past seven years, and a large body of rate data has been accumulated over the approximate range $250-650 \mathrm{~K}$. Reviews of the available rate data (Herron and Huie, 1973) and the general nature of the reactions have been given (Huie and Herron, 1975). Recommended values for rate constants are not given at temperatures greater than $1000 \mathrm{~K}$, since they are dependent on extrapolations of data from lower temperature measurements. Aside from the question of using these data for accurate modeling, it is doubtful in many cases if they are adequate even for the purpose of deciding which are the principal reaction paths.

In terms of high temperature rate measurements the data on $0+$ methane (a11 kinetic data and figures in this section are from Herron and Huie, 1973) shown in Figure 4.1, are the most extensive. The data 


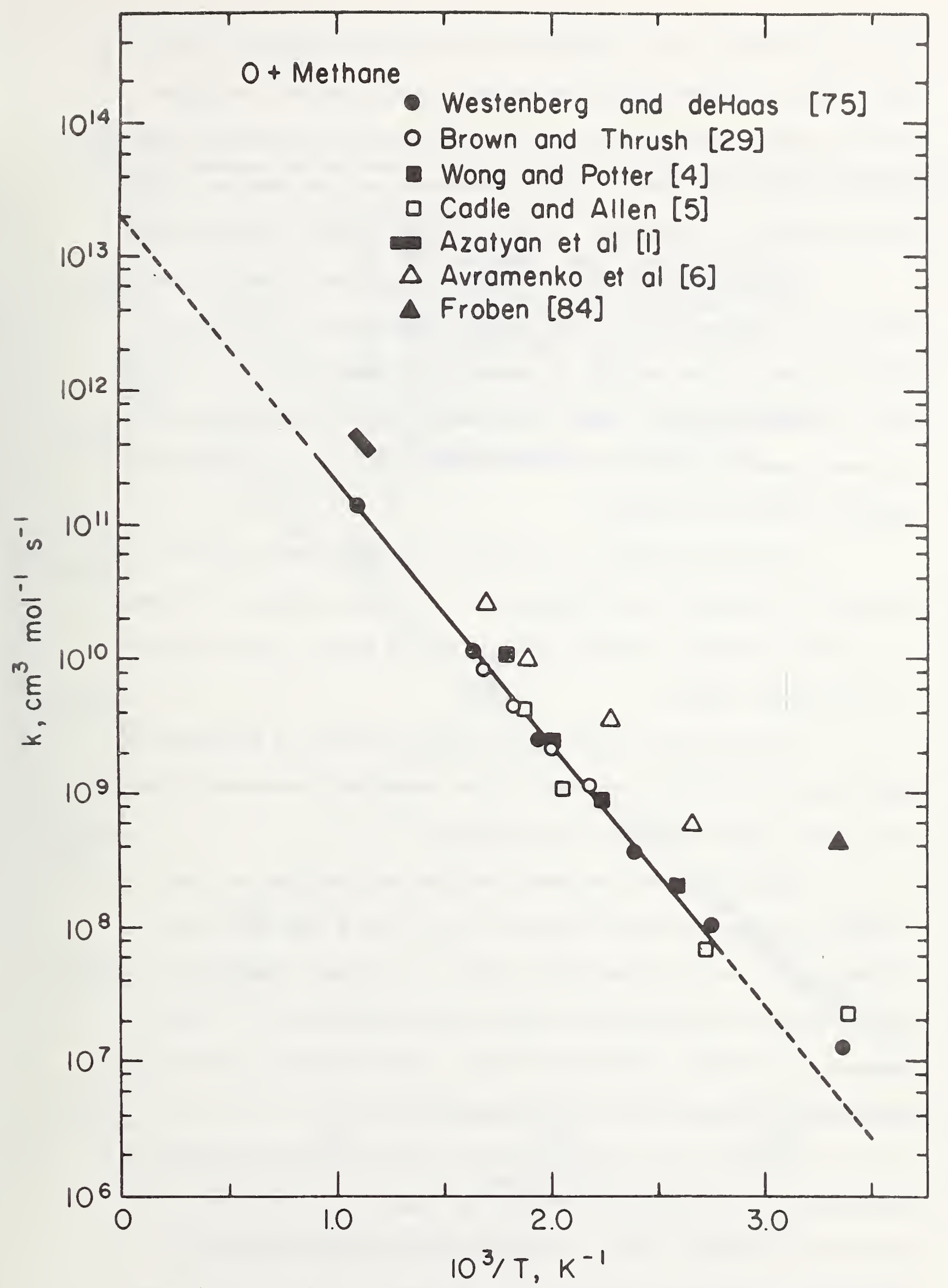

4.1 Arrhenius plot for the reaction of atomic oxygen with methane (Herron and Huie, 1973) 
look good and there is no indication of curvature. However, the best data in this plot (Westenberg and de Haas) were taken by a technique (electron spin resonance) that requires knowledge of the overall chemistry, and this introduces a note of real uncertainty into the meaning of the rate measurements. (See Herron, 1969, for a discussion of this problem.)

For ethane, illustrated in Figure 4.2 there is again a good linear fit, although in this case careful examination of the data of Westenberg and de Haas suggests a small degree of curvature. As in the case of the methane data, there is a question as to the meaning of the rate measurements. The flame data of Azatyan, et al. clearly suggest curvature starting near $1000 \mathrm{~K}$.

For larger alkanes, for example n-butane, shown in Figure 4.3, the data are scattered and extrapolation to higher temperatures becomes a very risky procedure. This is typical of the kind of data available for the larger alkanes.

In the course of the oxidation and pyrolysis of hydrocarbons significant quantities of olefins will be formed and subsequently react with atomic oxygen and other free radicals.

Figure 4.4 shows the data for ethylene. The very accurate resonance fluorescence data of Davis, et al. give a very good linear Arrhenius plot over the range 230 to $500 \mathrm{~K}$. At higher temperatures the available data strongly deviate from the extrapolation of the lower temperature resonance fluorescence data. There is no way of deciding if this effect is real or due to experimental error.

The plot of the 1-butene data, on the other hand, Figure 4.5 is clearly curved well below $1000 \mathrm{~K}$. The question, in this case, is whether the curvature is due to a change in mechanism (competition between abstraction and addition), to experimental error, or to a real temperature dependence of a specific reaction channel. 


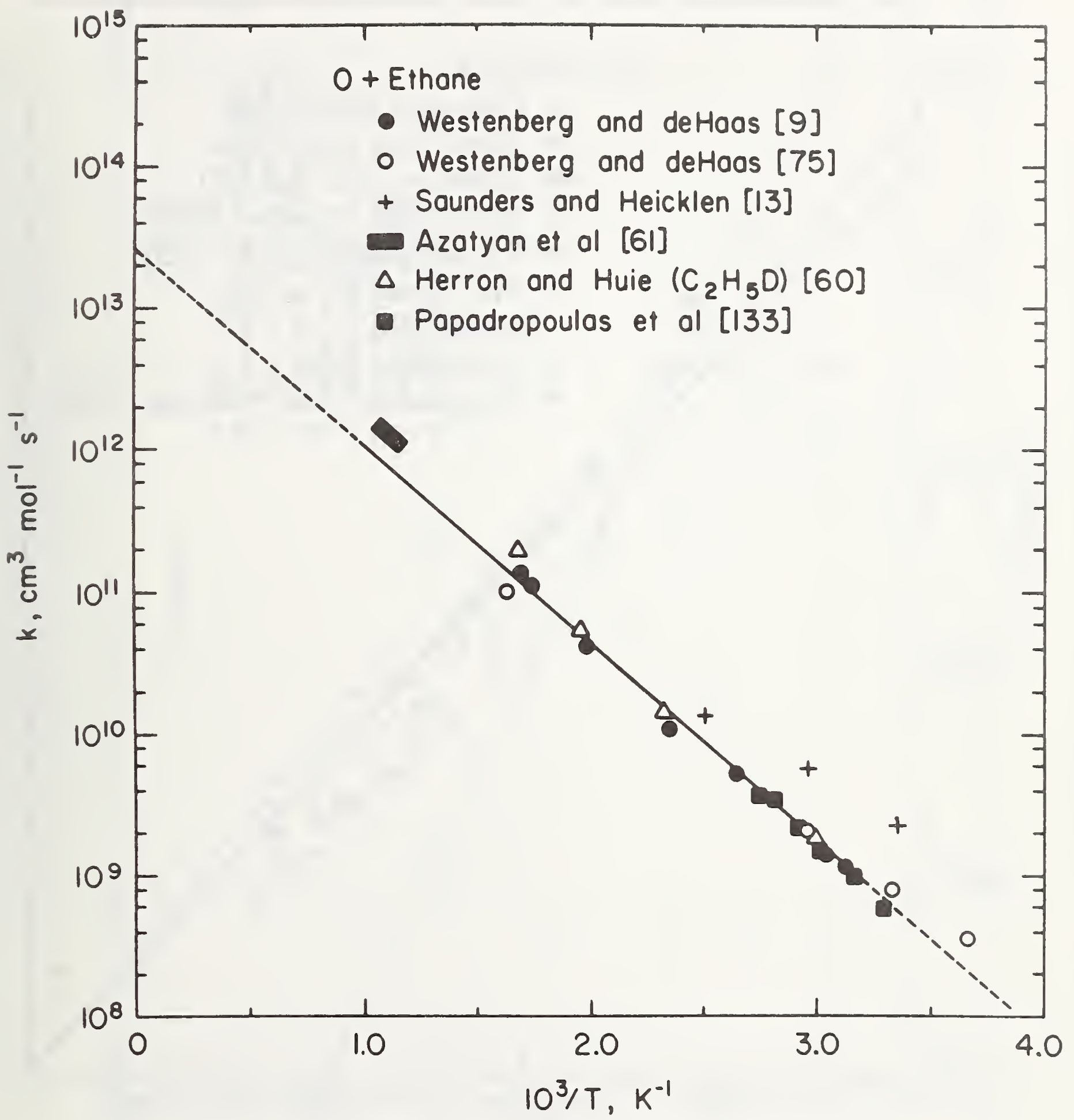

4.2 Arrhenius plot for the reaction of atomic oxygen with ethanr (Herron and Huie, 1973). 


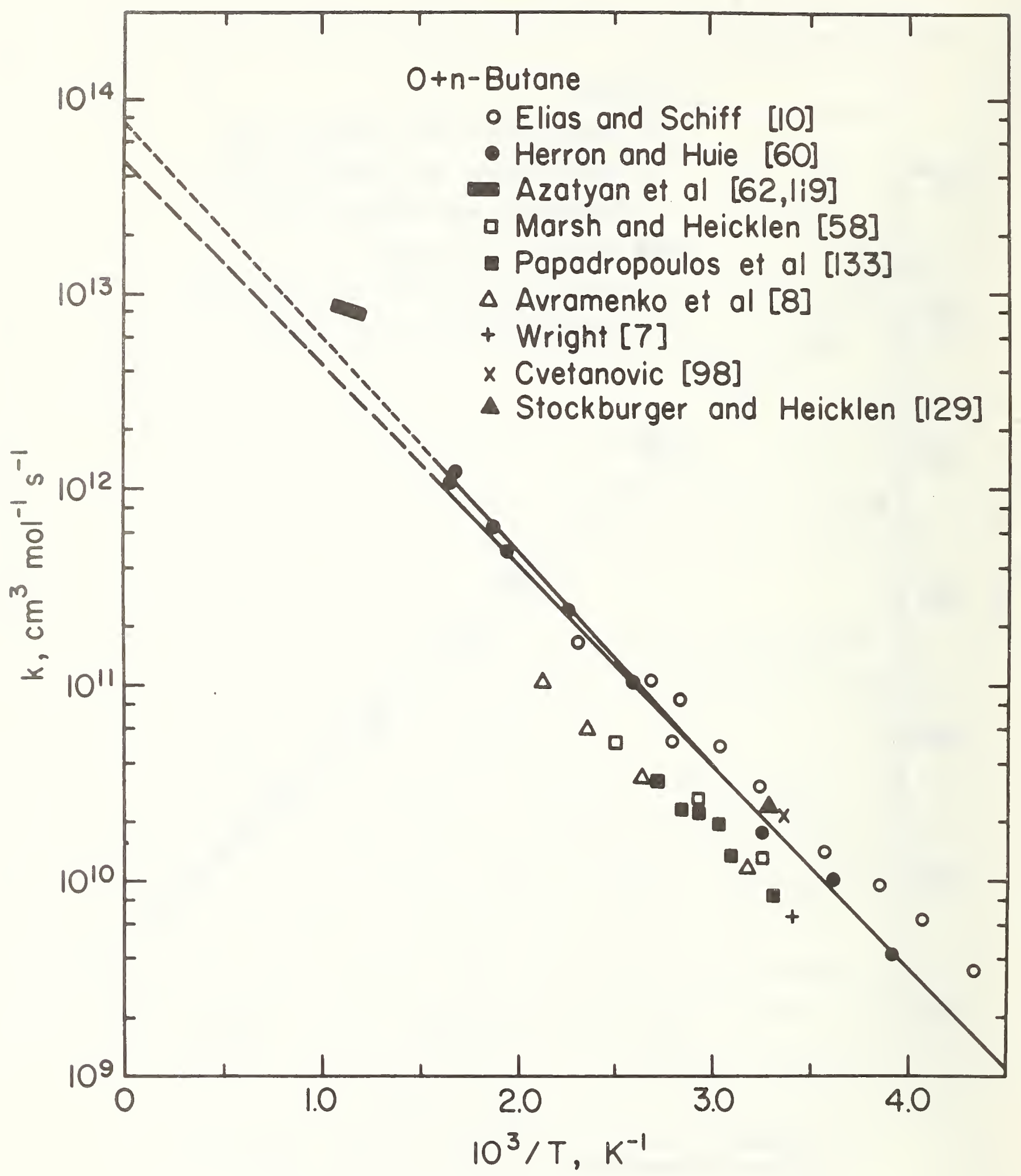

4.3 Arrhenius plot for the reactions of atomic oxygen with n-butane (Herron and Huie, 1973). 


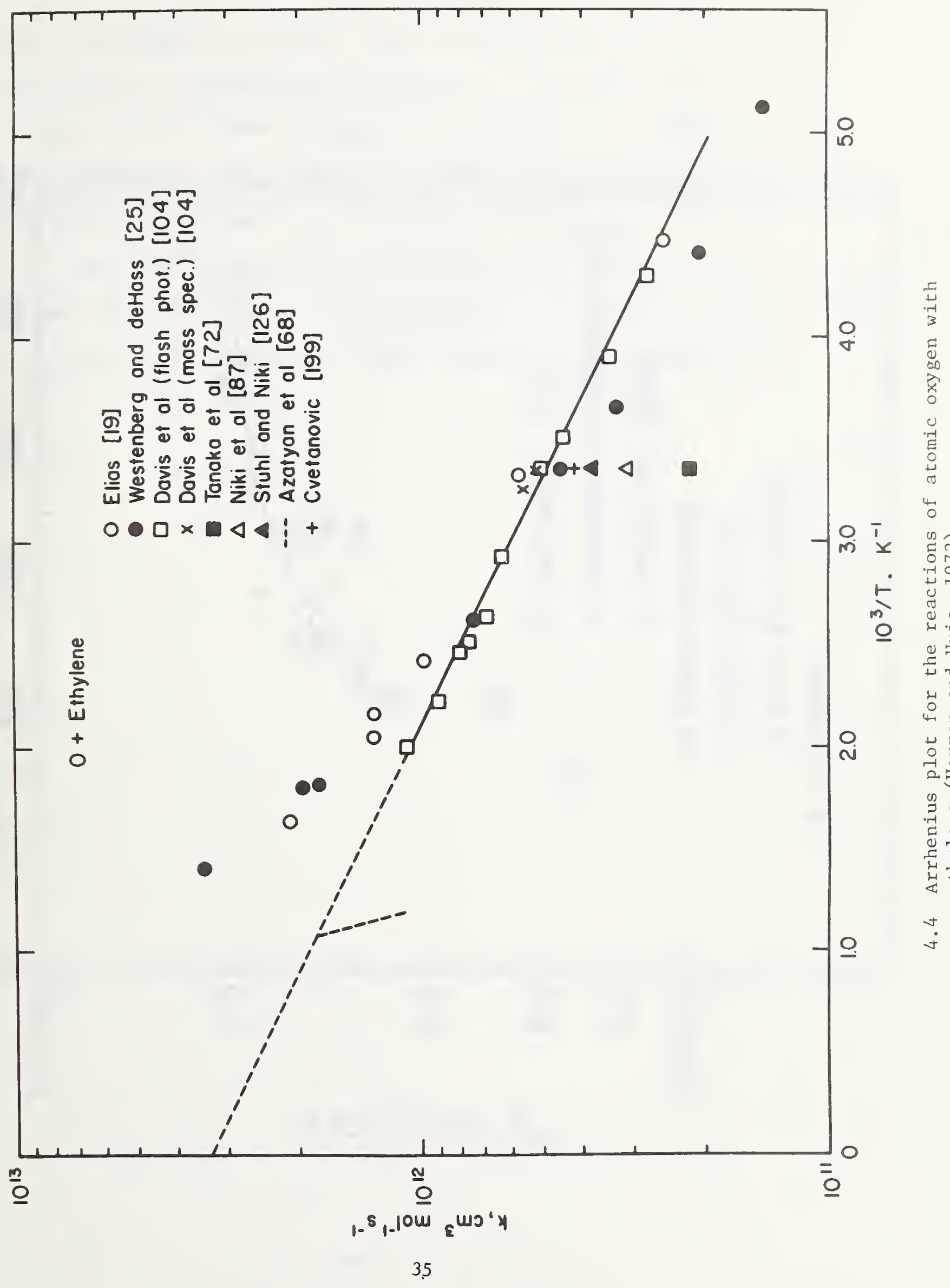




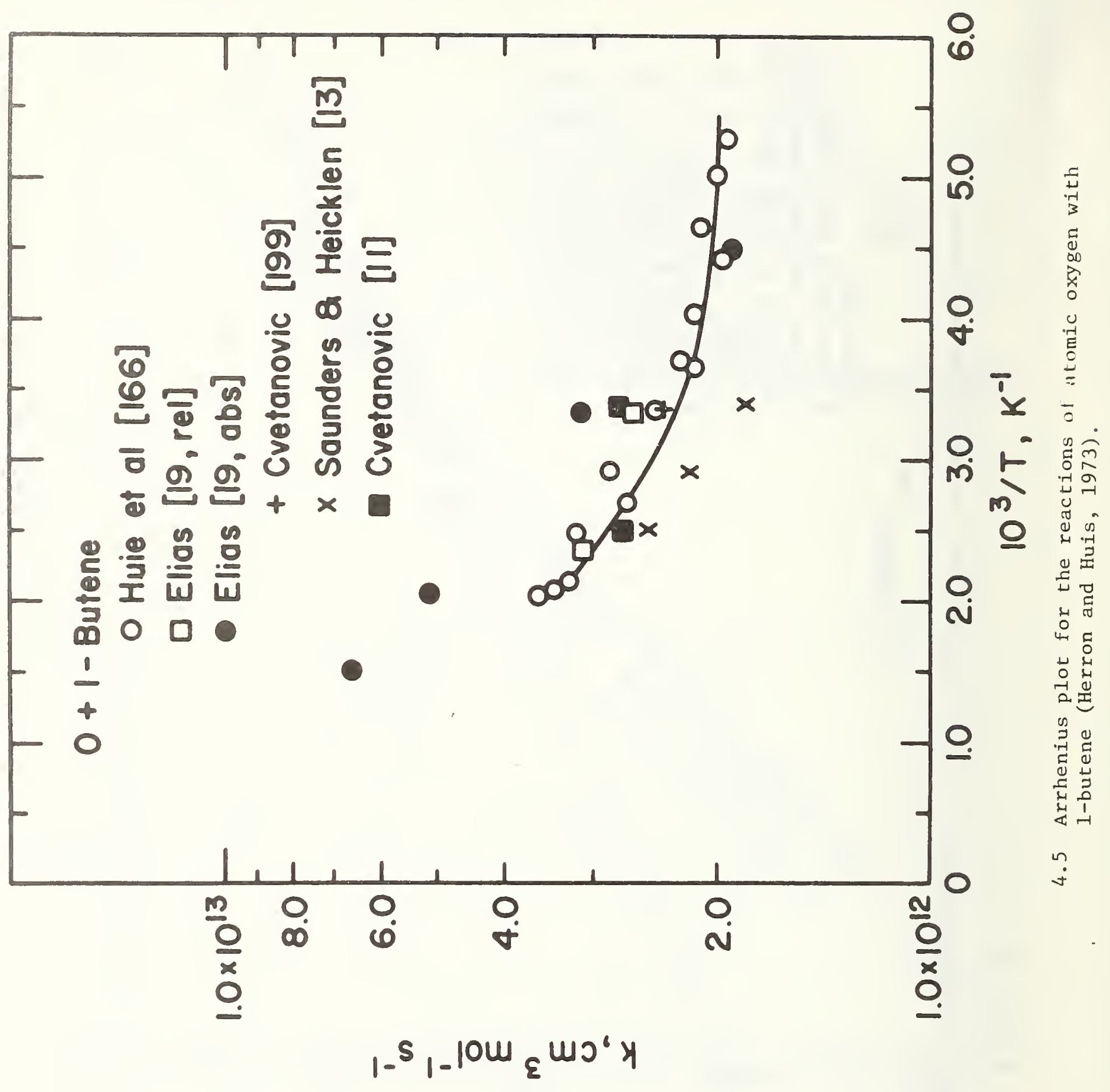


To compound the problem, Figure 4.6 shows data for cis-2-

butene in which a negative slope is observed. At this time it is impossible to even estimate the rate of this reaction at $\mathrm{T}>1000 \mathrm{~K}$. It should be noted that other reactions with small activation energies may behave in a simflar manner, e.g., $\mathrm{O}+\mathrm{NO}_{2}$ and $\mathrm{N}+\mathrm{NO}$.

The other reaction to be considered in this section is $0+$ acetylene, shown in Figure 4.7. The data appear to be 1inear, but do not go beyond $700 \mathrm{~K}$. Curvature at higher temperatures is a possibility. 


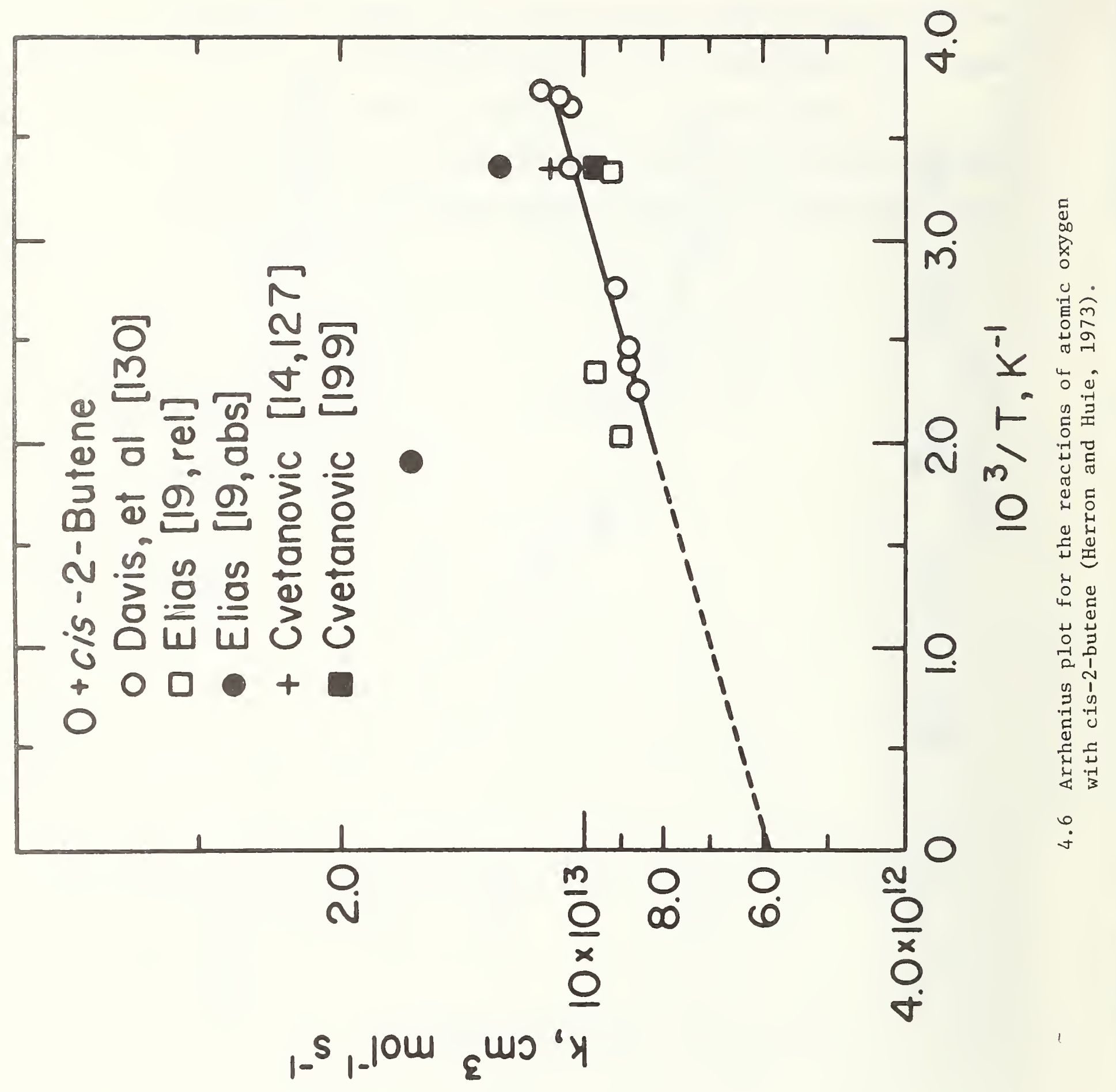




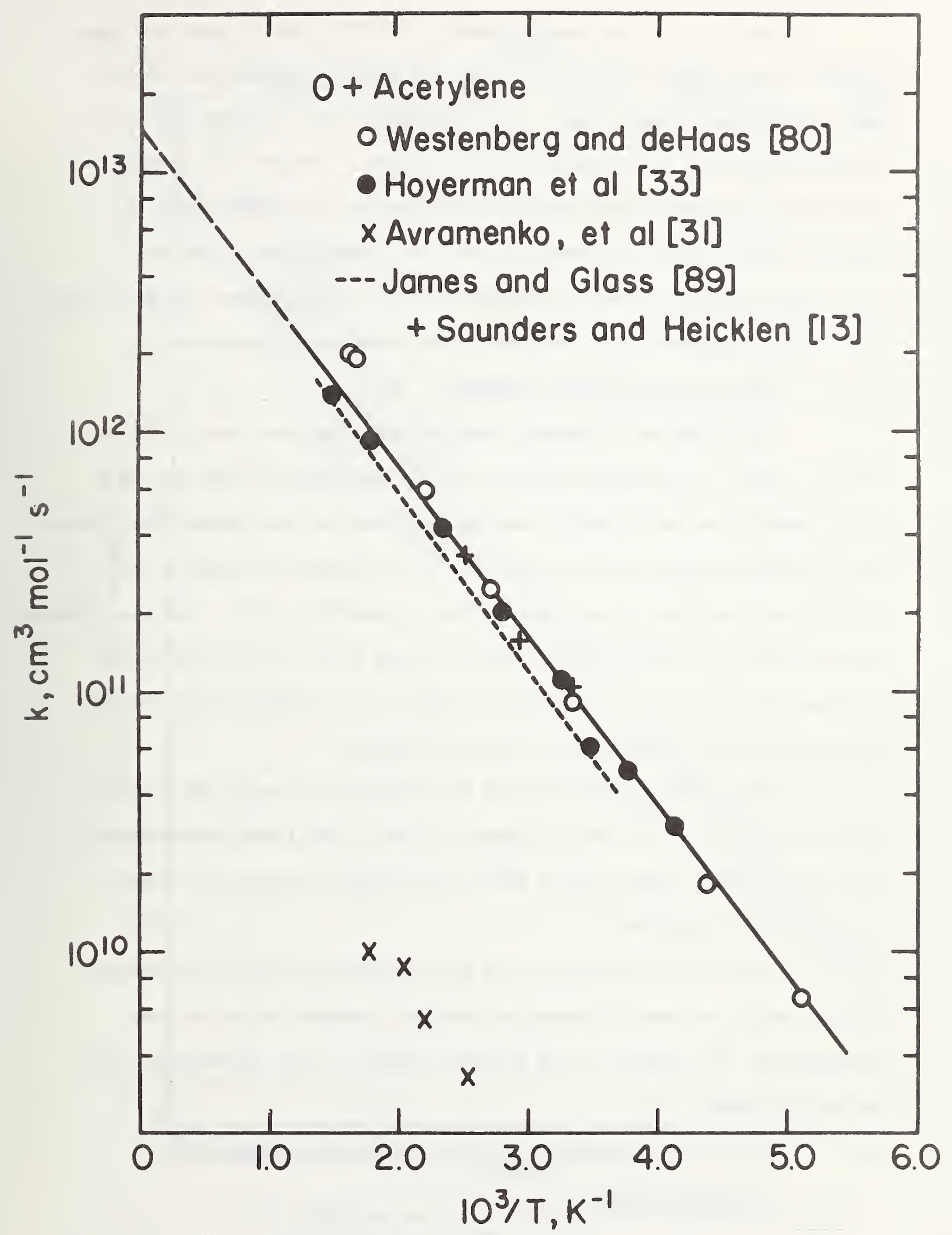

4.7 Arrhenius plot for the reactions of atomic oxygen with acetylene (Herron and Huie, 1973). 
Not only are the rate constants for the atomic oxygen reactions of great uncertainty at $\mathrm{T}>1000 \mathrm{~K}$, but the reaction mechanisms are not well established in many cases. It is probably safe to assume that the alkanes react only by hydrogen atom abstraction. However, the unsaturated compounds are known to have many avallable reaction channels (Huie and Herron, 1975). These are known only at room temperature. It is not known which reaction paths are dominant at high temperatures. In particular, the ratio of abstraction to addition is of fundamental importance. 4.2 Reactions of hydroxyl radicals

The kinetics of hydroxyl radical reactions have been reviewed (Wilson, 1972). As noted in section 6.5 the recommended value for $\mathrm{OH}+$ $\mathrm{CH}_{4}$ appears to be much greater than the one based on more recent experimental data. The same may be the case for the other alkanes, although great caution must be taken in so interpreting the avallable data. The discrepancies may arise due to curved Arrhenius plots as may be seen from examination of Figures 4.8 and 4.9. At this point there is no single set of reliable data to make such a determination for any alkane.

For ethylene and acetylene the situation is worse, as shown in Figures 4.10 and 4.11. Even allowing for recent additional measurements, it is not certain whether these plots are curved or whether the slopes are positive or negative.

In terms of mechanism, the same questions arise as for atomic oxygen. There are several competing reaction channels active at room temperature. The nature of the products formed at high temperature are as yet not known.

4.3 Reactions of hydrocarbon free radicals with atomic and molecular oxygen 


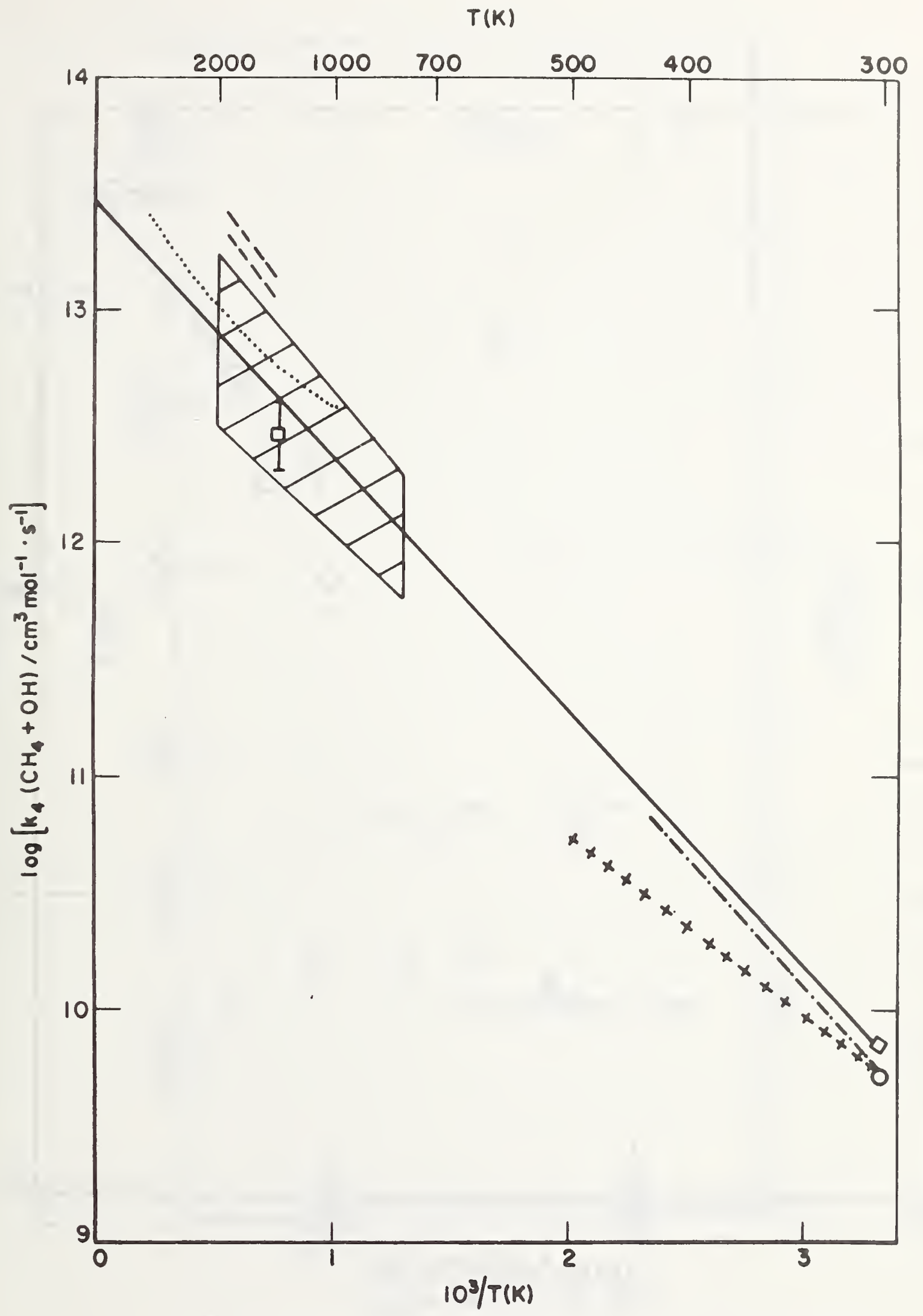

4.8 Arrhenius plot for the reaction of hydroxyl radicals with methane (Wilson, 1972). 


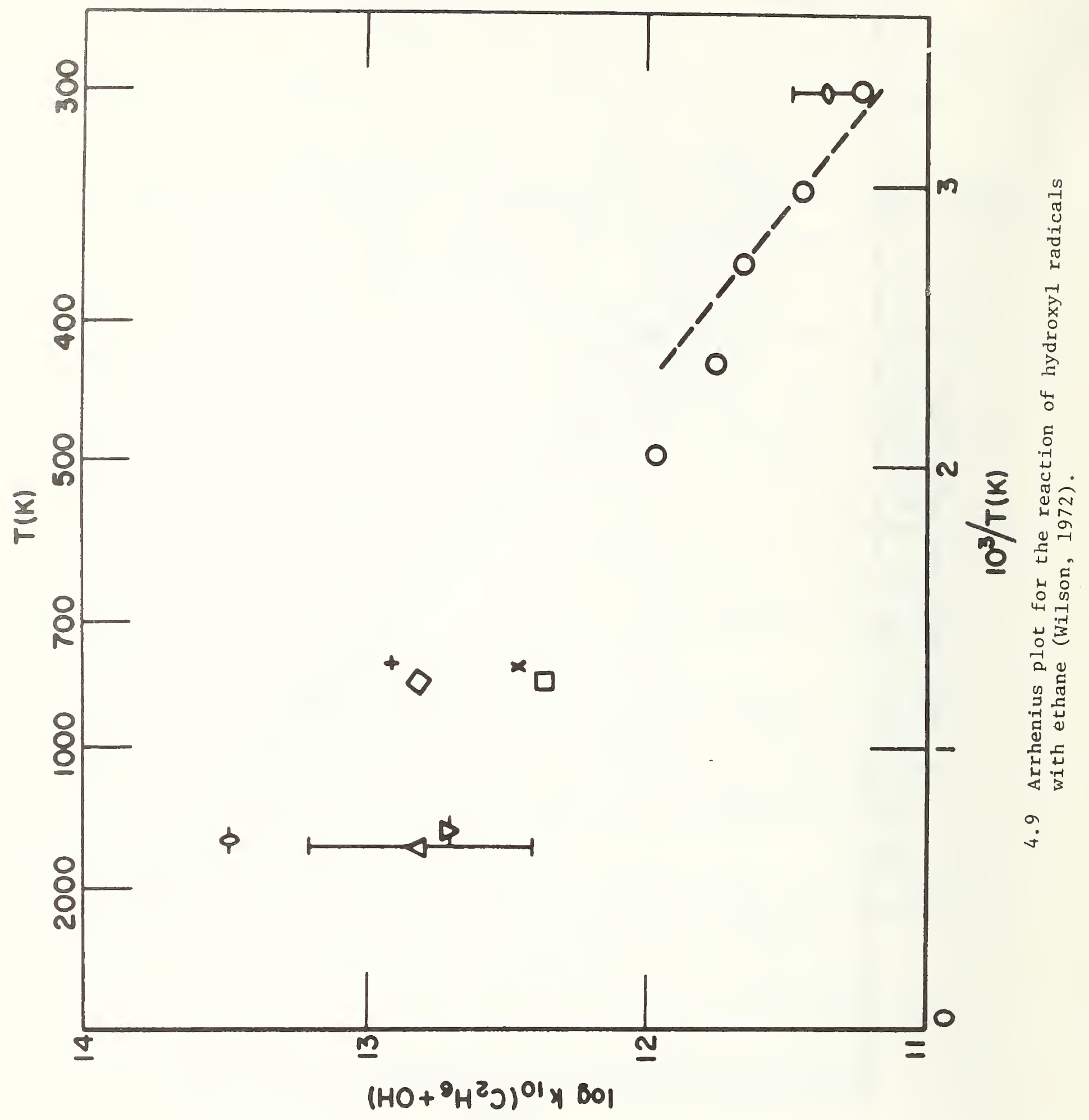




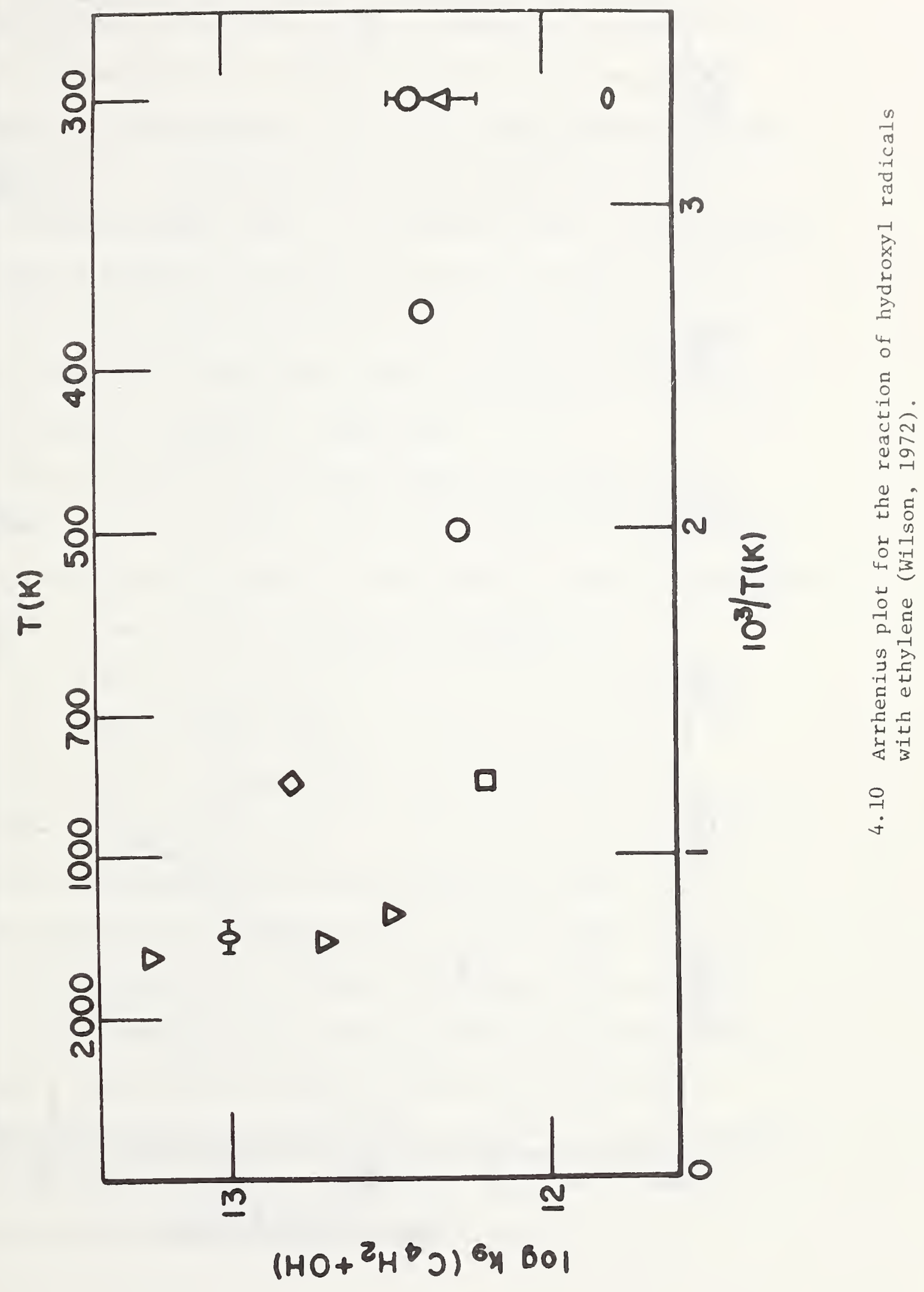




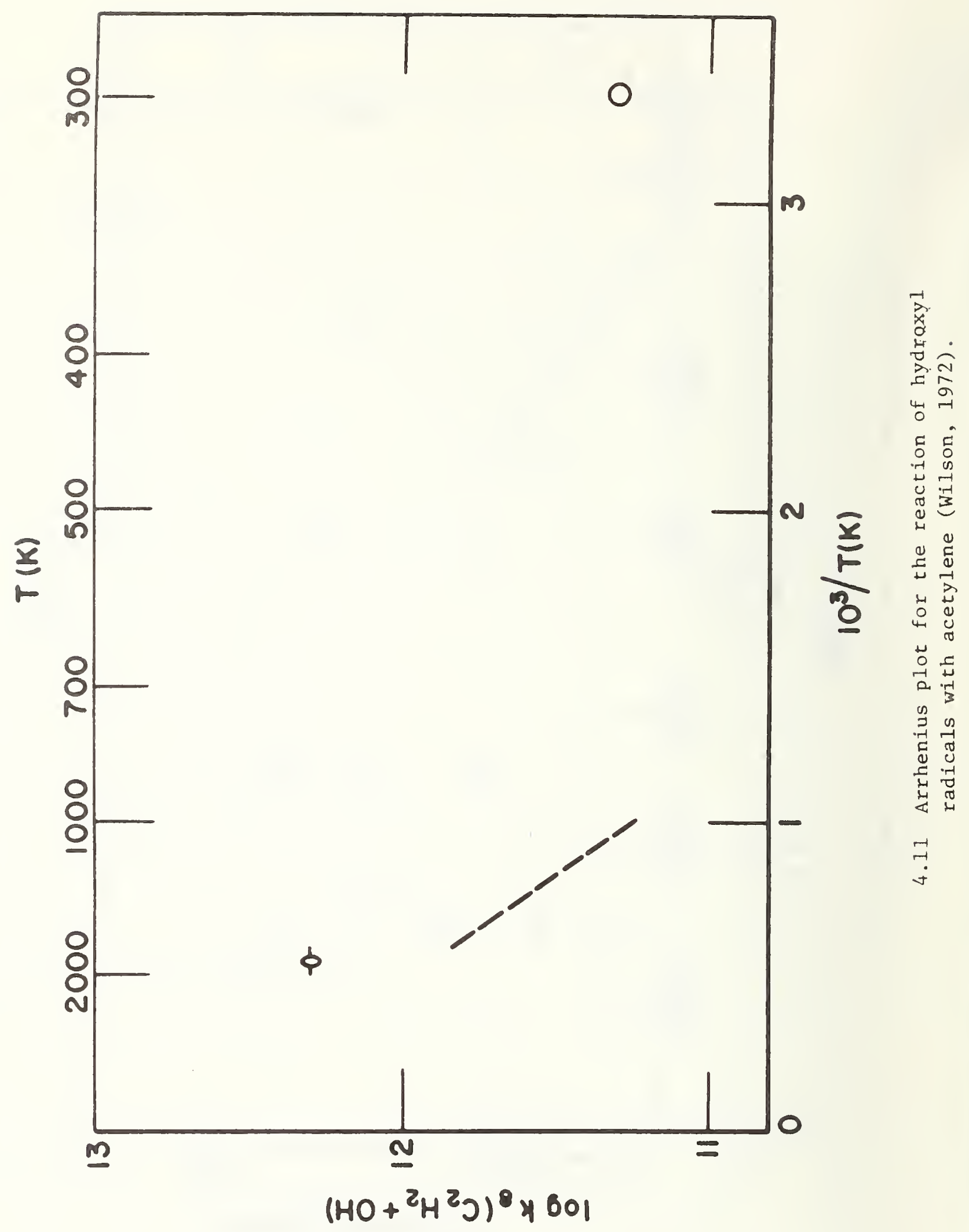


The kinetics and mechanisms of reaction of hydrocarbon free radicals with atomic and molecular oxygen at combustion temperatures are essentially unknown. The rate constant for $\mathrm{O}+\mathrm{CH}_{3}$ is known only at room temperature (Huie and Herron, 1975). For other radicals no direct data are available. The mechanisms of radical-oxygen atom reactions have been reviewed recently (ibid). For most reactions, several competing reaction paths have been postulated, as illustrated in Table 4.1, but there are few reliable data. This is an area in which application of unimolecular rate theory could make a major contribution in predicting branching ratios as a function of temperature.

The reactions with molecular oxygen are not significantly better known. Baldwin and Walker (1973) have recently reviewed the data from the point of view of oxidation of hydrocarbons at moderate temperatures (300 to $800 \mathrm{~K})$. The reactions considered by them are:

$$
\begin{array}{ll}
\text { 4. } & \mathrm{R}+\mathrm{O}_{2}+\mathrm{M} \rightarrow \mathrm{RO}_{2}+\mathrm{M} \\
\text { 5. } & \mathrm{R}+\mathrm{O}_{2} \rightarrow \text { olefin }+\mathrm{HO}_{2} \\
\text { 6. } & \mathrm{R}+\mathrm{O}_{2} \rightarrow \text { carbonyl }+\mathrm{OH} \\
\text { 7. } & \mathrm{R}+\mathrm{O}_{2} \rightarrow \text { cyclic }+\mathrm{OH}
\end{array}
$$

for which rate constants or rate constant ratios are known in a few cases at a limited number of temperatures. See, for example, Table 4.2 which lists data on reaction (5) (Baldwin and Walker, 1973). This appears to be the most important reaction in the $\mathrm{R}+\mathrm{O}_{2}$ series. Reaction (6) may have a high activation energy ( $\left.\sim 80 \mathrm{~kJ} \mathrm{~mol}^{-1}\right)$ and there is considerable uncertainty as to whether this reaction is of any importance in combustion, and if so, at what temperature. Reaction (7) involves addition and isomerization followed by decomposition: 


\begin{tabular}{|c|c|c|c|}
\hline Radical & Intermediate & Products & $\begin{array}{l}\Delta \mathbf{U}_{29 \varepsilon, 1} \\
\mathrm{~kJ} \mathrm{~mol}\end{array}$ \\
\hline $\mathrm{CH}_{3}$ & {$\left[\mathrm{CH}_{3}-\mathrm{O}\right]^{*}$} & $\begin{array}{l}\mathrm{H}_{3} \mathrm{CO} \\
\mathrm{H}_{2}+\mathrm{CHO} \\
\mathrm{H}+\mathrm{CH}_{2} \mathrm{O} \\
\mathrm{H}+\mathrm{H}_{2}+\mathrm{CO}\end{array}$ & $\begin{array}{l}-375 \\
-361 \\
-291 \\
-284\end{array}$ \\
\hline $\mathrm{CH}_{2} \mathrm{~F}$ & {$\left[\mathrm{CH}_{2} \mathrm{~F}-\mathrm{O}\right]^{*}$} & $\begin{array}{l}\mathrm{CH}_{2} \mathrm{FO} \\
\mathrm{HF}+\mathrm{CHO} \\
\mathrm{H}+\mathrm{CHFO}\end{array}$ & $\begin{array}{l}(-377)^{b} \\
(-477)^{b}\end{array}$ \\
\hline $\mathrm{CHF}_{2}$ & {$\left[\mathrm{CHF}_{2}-\mathrm{O}\right]^{*}$} & $\begin{array}{l}\mathrm{CHF}_{2} \mathrm{O} \\
\mathrm{HF}+\mathrm{CFO} \\
\mathrm{H}+\mathrm{CF}_{2} \mathrm{O}\end{array}$ & $\begin{array}{l}(-377)^{\mathrm{b}} \\
(-431)^{\mathrm{b}}\end{array}$ \\
\hline $\mathrm{CF}_{3}$ & {$\left[\mathrm{CF}_{3}-\mathrm{O}\right]^{*}$} & $\begin{array}{l}\mathrm{CF}_{3} \mathrm{O} \\
\mathrm{F}+\mathrm{CF}_{2} \mathrm{O}\end{array}$ & -328 \\
\hline $\mathrm{HC}_{2} \mathrm{O}$ & {$\left[\begin{array}{c}0 \\
1 \\
H-C=C=0\end{array}\right]^{*}$} & $\mathrm{H}+2 \mathrm{CO}$ & \\
\hline $\mathrm{CH}_{3} \mathrm{CO}$ & {$\left[\begin{array}{r}\mathrm{O} \\
\mathrm{CH}_{3}-\mathrm{C}=\mathrm{O}\end{array}\right]^{*}$} & $\begin{array}{l}\mathrm{CH}_{3} \mathrm{CO}_{2} \\
\mathrm{CH}_{3}+\mathrm{CO}_{2}\end{array}$ & $\begin{array}{c}(-435) \\
-478\end{array}$ \\
\hline $\mathrm{C}_{2} \mathrm{H}_{5}$ & {$\left[\begin{array}{c}\mathrm{H} \\
\mathrm{CH}_{3}-\underset{\mathrm{C}}{\mathrm{I}}-\mathrm{O} \\
\mathrm{H}\end{array}\right]^{*}$} & $\begin{array}{l}\mathrm{CH}_{3} \mathrm{CH}_{2} \mathrm{O} \\
\mathrm{H}+\mathrm{CH}_{3} \mathrm{CHO} \\
\mathrm{CH}_{3}+\mathrm{CH}_{2} \mathrm{O} \\
\mathrm{OH}+\mathrm{C}_{2} \mathrm{H}_{4}\end{array}$ & $\begin{array}{l}-385 \\
-305 \\
-332 \\
-266\end{array}$ \\
\hline $\mathrm{n}-\mathrm{C}_{3} \mathrm{H}_{7}$ & {$\left[\begin{array}{c}\mathrm{H} \\
\stackrel{1}{\mathrm{C}}-\mathrm{O} \\
\mathrm{CH}_{3}-\mathrm{CH}_{2} \\
\mathrm{H}\end{array}\right]^{*}$} & $\begin{array}{l}\mathrm{CH}_{3} \mathrm{CH}_{2} \mathrm{CH}_{2} \mathrm{O} \\
\mathrm{H}+\mathrm{CH}_{3} \mathrm{CH}_{2} \mathrm{CHO} \\
\mathrm{C}_{2} \mathrm{H}_{5}+\mathrm{CH}_{2} \mathrm{O} \\
\mathrm{OH}+\mathrm{C}_{3} \mathrm{H}_{6}\end{array}$ & $\begin{array}{l}-377 \\
-310 \\
-346 \\
-277\end{array}$ \\
\hline iso- $\mathrm{C}_{3} \mathrm{H}_{7}$ & {$\left[\begin{array}{c}\mathrm{O} \\
\mathrm{I} \\
\mathrm{CH}_{3}-\mathrm{C}-\mathrm{CH}_{3} \\
\mathrm{H}\end{array}\right]^{*}$} & $\begin{array}{l}\mathrm{CH}_{3} \mathrm{CHOCH}_{3} \\
\mathrm{H}+\left(\mathrm{CH}_{3}\right)_{2} \mathrm{CO} \\
\mathrm{CH}_{3}+\mathrm{CH}_{3} \mathrm{CHO} \\
\mathrm{OH}+\mathrm{C}_{3} \mathrm{H}_{6}\end{array}$ & $\begin{array}{l}-375 \\
-323 \\
-347 \\
-264\end{array}$ \\
\hline $\mathrm{n}-\mathrm{C}_{4} \mathrm{H}_{9}$ & {$\left[\begin{array}{r}\mathrm{H} \\
\mathrm{I} \\
\mathrm{CH}_{3}-\mathrm{CH}_{2}-\mathrm{CH}_{2}-\mathrm{C}-\mathrm{O} \\
\mid \\
\mathrm{H}\end{array}\right]^{*}$} & $\begin{array}{l}\mathrm{CH}_{3} \mathrm{CH}_{2} \mathrm{CH}_{2} \mathrm{CH}_{2} \mathrm{O} \\
\mathrm{H}+\mathrm{CH}_{3} \mathrm{CH}_{2} \mathrm{CH}_{2} \mathrm{CHO} \\
\mathrm{C}_{3} \mathrm{H}_{7}+\mathrm{CH}_{2} \mathrm{O} \\
\mathrm{OH}+\mathrm{CH}_{3} \mathrm{CH}_{2} \mathrm{CH}=\mathrm{CH}_{2}\end{array}$ & $\begin{array}{l}-377 \\
-302 \\
-345 \\
-276\end{array}$ \\
\hline
\end{tabular}




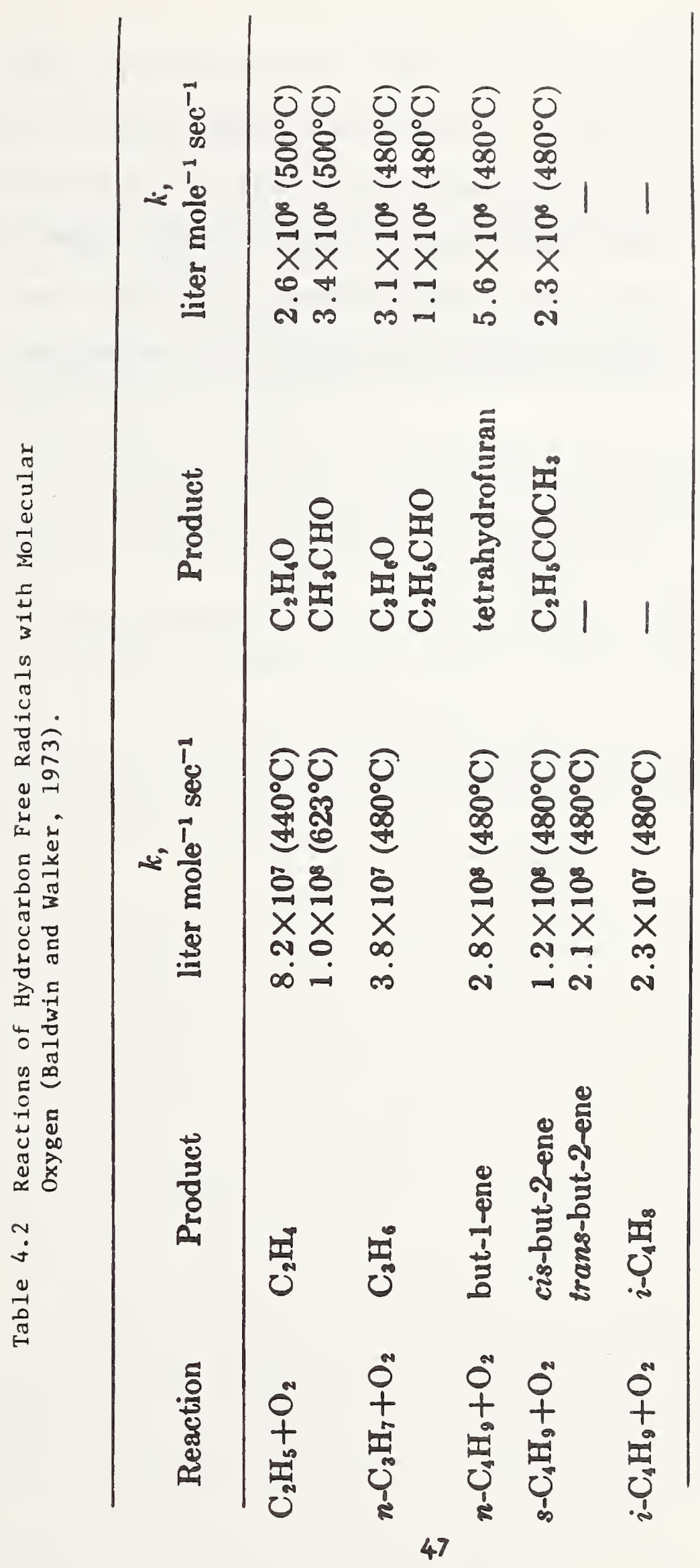




$$
7^{\prime} \cdot \mathrm{R}+\mathrm{O}_{2} \rightarrow \mathrm{RO}_{2} \rightarrow \mathrm{R}^{\prime} \mathrm{OOH} \rightarrow \text { cyclic hydrocarbon }+\mathrm{OH}
$$

The rate of this reaction depends on the strengths of the various $\mathrm{C}-\mathrm{H}$ bonds in the alkyl radical and the ring strain in the transition state. Here again the experimental data are sparse. These classes of reaction al1 require a great deal of both experimental and theoretical effort to gain a satisfactory knowledge of the kinetics and mechanisms. 
Baldwin, R. R., and Walker, R. W., "Problems and Progress in Hydrorarbon Oxidation," Symp. Combust. 14th (Combustion Institute, Pittsburgh, 1973) 241

Herron, J. T., "An Evaluation of Rate Data for the Reactions of Atomic Oxygen $\left(\mathrm{O}^{3} \mathrm{P}\right)$ with Methane and Ethane," Intern. J. Chem. Kinet. 1, 527 (1969)

Herron, J.T., and Huie, R. E., "Rate Constants for the Reactions of Atomic Oxygen $\left(\mathrm{O}^{3} \mathrm{P}\right)$ with Organic Compounds in the Gas Phase," J. Phys. Chem. Ref. Data 2, 467 (1973)

Huie, R. E., and Herron, J. T., "Reactions of Atomic Oxygen $\left(\mathrm{O}^{3} \mathrm{P}\right)$ with Organic Compounds," Prog. Reaction Kinet. 8, 1 (1975)

Wilson, W. E., Jr., "A Critical Review of the Gas-Phase Reaction Kinetics of the Hydroxyl Radical," J. Phys. Chem. Ref. Data 1, 535 (1972) 
The formation of combustion generated pollutants such as NO and $\mathrm{SO}_{2}$, is to a large extent a kinetically controlled process. For this reason, modeling of such systems, particularly in the case of NO, represents one of the most active areas of combustion modeling.

5.1 Formation of nitric oxide in combustion

It is generally accepted that the formation of NO in post flame gases is governed by the extended Zeldovich mechanism

$$
\begin{aligned}
& \text { 1. } \mathrm{O}+\mathrm{N}_{2} \underset{\leftarrow}{\mathrm{NO}}+\mathrm{N} \\
& \text { 2. } \mathrm{N}+\mathrm{O}_{2} \underset{\mathrm{NO}}{\mathrm{N}}+\mathrm{O} \\
& \text { 3. } \mathrm{N}+\mathrm{OH} \underset{\leftarrow}{\rightarrow} \mathrm{NO}+\mathrm{H}
\end{aligned}
$$

Because of the high activation energies of these reactions and the short time scale of combustion processes, the NO level never reaches its equilibrium value.

However, the observations of Fenimore that rates of formation of NO at the combustion zone (so-called "prompt" NO) were much greater than could be accounted for by this mechanism has led to considerable new research in this area. Two different suggestions have been made. One is that the excess rate is due to a superequilibrium concentration of free radicals in the combustion zone (Bowman, 1973) and the other that other reactions, i.e., those involving fuel derived species generate No, (Iverach, et al 1973) e.g.,

$$
\begin{aligned}
& \text { 4. } \mathrm{CH}+\mathrm{N}_{2} \rightarrow \mathrm{HCN}+\mathrm{N} \\
& \text { 5. } \mathrm{C}_{2}+\mathrm{N}_{2} \rightleftarrows 2 \mathrm{CN} \\
& \text { 6. } \mathrm{C}+\mathrm{N}_{2} \rightleftarrows \mathrm{CN}+\mathrm{N} \\
& \text { In fact both mechanisms may contribute depending on the fuel/air }
\end{aligned}
$$
ratio. 
An even more complex picture has been suggested by Merryman and Levy (1974) on the basis of flame probe experiments. They find $\mathrm{NO}_{2}$ to be the dominant ${ }^{N O}$ species in the flame zone, whereas NO dominates downstream. They suggest the reactions below as an explanation.

$$
\begin{aligned}
& \text { 7. } \mathrm{NH} \text { and/or } \mathrm{CN}+\mathrm{O}_{2} \rightarrow \mathrm{NO}+\mathrm{OH} \text { and/or } \mathrm{CO} \\
& \text { 8. } \mathrm{NO}+\mathrm{HO}_{2} \rightarrow \mathrm{NO}_{2}+\mathrm{OH} \\
& \text { 9. } \mathrm{NO}_{2}+\mathrm{O} \rightarrow \mathrm{NO}+\mathrm{O}_{2}
\end{aligned}
$$

Clearly, the mechanisms whereby NO is formed in combustion are not well understood. An added complication is that NO can be formed from fuel nitrogen.

\subsection{Formation of nitric oxide from fuel nitrogen}

The range of compounds associated with fuel nitrogen is not well defined. Most researchers have picked fairly simple compounds such as ammonia, pyridine or an amine to study the formation of NO from fuel nitrogen. The complete mechanism must involve pyrolysis for some nitrogen containing fuels, followed by reaction with atomic oxygen, hydroxyl radicals, molecular oxygen, etc. However, many heterocyclic type compounds will not readily pyrolyze, and can be expected to enter the combustion zone and react with free radicals, The problems here are identical to those described earlier in reference to the reactions of hydrocarbons with atoms and free radicals. The difference is that there is almost no base of information on the chemistry of such processes. These classes of reactions have yet to be studied.

\subsection{Formation of oxides of sulfur from fuel sulfur}

The general approach to the control of $\mathrm{SO}_{\mathrm{x}}$ produced in the combustion of coal or sulfur rich oil has been to remove the sulfur 
before burning, or to use stack gas cleaning processes. The basic question as to how $\mathrm{SO}_{2}$ or $\mathrm{SO}_{3}$ is formed has not been addressed. There is an inadequate data base from which to carry out modeling studies on sulfur oxidation, and to consider the importance of chemical kinetics in the formation and potentially, the control of $\mathrm{SO}_{\mathrm{x}}$. The review by Levy, et a1. (1970) discusses the role of various reactive intermediates such as $\mathrm{SO}, \mathrm{S}_{2} \mathrm{O}$, and $(\mathrm{SO})_{2}$. The role of $\mathrm{sO}$ in the oxidation process has yet to be established although it is readily observed in the combustion of sulfur containing fuels and may be the key intermediate in the sulfur oxidation process.

The sources of sulfur in the fuel will vary from mineral bound sulfur in coals to organic bound sulfur in both coal and oil, but if the initial processes lead to the formation of SO, a common kinetic base can be used for subsequent modeling and control strategies. 


\section{REFERENCES TO SECTION 5}

Bowman, C. T., "Kinetics of Nitric Oxide Formation in Combustion Processes," Symp. Combust. I4th (Combustion Institute, Pittsburgh, $1973(729$

Iverach, D., Basden, K. S., and Kirov, N. Y., "Formation of Nitric Oxide in Fuel-Lean and Fuel-Rich Flames," Symp. Combust. 14th (Combustion Institute, Pittsburgh, 1973) 767

Levy, A., Merryman, E. L., and Reid, W. T., "Mechanisms of Formation of Sulfur Oxides in Combustion," Environ. Sci. Techn. 4 , 653 (1970)

Merryman, E. L., and Levy, A., "Nitrogen Oxide Formation in Flames: The Roles of $\mathrm{NO}_{2}$ and Fuel Nitrogen," Symp. Combust. 15th, Abstracts of papers (Combustion Institute, Pittsburgh, 1974) 209 


\section{Data and Prediction Schemes}

\section{$6.1 \quad$ Introduction}

The resources now available are summarized here. They are of several types.

(a) Evaluations of experimental data with recommended rate constants. The chemical kinetics program of the Office of Standard Reference Data, NBS, is devoted to the preparation and publication of such work. There are analogous and complementary programs in the UK and the USSR. The reference data programs in these three countries have supported almost all of the modern chemical kinetics data evaluation work.

The two principal on-going data centers for evaluation of chemical kinetics measurements are the High Temperature Reaction Rate Group at the University of Leeds, England and the Chemical Kinetics Data Center, Physical Chemistry Division, NBS. Continuing liaison is maintalned between these centers.

(b) Methods for predicting rate data. These have been developed by individuals and published as regular scientific articles. A group at the Stanford Research Institute has made many important contributions.

(c) Original measurements. These are published as regular scientific articles. A substantial fraction of these articles has been collected by the Chemical Kinetics Information Center, NBS. This collection is avaflable for use in developing a data base. 
These resources are viewed as a starting point for the development of a comprehensive publicly available combustion kinetics data base. They will make it possible for an initial version of the data base to include values for many of the reactions of interest.

Reliance on existing evaluations in the early stages of the development of a data base means that essentially all of the output of the world-wide data evaluation effort will become readily available to designers and engineers.

Expansion of the data base beyond that point will require work of several types in many laboratories.

(a) More evaluations - principally for major reactions that have not been examined by evaluators and for cases where new data are available.

(b) New measurements - to resolve conflicts in the data, to fill gaps and extend the usefulness of existing data.

(c) Major use of prediction schemes to extend existing data to reactions that have not been studied.

6.1.1 Topics treated in this chapter

In section 6.2 are listed the major data compilations upon which any data base must draw. This forms a major resource. Sections 6.3 and 6.4 are a review of methods for predicting rate data. There are many methods. They are described in some detail here because many chemists are not aware of the extensive developments in this area of kinetics - developments that suggest that prediction schemes will be of increasing importance in the future. Section 6.5 is a discussion of a major data evaluation problem - how to extrapolate low temperature kinetics data up to combustion temperatures. A summary concludes the chapter. 
6.2 Major data compilations and evaluations pertinent to combustion chemistry. These are listed by author and topic. Unless otherwise noted the compilations include recommended values and cover data applicable in the range $300-1000 \mathrm{~K}$.

Benson and $0^{\prime} \mathrm{Nea} 1,(1970)$. Evaluated data on over 500 unimolecular reactions. This is the basic source for rate data on the pyrolysis of organic compounds.

Herron and Huie, (1973). Compllation and evaluation of rate data for reactions of 0 atoms with 107 organic compounds in the gas phase.

Wilson, W. E., (1972). Reactions of the hydroxyl radical. Herron, J. T., (1969). Evaluation of rate data for reaction of oxygen atoms with methane and ethane.

Baulch, Drysdale, Horne and Lloyd (1972, 1973). Two volumes of evaluated rate data for the hydrogen/nitrogen/oxygen system. Data for temperatures from $300 \mathrm{~K}$ to the upper end of the experimental range are included. Often this includes the combustion regime.

Drysdale and Lloyd, (1970). Hydroxyl radical reactions.

Kerr and Parsonage, (1972). A comprehensive survey of evaluated kinetic data on gas phase addition reactions.

"Chemical Kinetics Data Survey" (1973-75). NBS rate data tables and evaluations, principally for reactions pertinent to atmospheric chemistry near room temperature but including many radical-molecule reactions.

Allara, D., (1973). Rate data evaluation and estimates for 475 reactions of interest in combustion studies, for temperatures near $700 \mathrm{~K}$. 
Other compilations are listed in NBS List of Publications No.

73 which is a catalog of the world-wide activity in the area of kinetics data evaluation.

6.3 The Prediction of Reaction Rate Data - General

6.3.1 Introduction

In a complex chemical system such as combustion many chemical

reactions will occur or will have to be considered in developing suitable models for equipment. These reactions may be important in energy

conversion, pollutant formation and control, blow-out phenomena, soot formation, effects of fuel additives etc.

Inevitably many of the reactions of interest will not have been studied in the laboratory under conditions suitable for application to the problem at hand. Prediction schemes offer a method for filling the gaps prior to making accurate measurements.

Why should prediction schemes by considered an important resource? As more accurate measurements of kinetics data are made it becomes apparent that similar chemical reactions have similar mechanisms and similar rate parameters. Prediction schemes reproduce this "normal" behavior and in many cases provide accurate means for extending the existing information to similar molecules. In many cases this should be sufficient for screening purposes for deciding which reactions should be included in a model. In some cases the predictions may be good enough to eliminate the need for measurement. This is most likely to be true for reactions of large organic molecules.

Some cautionary remarks are in order. First, the object of prediction schemes is to come close to reproducing good experimental data but not to do this exactly. It is more important to predict 
$k$ to within a factor of 2 to 5 for a type of reaction than to pin down an accurate value for an important reaction. That must be measured. Second, no one scheme does the job for all reactions. Third, some types of reactions are not treated well by any method. Fourth, the comparison with experiment for each method have been done separately and at different times. There has been no systematic cross-comparison of methods. Good high temperature data for such comparisons are rare. Fifth, activation energy predictions are less important for reactions at high temperatures than are predictions of entropies of activation. That is, errors of \pm 8 $\mathrm{kJ} / \mathrm{mol}$ have much less effect above $1000 \mathrm{~K}$ than do errors in entropies of activation.

A general characterization of prediction methods is given in section 6.3.2. This is followed by a summary of terms and definitions used in kinetics section 6.3.3. Then twenty methods that have been proposed are described in section 6.4. It should become apparent that the prediction of rate parameters is an active and successful, although smal1, branch of chemical kinetics. But it must be emphasized, in line with the general remarks above, that much more systematic work is needed in this area. This must go hand-in-hand with experimentation on reactions that can extend and delimit the utility of the various methods. 6.3.2 Types of methods for the prediction of rate constants

These should all be considered to be empirical. But almost always they have some tie to a theoretical model (often very tenuous) and frequently they are calibrated against experiment. They fall into several classes.

(a) Correlations of rate constants within a series of related reactions. Examples:

(1) Reactions of oxygen atoms with alkenes: $\mathrm{O}+\mathrm{RCH}=\mathrm{CHR}^{\prime} \rightarrow$ products. 
(2) Simple bond fissions: $R-R^{\prime} \rightarrow R^{\cdot}+R \cdot$ ' These can be entirely empirical and based entirely on kinetic measurements.

(b) Correlations of rate constants or rate parameters with thermodynamic quantities (or other physical properties). Example: $E^{*}=$ $11.5-0.25 \Delta \mathrm{H}$ (The Evans-Polanyi-Semenov relation).

(c) Theoretical (?) relationships relating the rate constants of reactions within a class.

Example: Prediction of the rate constant for $R^{\cdot}+R^{\prime} \rightarrow R^{\prime}$ from those for $R^{\cdot}+R^{\cdot} \rightarrow R R$ and $R^{\prime}{ }^{\prime}+R^{\prime} ' \rightarrow R^{\prime} R^{\prime}$

(d) Establishment of a typical transition-state structure for a class of reactions and then calculation of $\Delta \mathrm{S}^{\dagger}$ and $\Delta \mathrm{H}^{\dagger}$ according to a set rule.

Example: Unimolecular decomposition reactions using group additivity techniques.

(e) Definition of a reaction coordinate (path from reactants to products) and then calculation, according to rule, of the geometry of the transition state, its properties and the energy barrier. Example: Bond-energy bond-order method for atom transfer reactions.

(f) Generalized rate expressions of an empirical nature.

Needless to say there are some methods that could be placed in more than one of the classes described above. Also there are some that do only part of the job described for a particular class.

\subsubsection{Terminology and Principles}

A brief statements are given here defining important terms and summarizing principles that are invoked in the estimation of rate data.
(a) Rate of reaction
Rate $=\mathrm{k}(\mathrm{T}) \cdot \mathrm{f}(\mathrm{c})$

where $k(T)$ is the rate constant, a function of temperature and $f(c)$ is 
a function of reactant and product concentrations.

(b) The function of concentrations

$\underline{f(c)}$ may be complex for a complex chemical process consisting

of many steps. However, for each of the individual steps it is a very simple product of reactant concentrations.

\section{(c) Elementary reactions}

These are the individual molecular transformations that combine to make up the mechanism of a complex process, such as combustion. The rate data for elementary reactions are transferable from one complex system to another. Overall rate data are not.

It is a primary function of kinetic studies to determine the mechanism, the elementary steps, that occur in a complex process. Only after this is done are rate data for elementary reactions useful.

\section{(d) The rate constant, $k(T)$}

Experimentally this is usually represented by the Arrhenius equation, shown here in extended form

$$
\mathrm{k}(\mathrm{T})=\mathrm{A} \mathrm{T}^{\mathrm{b}} \exp \left(-\mathrm{E}^{*} / \mathrm{RT}\right)
$$

where $\mathrm{AT}^{\mathrm{b}}$ is the "pre-exponential factor" and $\mathrm{E}^{*}$ is the "activation energy".

The terms, $\underline{A}, \underline{b}$ and $\underline{E}^{*}$ are usually considered as constants. $\underline{b}$ often is preset at zero, but may be in the range $-2.5<\mathrm{b}<2.5$. $\mathrm{E}^{*}$ usually is positive (it is an energy barrier) but may be zero or, for curve fitting, slightly negative.

\section{(e) Absolute rate theory form of $\mathrm{k}(\mathrm{T})$}

This formulation is more informative and is used in most prediction schemes. For a bimolecular process

$$
\begin{gathered}
A+B \rightarrow[A--B]^{\dagger} \rightarrow C+D \\
k(T)=\frac{k T}{h} \exp \left(\Delta S^{\dagger} / R\right) \exp \left(-\Delta H^{\dagger} / R T\right)
\end{gathered}
$$


where $\Delta S^{\dagger}$ is the "entropy of activation" a measure of molecular configuration change in going from reactants to the "transition state" [A---B]", $\Delta \mathrm{H}^{\dagger}$ is the "enthalpy of activation", the potential energy barrier to be overcome in forming the transition state, $k$ is the Boltzman constant,

and

$\mathrm{h}$ is the Planck constant.

In principle, $\Delta S^{\dagger}$ and $\Delta H^{\dagger}$ are weak functions of temperature. Other types of reactions such as unimolecular decompositions and addition reactions have similar rate constant expressions.

\section{(f) "Intrinsic" activation energy or enthalpy of activation}

This term means the activation energy for an exothermic reaction, one that releases energy. It is entirely kinetic in origin. This is the quantity estimated in prediction schemes. The activation energy for an endothermic (heat absorbing) reaction is the intrinsic activation energy plus the heat of the reaction.

\section{(g) Rate constants and equilibria}

For the reaction system

$$
\mathrm{A}+\mathrm{B} \stackrel{\rightarrow}{\leftarrow}+\mathrm{D}
$$

at equilibrium the rate of the forward reaction (arrow running to the right) equals that of the backward reaction.

$$
\begin{aligned}
& \mathrm{R}_{f}=\mathrm{k}_{\mathrm{f}}[\mathrm{A}][\mathrm{B}]=\mathrm{k}_{\mathrm{r}}[\mathrm{C}][D]=\mathrm{R}_{\mathrm{r}} \\
& \mathrm{k}_{\mathrm{f}} / \mathrm{k}_{\mathrm{r}}=[\mathrm{C}][\mathrm{D}] /[\mathrm{A}][\mathrm{B}] \equiv \mathrm{k}_{\mathrm{eq}}
\end{aligned}
$$

This expression is often used to calculate $k_{r}$ from $k_{f}$ (or vice-versa) in prediction schemes. 
This class of reactions includes almost all of the types of

processes that occur in pyrolysis of organic molecules: simple bond fissions, free radical decompositions, isomerization, molecular elimination (complex fission) and ring opening.

The prediction method has been developed by S. W. Benson and co-workers. It has been reviewed by Golden (1973), is developed in detail in Benson (1968) and is exploited in Benson and O'Neal (1970). These references and individual papers give examples of the application of the method.

The method uses absolute rate theory as a model. For each class of reactions a general transition-state configuration is determined whose calculated entropy of activation is consistent with experimental data. Then, for individual reactions detailed calculations of the entropies of activation are made using the class model and molecular parameters. Enthalpies of activation are not calculated by this method. In the special case of simple bond breaking reactions $\Delta \mathrm{H}^{\dagger}$ is taken as the enthalpy of reaction. Thus this method, closely tied to experiment, scales the estimates to match a class model and properties of individual reactions. The estimates are made using a detailed "group additivity" method that is an extension of the very successful technique used for estimating thermochemical quantities developed by Benson. (Benson et a1. 1969; O'Neal and Benson, 1973).

The accuracy of the estimates of rate constants is difficult to assess because many of the available data are poor. Pre-exponential factors based on the entropies of activation are probably good to a factor of two in most cases. The accuracy of the rate constant estimates

* See Table 6.1 for a summary of the methods described here. 


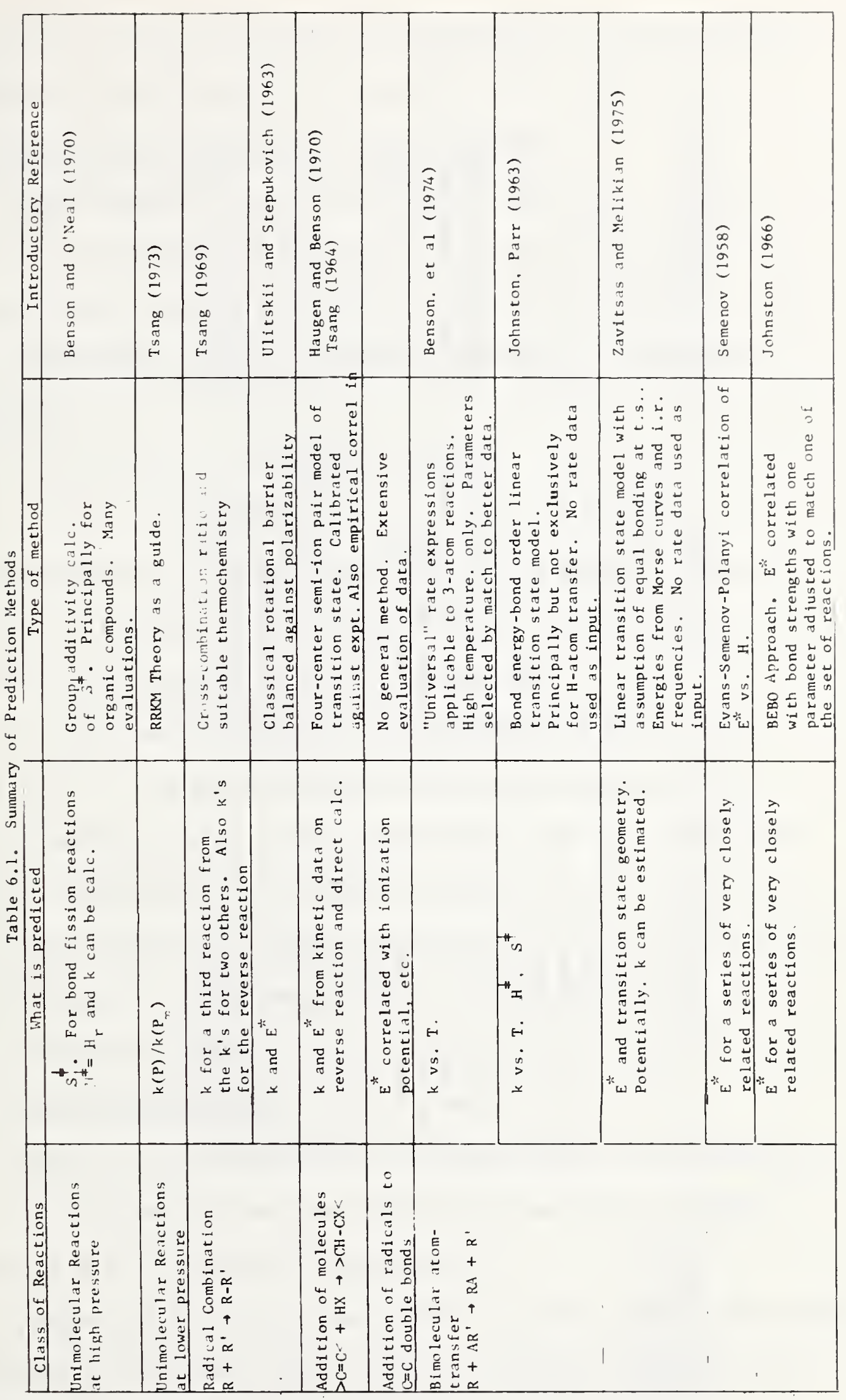




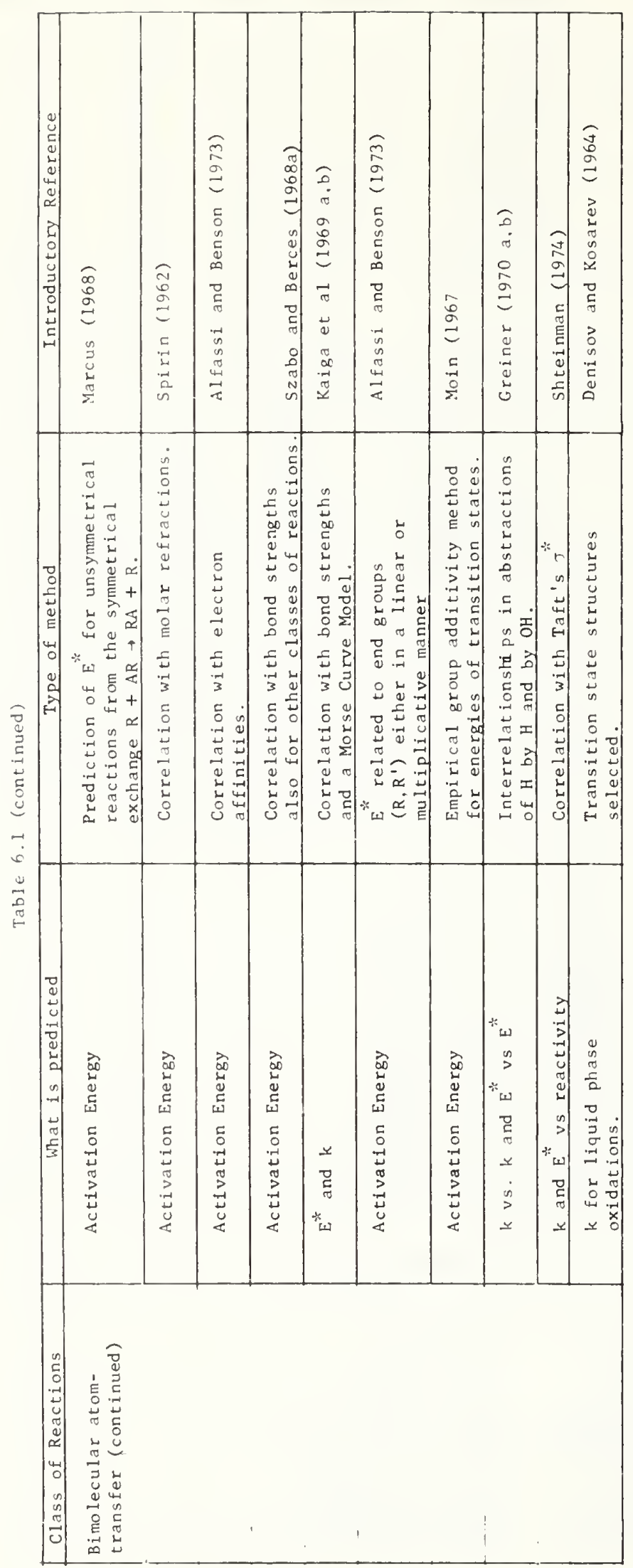


is also limited by the inaccuracies of our knowledge of bond strengths, or, equivalently, the enthalpies of formation of free radicals.

6.4.2 Unimolecular reactions at lower pressures

These decomposition and rearrangement reactions, formally

written $A \rightarrow B$, all involve the transfer to $A$ of sufficient energy to split a bond, expel a molecular fragment, or cause isomerization. That is, there is an energy transfer component. The simplest mechanism showing this is

$$
\begin{aligned}
& A+M \stackrel{*}{*} A^{*}+M \text { (energy transfer) } \\
& A^{*} \rightarrow B \text { (reaction) }
\end{aligned}
$$

where $\underline{M}$ is any molecule in the system. Thus the overall rate constant shows a pressure dependence and, ultimately there is a change from first order to second order kinetics at very low pressure.

The experimental dependence of $\mathrm{k}$ on pressure (or total gas concentration) is not simple. Since the 1920's theories have been developed to account for it. The current theory, the Rice-RamspbergerKasse1-Marcus theory has been reasonably successful in reproducing the behavior of many reactions. It has been applied as an empirical correlation of data in evaluation work (Tsang, 1973). Such procedures will be needed in combustion kinetics.

$$
\text { 6.4.3 Radical combinations } R^{\cdot}+R^{\prime} \cdot \rightarrow R^{\prime}
$$

Almost all such measurements have been made at room temperature.

There is a major question about the temperature coefficient of such reactions that must be resolved by measurement.

Prediction For combustion kinetics the most reliable technique is calculation of the rate from the reverse, decomposition reaction and the equilibrium constant.

A "cross-combination ratio" holds for the rate constants of the related reactions 
1. $R+R \rightarrow R-R$

2. $R^{\prime}+R^{\prime} \rightarrow R^{\prime}-R^{\prime}$

and $\quad \mathrm{R}+\mathrm{R}^{\prime} \rightarrow \mathrm{R}-\mathrm{R}^{\prime}$ where $\mathrm{k}_{\mathrm{C}} \sim 2\left(\mathrm{k}_{\mathrm{A}} \cdot \mathrm{k}_{\mathrm{B}}\right)^{1 / 2}$

Deviations from the factor of 2 are no more than $25 \%$ in comparisons with experiment .

This is a very powerful technique for extending measurements. Given $\mathrm{n}$ rate constants of the type reactions (1) and (2) then $n(n-1) / 2$ rate constants of the reaction type (3) may be calculated. With suitable thermochemistry for the stable molecules this correlation can be applied to the reverse bond-breaking reaction (Tsang, 1969).

A set of these rate constants that is sufficient for combustion kinetics now exists for alkyl radicals.

Measurements may be required on other classes of radicals. However many of them will undergo decomposition or oxidation in preference to combination.

There are few data and no established methods for reliable predictions for the important class of reactions: $\mathrm{R}+\mathrm{O}_{2} \rightarrow \mathrm{RO}_{2}$.

Ulitskii and Stepukovich (1963) used a mode1 that set the activation barrier for combination reactions as the difference between a centrifugal energy and the polarizability of the molecule formed in $R$ $+R^{\prime} \rightarrow R R^{\prime}$. The $R-R^{\prime}$ distance at the potential maximum is determined as well as $\mathrm{E}^{*}$, hence pre-exponential factors can be obtained. Only limited comparisons were made with experiment. $\mathrm{k}^{\prime} \mathrm{s}$ shown agree to a factor of 2 to 5 .

6.4.4 Addition reactions: $\mathrm{RCH}=\mathrm{CHR}^{\prime}+\mathrm{HX} \rightarrow \mathrm{RCH}_{2} \mathrm{CHXR}^{\prime}$

Predictions The method is to calculate the rate constant from that for the decomposition reaction and the equilibrium constant. These are "four center reactions". The basic model is a "semi-ion pair" treatment (Benson and Bose, 1963; Benson and Haugen, 1965; Haugen and 
Benson, 1970). It has been modified recently to overcome failure when polar groups were present in the alkene (Maltman et al, 1974; TschuikowRoux and Maltman, 1975). In 55 comparisons with experiment, 28 activation energies agreed to better than $4 \mathrm{~kJ} / \mathrm{mol}$ and 19 more to better than 12 $\mathrm{kJ} / \mathrm{mol}$.

There is also a completely empirical correlation for dehydrohalogenation reactions that predicts rate constants to within $20-30 \%$. It is based on constancy of the pre-exponential factors and a correlation between $\mathrm{E}^{*}$ and the ion dissociation energy of the alkyl halide (Tsang, 1964).

6.4.5 Addition reactions of radicals and atoms

$$
\begin{aligned}
& \mathrm{H}+\mathrm{RCH}=\mathrm{CHR}^{\prime} \rightarrow \mathrm{RCH}_{2} \mathrm{CHR}^{\prime} \\
& \mathrm{O}+\mathrm{RCH}=\mathrm{CHR}^{\prime} \rightarrow \text { addition complex } \\
& \mathrm{HO}+\mathrm{RCH}=\mathrm{CHR}^{\prime} \rightarrow \text { addition complex }
\end{aligned}
$$

There are extensive compilations and evaluations of data for reactions of this type (Kerr and Parsonage, 1972; Herron and Huie, 1973). The subject has been reviewed frequently over the past decade. (For a recent review on 0-atom additions, see Huie and Herron, 1975). Most of the measurements have been at relatively low temperatures, $<500 \mathrm{~K}$. Extrapolation to higher temperatures is very uncertain. The model for the transition state has not been established unambiguously. Prediction schemes of wide applicability are not avallable, although correlations have been made with various molecular parameters for limited sets of reactions. A correlation of activation energies with the ionization potential of the alkene is fairly effective. Kerr and Parsonage (1972) give a general discussion of the question.

Much more work is needed in this area, both measurements and correlations. For high temperature chemistry perhaps the most important 
kinetics problem to be solved is determining the relative efficiencies of addition and abstraction.

6.4.6 Bimolecular atom transfer reactions (abstraction reactions); These are of the type

$$
\mathrm{R}+\mathrm{A}-\mathrm{R}^{\prime} \rightarrow \mathrm{R}-\mathrm{A}+\mathrm{R}^{\prime}
$$

where $A$ is an atom and $R$ and $R^{\prime}$ may be either atoms or groups.

A substantial number of techniques have been proposed for predicting rate constants and activation energies. The major emphasis has been on hydrogen atom transfer reactions, i.e., $A=H$. This is the largest class of transfer reactions and the most important for combustion kinetics. There is very little information on the transfer of oxygen atoms, also very important. An experimental data base must be accumulated for such reactions.

Methods that predict rate constants are described first, then those that treat only activation energies.

(a) A Generalized Method for three atom systems where the atoms are $\mathrm{H}, \mathrm{N}$ and $\mathrm{O}$

This method (Benson et al, 1974) treats bimolecular atom transfer reactions and combination reactions. It is intended to be used only for high temperature reactions.

Universal rate constants are established that apply to an entire class. For example, for the eight reactions

$$
\begin{aligned}
& \mathrm{O}+\mathrm{OH} \underset{\leftarrow}{\mathrm{O}_{2}}+\mathrm{H}
\end{aligned}
$$

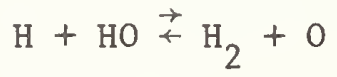

$$
\begin{aligned}
& \mathrm{N}+\mathrm{NO} \underset{\leftarrow}{\mathrm{N}_{2}}+\mathrm{O} \\
& \mathrm{N}+\mathrm{O}_{2} \rightleftarrows \mathrm{NO}+\mathrm{O}
\end{aligned}
$$

the same pre-exponential factor is used. The enthalpy of activation (for the exothermic direction) is either $29 \mathrm{~kJ} / \mathrm{mol}$ or $-4 \mathrm{~kJ} / \mathrm{mol}$. 
The latter is used if the transition state has a stable molecule as its analog. Stable means $\Delta \mathrm{H}_{\mathrm{f}} \leq$ the sum of the heats of formation of the reactants minus $12 \mathrm{~kJ} / \mathrm{mol}$.

This method has been compared, successfully, against the high temperature rate data evaluated by Baulch, Drysdale, Horne and Lloyd (1972, 1973). In some cases the predictions are easily as representative of the data as the evaluations. This may reflect more on the quality of the data than on the evaluations.

Similar simple rules apply to the combination reactions.

These authors are extending the method to cover all the threeatom reactions in the $\mathrm{H} / \mathrm{C} / \mathrm{N} / \mathrm{O}$ system.

\section{(b) Bond-energy bond-order method}

This technique treats

$$
R+A-R^{\prime} \rightarrow R A+R^{\prime}
$$

where $R$ and $R^{\prime}$ may be atoms or groups and $A$ usually is $H$ but, in variants of the method, may be a halogen atom or an oxygen atom. No kinetic data are used. The rate constant is calculated using molecular properties and the formalism of absolute rate theory. Many of the features of this method are found in other techniques to be discussed later. The scheme (Johnston and Parr, 1963; Johnston, 1966) is as follows.

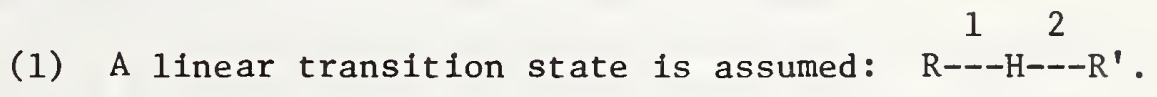

(2) Three potential energy interactions are assumed, each being of the form known for $\mathrm{H}-\mathrm{H}$ and of a strength controlled by internuclear separations. Those between $\mathrm{R}---\mathrm{H}$ and $\mathrm{H}---\mathrm{R}^{\prime}$ are attractive and that between $R---R^{\prime}$ is repulsive. 
(3) As one bond, $H-R^{\prime}$, weakens, the other bond, $R-H$ forms in a manner such that the "orders" of the bonds add up to unity (a single bond). This order relationship is based on a general rule developed by Pauling.

(4) A closed algorithm embodying the three points above permits calculation of the energy barrier and the configuration (bond distances) in the transition state. Given this configuration, the entropy of activation is calculated using simplified absolute rate theory.

(5) The calculation is repeated for several temperatures over the range of interest. (The pre-exponential factor is temperature dependent). Activation energies calculated by this method agree with experiment to within $8 \mathrm{~kJ} / \mathrm{mol}$ in most cases. Rate constants are often within a factor of 2. A factor of five discrepancy is unusual.

The importance of this method is the complete absence of kinetics data in the expressions used for the calculation. Spectroscopic and thermochemical data (bond strengths) are needed. One variant of this method is applicable to halogen atom transfer reactions. Another treats oxygen atom transfers and introduces several general postulates about reaction paths. (Mayer, 1969; Mayer et a1, (1967)) . 
Clark and Dove (1973) have introduced a method for correcting for effect of the end groups $R$ and $R^{\prime}$ being multi-atom groups, e.g. $\mathrm{CH}_{3} \mathrm{CH}_{2} \cdot$, and have obtained good fits to experimental data for three reactions when the repulsion term for $R-R^{\prime}$ is a (slightly) adjustable parameter. Curvature in the Arrhenius plots is noticeable. Arthur et al (1974) also have developed a new repulsive energy approximation that leads to somewhat better agreement with experiment for reactions of $\mathrm{CH}_{3}$ and $\mathrm{CF}_{3}$. About 400-500 BEBO calculations have been reported in the scientific literature (See, for example, Mayer and Schieler, 1968; Carr, 1972). A systematic comparison of the results of this method against the evaluations of Baulch et al $(1972,1973)$ should be made. It would give an indication of reliability and a comparison with the estimation method of Benson, et a1., described earlier.

\section{(c) Activation energies from bond strengths and vibrational}

\section{$\underline{\text { frequencies }}$}

This is a linear transition state model for hydrogen atom transfer reactions that bears a family relationship to $B E B O$ but uses a different definition of the transition state and different, non-kinetic, input data. It has been presented and tested only as a method for computing activation energies. However rate constants could be calculated using standard absolute rate theory methods for the pre-exponential term, since the geometry of the transition state is defined. How well, or poorly, the rate constants would match with experiment is not known. 
Two formulations have been presented (Zavitsas, (1972);

Zavitsas and Melikian, (1975). The latter is described here.

(1) A linear transition state is assumed.

(2) For the transition state A--H---B

bonding energies for $\mathrm{A}-\mathrm{H}$ and $\mathrm{H}-\mathrm{B}$ are calculated from Morse curves based on observed dissociation energies and vibrational frequencies. Antibonding between $A-B$ is estimated using a Sato repulsive "Morse Curve". A fixed delocalization energy term (for the odd electron being on any of the three groups) is included. Its value is based on that for the allylic radical, $\mathrm{CH}_{2}=\mathrm{CH}-\mathrm{CH}_{2} \cdot$.

(3) The bond distances in the transition state are defined as those with equal bonding energy in $\mathrm{A}-\mathrm{H}$ and $\mathrm{H}-\mathrm{B}$ that produce a minimum total energy for the three group system (measured from the dissociation energy of reactant $\mathrm{A}-\mathrm{H}$ ) .

Comparisons are made with experiment for 83 reactions. The overall statistics show the following performance.

No. of activation energies

26

7

11
Range

Within spread of reported measurements.

Less than $4 \mathrm{~kJ} / \mathrm{mol}$ from range of measurements.

Between 4 and $8 \mathrm{~kJ} / \mathrm{mol}$ from measurements.

Greater than $8 \mathrm{~kJ} / \mathrm{mol}$ from measurements.

The authors discuss the causes of some of the discrepancies and apply the method to revise bond strengths.

This is a method that should be studied in detail in order to define its limits. 
6.4.6 Methods for estimating activation energies for bimolecular

\section{reactions}

Techniques have been proposed and tested since the 1930 's. Some are correlations of kinetics data and some are correlations of activation energies with molecular properties. They all work best for closely related reactions. Those that correlate $\mathrm{E}^{*}$ with molecular parameters rely on the fact that molecular properties vary in a regular manner for a series of closely related molecules.

$$
\begin{aligned}
& \text { (a) The Evans-Polanyi-Semenov correlation. This is } \\
& \mathrm{E}^{*}=\mathrm{A}-\mathrm{b} \cdot \mathrm{q}
\end{aligned}
$$

where $q=-\Delta H$, the heat released by the reaction (Evans and Polanyi, 1938). Semenov (1958) showed that agreement with experiment to \pm 8 $\mathrm{kJ} / \mathrm{mol}$ could be obtained for the complete set of atom-molecule reactions available at that time. Various workers have correlated very closely related sets of reactions to better than $\pm 2 \mathrm{~kJ} / \mathrm{mol}$. It remains a very useful method, although many alternatives have been proposed.

(b) The BEBO correlation. An empirical equation was developed (Johnston, 1966, page 209, 347)

$$
\mathrm{E}^{*} / \mathrm{E}_{2}=\left(1-\mathrm{q} / \mathrm{E}_{2}\right)\left\{1-\left[1+\left(1-\mathrm{q} / \mathrm{E}_{2}\right)^{\mathrm{p} / \mathrm{p}-1}\right]^{1-\mathrm{p}}\right\}
$$

where $q$ is the energy released, $E_{2}$ is the energy of the bond formed and $\mathrm{p}$ is an adjustable constant related to the "bond order". The parameter $\mathrm{P}$ is set using $\mathrm{E}^{*}$ and $\mathrm{E}_{2}$ for one of a related set of reactions. Then $\mathrm{E}^{*}$ 's for others are estimated using the known $\mathrm{E}_{2}$ 's. Trends in reactivity are reproduced in a reasonable manner. Rate constants can be calculated since the geometry of the transition state is defined when $\mathrm{P}$ and $\mathrm{E}^{*} / \mathrm{E}_{2}$ are known. Performance equal to or better than the Evans-Polanyi-Semenov relation is claimed. 
This technique should be tested on cases where close

agreement has been found for the EPS relation and also to find out where it fails. It is important because only one well defined reaction is needed to set the scale.

(c) Marcus' generalized method. An expression is presented for calculating activation energies of electron-transfer reactions in solution and atom transfer reactions in the gas phase (Marcus, 1968). It contains $\mathrm{BEBO}$ as a special case. The most interesting feature is its ability to predict the activation energy of

$$
\mathrm{A}+\mathrm{HB} \rightarrow \mathrm{AH}+\mathrm{B}
$$

from

$$
\mathrm{A}+\mathrm{HA} \rightarrow \mathrm{AH}+\mathrm{A}
$$

and

$$
\mathrm{B}+\mathrm{HB} \rightarrow \mathrm{BH}+\mathrm{B}
$$

Forty five comparisons were made with BEBO calculations. Marcus' method yields slightly lower $\mathrm{E}^{*}$. Eighteen cases agreed to $<2 \mathrm{~kJ} / \mathrm{mol}, 12$ to $\sim 4 \mathrm{~kJ} / \mathrm{mol}, 13$ to $\sim 8 \mathrm{~kJ} / \mathrm{mol}$ and two to $10-12 \mathrm{~kJ} / \mathrm{mol}$.

(d) Correlation with references. Spirin (1962) proposed

a correlation for the reaction $\mathrm{A}+\mathrm{BC} \rightarrow \mathrm{AB}+\mathrm{C}$

$$
\mathrm{E}^{*}=0.066\left[(0.751)_{\mathrm{AC}}-\mathrm{Q}\right]\left[1 / \mathrm{P}_{\mathrm{A}}+1 / \mathrm{P}_{\mathrm{C}}\right]-1.6
$$

where $D_{A C}$ is the bond strength of the $A-C$ molecule, $Q$ is the heat of reaction, and the $\mathrm{P}^{\prime}$ s are modified molar refractions. The Evans-Polanyi-Semenov relationship is, formally, a special case. For 40 cases tested, 32 agreed with experiment to within $\pm 8 \mathrm{~kJ} / \mathrm{mol}$.

(e) Correlation of activation energies with electron affinities.

Alfassi and Benson (1973) produced a two constant correlation 


$$
E^{*}=a-b I \text { for } E^{*}>0 \text {, otherwise } E^{*}=0
$$

where $I$ is the sum of the electron affinities of $R$ and $R^{\prime}$ in $\mathrm{R}+\mathrm{A}-\mathrm{R}^{\prime} \rightarrow \mathrm{RA}+\mathrm{R}^{\prime}$ and $\mathrm{a}$ and $\mathrm{b}$ are adjustable constants. Based on 30 comparisons with experiment the average fit is $\pm 1.7 \mathrm{kcal}$. The biggest limitation of the method is the dearth of electron affinity data.

(f) Empirical end-group correlations. Alfassi and Benson (1973) also proposed and tested two empirical expressions

$$
E^{*}=X+X^{\prime}
$$

and

$$
E^{*}=F \cdot F^{\prime}
$$

for the process $R+A R^{\prime} \rightarrow R A+R^{\prime}$ where the $X^{\prime} s$ or $F^{\prime}$ 's are set by comparison with experiment. Note that these approaches ignore the transferred atom, as do others. Both models were tested against 50 measurements (38 of which were hydrogen atom transfers). The average agreement in both cases in about $\pm 1 \mathrm{kcal}$.

Reactions of highly polar groups are not fit well. A point-dipole model is presented and applied to $\mathrm{CF}_{3}$ as a correction on the estimates.

(g) Correlation of activation energies and entropies by class of reaction. In a series of papers $\mathrm{Szabo}$ and Berces present a formal classification of gas phase reaction based on types of transition state (Szabo, 1967) and develop a calculation formula for activation energies for each class (Szabo and Berces, 1968a). Later they give activation entropies for classes of unimolecular reactions (Szabo and Berces, 1968b).

The activation energy formula is

$$
E^{*}=\Sigma D(\text { broken })-\alpha \Sigma D(\text { formed })
$$


where the D's are bond strengths, either measured or obtained

from an estimation scheme. $\alpha$ is a parameter fitted to the general type of reaction. Comparisons with experiment are given for 28 atom transfer reactions (among others). Seventeen of these fit to $<1 \mathrm{kcal}$ and ten more to $<2 \mathrm{kcal}$. It is not apparent how many of the reactions presented were used to derive the $\alpha$ 's used in the correlation. In a sense this technique is an elaboration of the EPS method described earlier. This point is discussed by Szabo and Konkoly-Thege (1973).

(h) Group additivies for activation energies. Moin (1967) estimates the activation energies for both bimolecular abstraction reactions and unimolecular reactions using a group additivity approach. Only the former is described here. For the transition state

$$
\mathrm{R}---\mathrm{X}---\mathrm{R}^{\prime}
$$

(where the transferred atom is $\mathrm{H}$ in practice) the energy of dissociation of the complex is postulated to be the sum of the dissociation energies of the stretched bonds $\mathrm{R}---\mathrm{X}$ and $\mathrm{X}---\mathrm{R}^{\prime}$. In addition, the dissociation energy of $\mathrm{R}---\mathrm{X}$ is postulated to be independent of $R^{\prime}$. Then the activation energy is

$$
E^{*}=D(R-X)-\left(D(R--X)+D\left(R^{\prime}---X\right)\right)
$$

Tables of $\mathrm{D}(\mathrm{R}---\mathrm{X})$ are constructed using selected reactions and activation energies predicted for others. For 29 reactions tested agreement to $<1 \mathrm{kcal}$ was found for 24 cases. There should be a strong correlation between this method and that of Alfassi and Benson described above.

(i) Activation energies from superposition of Morse Curves Kaiga et al. (1969a) defined a reaction path for the process $A+X B \rightarrow A X+B$ whose energy was specified by the sum of the 
energies of Morse type potential energy curves for the reactant and product molećles.

The bonding energies of the two partial bonds in the transition state are set equal to each other and the parameters of the Morse curves are defined by an empirical relationship involving the energy of activation. (Compare: Zavitsas model, above). Agreement to $\pm 8 \mathrm{~kJ} / \mathrm{mol}$ is found in many cases.

From the model given above Kaiga et al (1969b) developed an empirical two parameter relationship expressing $\mathrm{E}^{*}$ in terms of a linear combination of the dissociation energies of the reactant and product model. The Evans-Polanyi-Semenov relation is a special case. Agreement to $\pm 8 \mathrm{~kJ} / \mathrm{mol}$ was found for most tests. The method is also used to interpret Hammett type reactivity correlations.

\subsubsection{Miscellaneous}

(a) Johnston and Birks (1972) present a conceptual model to explain why activation energies for the dissociation of diatomic molecules are less than the dissociation energy. This is not a method for estimating rate data. The principle is that the dissociating molecule can be treated as a truncated harmonic oscillator with all vibrational energy states contributing equally to the rate of dissociation.

(b) Denisov and Kosarev (1964) have made transition state calculations for radical reactions important in liquid phase oxidations. The types are

$$
\begin{aligned}
& \mathrm{R}+\mathrm{O}_{2} \rightarrow \mathrm{RO}_{2} \\
& \mathrm{RO}_{2}+\mathrm{RH} \rightarrow \mathrm{ROOH}+\mathrm{R}^{\prime} \\
& \mathrm{RO}_{2}+\mathrm{RO}_{2} \rightarrow \text { products }
\end{aligned}
$$


The potential importance of this work is that the authors define transition state geometry that may be applicable to similar reactions in the gas phase.

(c) Specific correlations. Most of the techniques discussed above are intended to be applicable to large classes of reactions. In general their performance is reasonable but not outstanding. There is another approach that often does very well for a restricted group of reactions. These highly specific correlations may prove to be more useful than the more general ones. Two examples are given here.

Greiner (1970a) develops a formula correlating rate constants for the abstraction by $\mathrm{OH}$ of a hydrogen atom from straight and branched chain alkanes from methane to 2,2,4 trimethyl pentane. Although problems may arise in extrapolating to $\mathrm{n}$-decane, the approach should be very useful for the lighter hydrocarbons. Greiner (1970b) has also correlated the activation energies for abstraction by $\mathrm{OH}$ with those for abstraction by $H$. In both of these correlations the essential factor is the number of primary, secondary and tertiary $\mathrm{C}-\mathrm{H}$ bonds in the alkane.

Rate constants and activation energies for $\mathrm{H}$-atom abstraction from aliphatic organic compounds have also been correlated by Shteinman (1974). These correlations relate the rate parameters to the reactivity parameter $\sigma^{*}$ developed by Taft and widely used for solution reactions. This work is of interest because it connects the attempts to predict gas phase rates to the much larger body of correlations developed by physical organic chemists. 


\section{High Temperature}

A quite different aspect of the problem of constructing a kinetics data base is examined here. The problem is how to make best use of data taken at lower temperatures.

There exists a large body of data for many of the elementary reactions of interest to combustion scientists. The vast majority of it was obtained at temperatures well below $1000 \mathrm{~K}$. Two questions arise: are the same products formed at higher temperatures, and how should the low temperature rate data be extrapolated to temperatures beyond $1000 \mathrm{~K}$. The first question - about what products are formed - is a matter of mechanism. The kineticist speaks of the branching ratio, the measure of the relative importance of two or more possible reaction paths starting with the same reactants, An example is

$$
\begin{aligned}
\mathrm{O}+\mathrm{C}_{2} \mathrm{H}_{4} & \rightarrow \mathrm{CHO}+\mathrm{CH}_{3} \\
& \rightarrow \mathrm{C}_{2} \mathrm{H}_{2} \mathrm{O}+\mathrm{H}_{2}
\end{aligned}
$$

At present branching ratios must be determined by experiment for the most important cases.

The second question - about extrapolating data - may be illustrated by an unresolved problem in the combustion of methane. Here a basic question stands out: what reactive species are responsible for the removal of $\mathrm{CH}_{4}$ ? Peters and Mahnen (1973) argue that methane is principally removed by $\mathrm{OH}$,

$$
\text { 1. } \mathrm{CH}_{4}+\mathrm{OH} \rightarrow \mathrm{CH}_{3}+\mathrm{H}_{2} \mathrm{O}
$$

On the other hand Dryer and Glassman(1973) argue that the $\mathrm{OH}+\mathrm{CH}_{4}$ reaction is less important than

$$
\text { 2. } \mathrm{O}+\mathrm{CH}_{4} \rightarrow \mathrm{CH}_{3}+\mathrm{OH}
$$

The argument turns on the values of the rate constants for reactions ( 1 ) and (2) which are derived at flame temperatures by extrapolation 
of lower temperature data. Figure 6.1, taken from Dryer and Glassman (1973), illustrates the problem. The older rate evaluations for reaction (1) by Drysdale and Lloyd (1970) and Wilson and Westenberg (1967) give rate constants much higher at flame temperatures than those obtained by extrapolation of the more recent experimental data of Greiner (1970). The former results in $\mathrm{k}\left(\mathrm{OH}+\mathrm{CH}_{4}\right) \gg \mathrm{k}\left(\mathrm{O}+\mathrm{CH}_{4}\right)$; the latter $\mathrm{k}\left(\mathrm{OH}+\mathrm{CH}_{4}\right)$ $<\mathrm{k}\left(\mathrm{O}+\mathrm{CH}_{4}\right)$. The new data does not completely resolve the problem however, as the whole question of the validity of extrapolating Arrhenius plots to higher temperatures is open to serious question.

For the vast majority of reactions, the dependence of the rate constant on temperature can be expressed by means of the Arrhenius equation, $k=A e^{-E / R T}$. For all practical purposes this is an empirical expression which has had a remarkable success in fitting the vast majority of rate data. Unfortunately, the success of the Arrhenius expression had led to the discounting of data which could not be fitted in the linear $\log \mathrm{k}$ vs $1 / \mathrm{T}$ form. In particular shock-tube data have been discounted since the rate constants have often been found to be considerably higher than would be predicted by linear Arrhenius extrapolations. There is now reason to believe that the extrapolation procedure is incorrect, and that the shock-tube data cannot be rejected out-of-hand. Figure 6.2, taken from Baulch, Drysdale and Horne (1973), gives the data for Co $+\mathrm{OH}$, a key combustion reaction. Linear extrapolation of the data below $1000 \mathrm{~K}$ clearly leads to considerable error in the rate constant at $\mathrm{T}>1000 \mathrm{~K}$. The curved Arrhenius plot for $\mathrm{CO}+\mathrm{OH}$ has been justified on the basis of transition state calculations (Dryer et al, 1971). Evidence for nonArrhenius behavior has now been reported for $\mathrm{OH}+\mathrm{H}_{2}$ and $\mathrm{OH}+\mathrm{OH}$, (Gardiner et a1, 1973) and for $\mathrm{CH}_{3}+\mathrm{C}_{2} \mathrm{H}_{6}$ and $\mathrm{CH}_{3}+\mathrm{H}_{2}$. (Clark, 1973). 


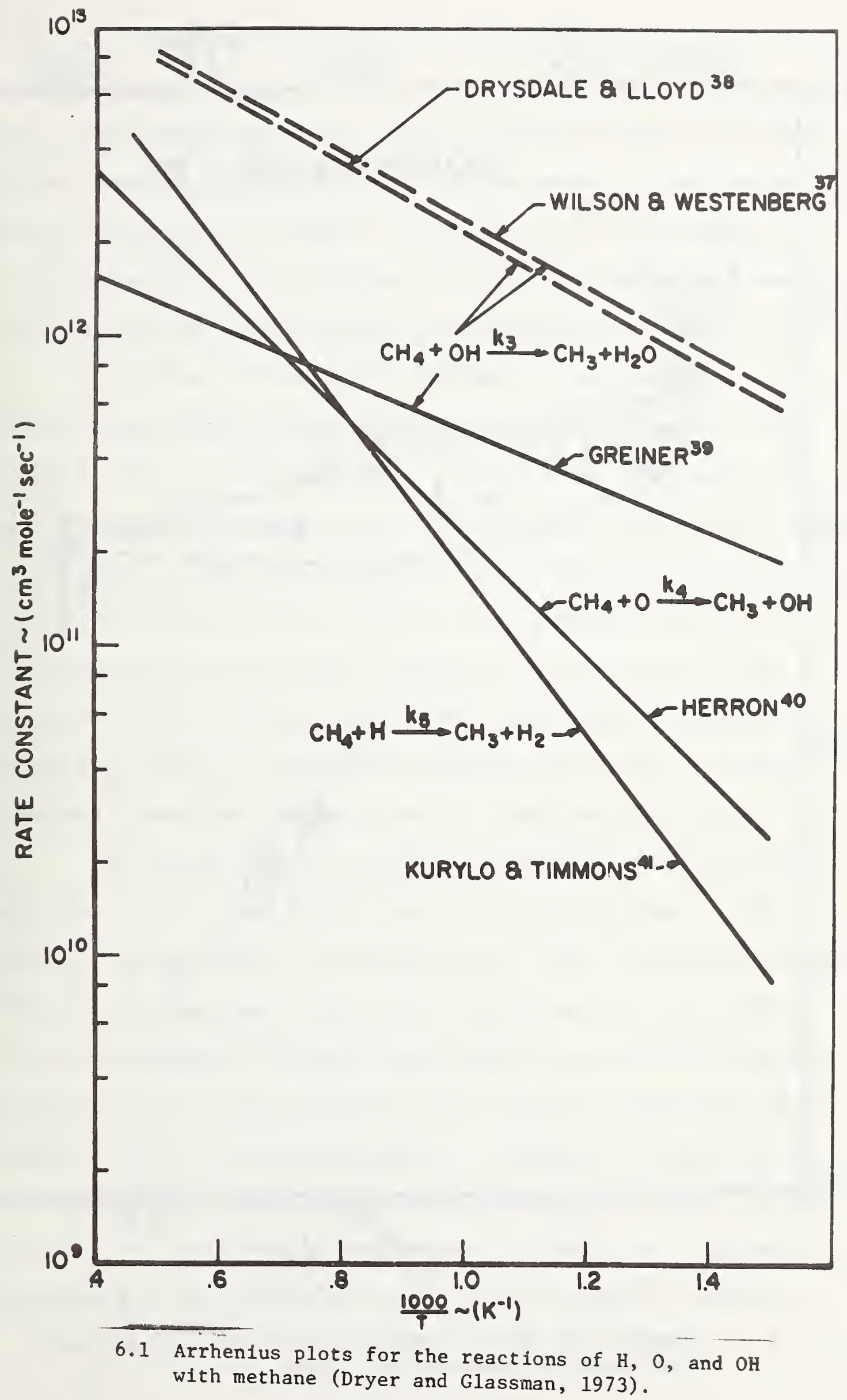




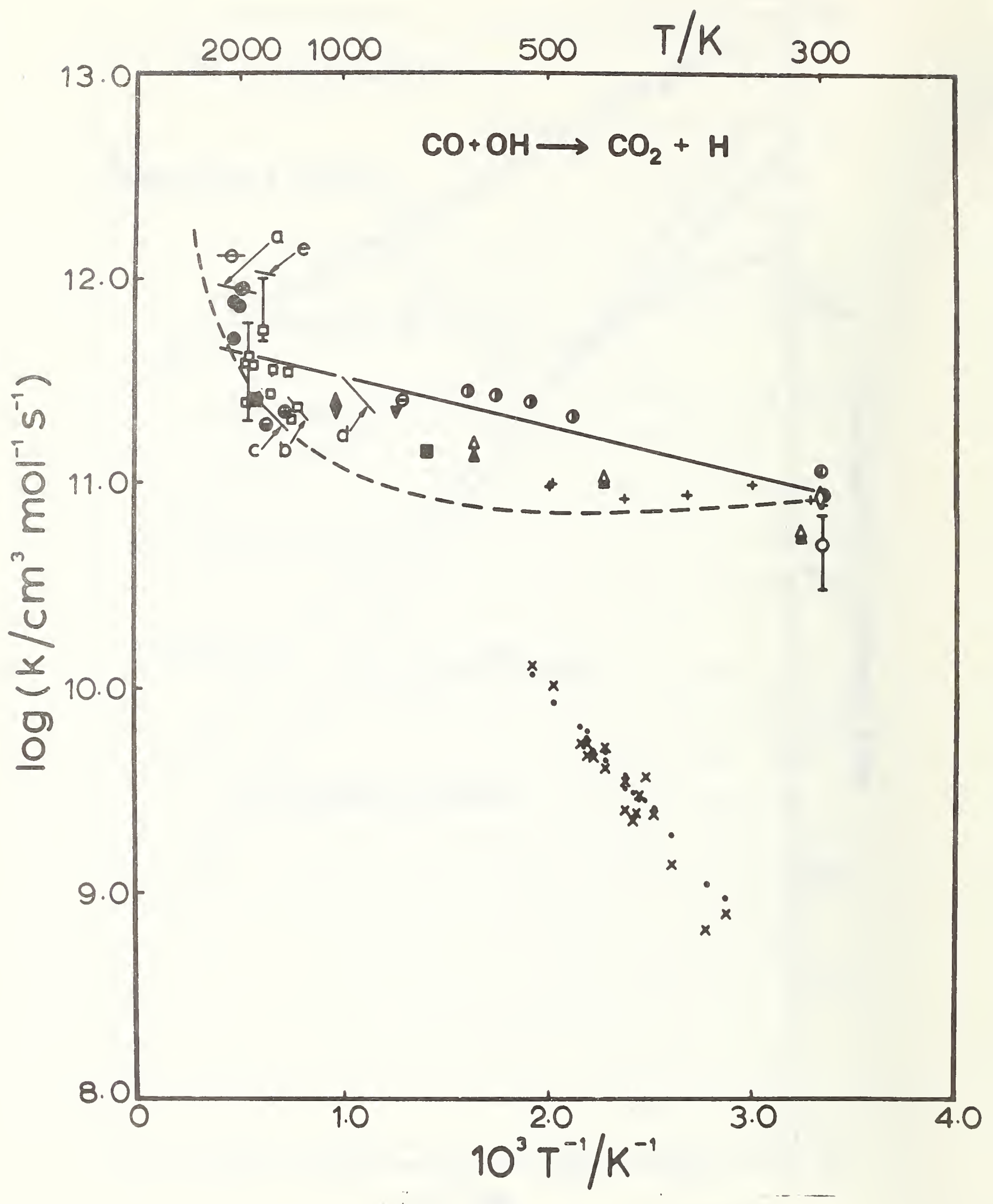

6.2 Arrhenius plot for the reaction of hydroxyl radicals with carbon monoxide (Baulch et al, 1973). 
It should be emphasized that curved Arrhenius plots can arise for reasons other than the formalism of the rate expression. For example, the reaction may involve competing reaction channels which have different temperature dependencies. A further source of complication in bimolecular reactions arises when the Arrhenius activation energy, E, has a negative value. For reactions with activation energies of several $\mathrm{kJ}$ or less, this may be more common than is realized at present.

Aside from the fundamental problems of reaction kinetics, there is an additional problem encountered in extrapolating Arrhenius type plots. This is a data problem. It arises from the procedure of deriving "consensus" values of rate constants by the statistical treatment of large bodies of data from different sources. The result of this procedure is to wash out fine structure in any particular study. The basic problem here is the lack of criteria for the rejection of less accurate data. The very great improvement in experimental technique over the past decade, if applied in a consistent and methodical manner to combustion reactions, should allow us to overcome this problem.

For certain classes of combustion reactions involving reactive species such as $\mathrm{O}, \mathrm{H}$, and $\mathrm{OH}$ there now exist highly accurate $( \pm 10 \%)$ techniques for measurement of rate constants. These techniques include flash photolysis-resonance fluorescence, modulation photolysis, shocktube, laser paramagnetic resonance spectroscopy, and mass spectrometry. They have not been (aside from shock-tube) applied at temperatures much in excess of $500 \mathrm{~K}$. A primary objective of combustion research should be the application of these techniques at temperatures greater than 500 $\mathrm{K}$, 1.e., in the range $500-1300 \mathrm{~K}$ to provide the basis for a fundamental understanding of the temperature coefficients of combustion reactions. 
Such data should then be used in conjunction with theoretical expressions to extrapolate the rate expressions to higher temperature and overlap the shock tube data. The BEBO (bond energy-bond order) approach (Johnston, 1966) appears to be well suited to a solution of this problem.

\subsection{Summary}

(a) The present resources in the form of evaluated rate data are large and are immediately applicable to high temperature kinetics problems .

(b) Additional evaluations of data for important reactions will be required.

(c) New experimental and theoretical work is needed to resolve the problem of how best to extrapolate low temperature kinetics data to temperatures above $1000 \mathrm{~K}$.

(d) Inevitably there will be many reactions of interest for which there are no reliable rate data but for which rate constants will be needed in the near future. Methods for predicting many of these, but not a11, exist.

(e) There is a wide variety of prediction schemes, most of which do only part of the job of estimating rate constants as a function of temperature. Many of them have been demonstrated to have reasonable performance. However, it is not now known which are the most reliable and the most widely applicable. There is a need for a detailed study and cross comparison of the methods, particularly those that estimate rate constants and entropies of activation. Methods that estimate or correlate activation energies are useful but less important for high temperature studies. 
Alfassi, Z. B., and Benson, S. W., "A Simple Empirical Method for the Estimation of Activation Energies in Radical Molecule Metathesis Reactions," Intern. J. Chem. Kinet. 5, 879 ( 1973)

Allara, D. L., "A Compilation of Kinetic Parameters for the Thermal Degradation of n-Alkane Molecules," (Bell Telephone Laboratories, 1973, typescript)

Arthur, N. L., Donchi, K. F., and McDonell, J. A., "BEBO Calculations. III. A New Triplet Repulsion Energy Term," J. Chem. Phys. 62, 1585 (1975)

Baulch, D. L., and Drysdale, D. D., "An Evaluation of the Rate Data for the Reaction $\mathrm{CO}+\mathrm{OH} \rightarrow \mathrm{CO}_{2}+\mathrm{H}, "$ Combust. Flame 23, 215 (1974)

Baulch, D. L., Drysdale, D. D., Horne, D. G., and Lloyd, A. C., "Evaluated Kinetic Data for High Temperature Reactions Volume 1: Homogeneous Gas Phase Reactions of the $\mathrm{H}_{2} \mathrm{O}_{2}$ Systems, (Butterworths, London, 1972)

Baulch, D. L., Drysdale, D. D., and Horne, D. G., "Evaluated Kinetic Data for High-Temperature Reactions, Volume 2: Homogeneous Gas Phase Reactions of the $\mathrm{H}_{2}-\mathrm{N}_{2}-\mathrm{O}_{2}$ System," (Butterworths, London, 1973)

Baulch, D. L., Drysdale, D. D., and Horne, D. G., "An Assessment of Rate Data for High-Temperature Systems," Symp. Combust. 14th (Combustion Institute, Pittsburgh, 1973) 107

Benson, S. W., "Thermochemical Kinetics," (John Wiley and Sons, 1968)

Benson, S. W., and Bose, A. N., "Structural Aspects of the Kinetics of Four-Center Reactions in the Vapor Phase," J. Chem. Phys. 39, 3463 (1963)

Benson, S. W., Cruickshank, F. R., Golden, D. M., Haugen, G. R., O'Neal, H. E., Rodgers, A. S., Shaw, R., and Walsh, R., "Additivity Rules for the Estimation of Thermochemical Properties," Chemical Reviews 69, 279 (1969)

Benson, S. W., Golden, D. M., Lawrence, R. W., Shaw, R., and Woolfolk, R. W., "Estimation of Rate Constants as a Function of Temperature for Reactions $X+Y Z \rightleftarrows X Y+Z$,

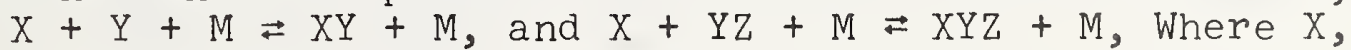
$Y$, and $Z$ are Atoms, $H, N, O, "$ Presented at the Symposium on Chemical Kinetics Data for the Lower and Upper 
Atmosphere, September 16-18, 1974, Airl1e House, Warrenton, Virginia, U.S.A.. To be published in Intern. J. Chem. Kinet.

Benson, S. W., and Haugen, G. R., "A Simple, Self-Consistent Electrostatic Model for Quantitative Prediction of the Activation Energies of Four-Center Reactions," J. Amer. Chem. Soc. 87, 4036 (1965)

Benson, S. W., and O'Neal, H. E., "Kinetic Data on Gas Phase Unimolecular Reactions," U.S. National Bureau of Standards, NBS-NSRDS-21, 645pp., (1970)

Carr, R. W., Jr., "Predictions of the Rates of Hydrogen Abstraction by $\mathrm{CH}_{2}\left({ }^{3} \mathrm{~B}_{1}\right)$ by the Bond-Energy Bond-Order Method," J. Fhys. Chem. 76, 1581 (1972)

Clark, T. C., "Comments," on Gardiner, et a.l., pp. 61 Symp. Combust. 14th (Combustion Institute, Pittsburgh, 1973) 73

Clark, T. C., and Dove, J. E., "Examination of Possible NonArrhenius Behavior in the Reactions $\mathrm{H}+\mathrm{C}_{2} \mathrm{H}_{6} \rightarrow \mathrm{H}_{2}+\mathrm{C}_{2} \mathrm{H}_{5}$, $\mathrm{H}+\mathrm{CH}_{4} \rightarrow \mathrm{H}_{2}+\mathrm{CH}_{3}, \mathrm{CH}_{3}+\mathrm{C}_{2} \mathrm{H}_{6} \rightarrow \mathrm{CH}_{4}+\mathrm{C}_{2} \mathrm{H}_{5}$," Can. J. Chem. 51, 2147 (1973)

Denisov, E. T., and Kosarev, V. P., "Calculation of the PreExponential Factors for Certain Elementary oxidation Reactions," Russ. J. Phys. Chem. 38, 1564 (1964).

Dryer, F. L., and Glassman, I., "High Temperature Oxidation of $\mathrm{CO}$ and $\mathrm{CH}_{4}$," Symp. Combust. 14th (Combustion Institute, Pittsburgh, 1973) 987

Dryer, F., Naegeli, D., and Glassman, I., "Temperature Dependence of the Reaction $\mathrm{CO}+\mathrm{OH}=\mathrm{CO}_{2}+\mathrm{H}, "$ Combust. Flame 17, 270 (1971)

Drysdale, D. D., and Lloyd, A. C., "Gas Phase Reactions of the Hydroxyl Radical," Oxidation and Combustion Rev. 4 , 157 (1970)

Evans, M G., and Polanyi, M., "Inertia and Driving Force of Chemical Reactions," Trans. Faraday Soc. 34, 11 (1938) 
Gardiner, W. C., Jr., Mallard, W. G., McFarland, M., Morinaga, K., Owen, J. H., Rawlins, W. T., Takeyama, T., and Walker, B. F., "Flementary Reaction Fates from PostInduction-Period Profiles in Shock-Initiated Combustion," Symp. Combust. 14th (Combustion Institute, Pit,sburgh, 1973) 61

Golden, D. M., "Estimation of Rate Constants of Elementary Processes-A Review of the State of the Art," Symp. Combust. 14th (Combustion Institute, Fittsburgh, 1973) 121

Greiner, N. R., "Hydroxyl Radical Kinetics by Kinetic Spectroscopy. VI. Reactions with Alkanes in the Range 300-500 K," J. Chem. Phys. 53, I070 (1970a)

Greiner, N. R., "Comparison of the Kinetics of Alkane H-Atom Abstraction by Methyl and Hydroxyl Radıcalı, "T. Chem. Phys. 53, 1285 (1970b)

Haugen, G. R., and Eenson, S. W., "A Simple, Self-Consistent Electrostatic. Model for Quantitative Prediction of the Activation Energies of Four-Center Reactions. II.," Intern. J. Chem. Kinet. 2, 235 (1970)

Herron, J. T., "An Evaluation of Rate Data for the Reactions of Atornic oxygen ( $\left.O^{3} \mathrm{P}\right)$ with Methane and Ethane," Intern. J. Chem. Kinet. I, 527 (1969)

Herron, J.T., and Huie, R. E., "Rate Constants for the Reactions of Atomic Oxygen $\left(O^{3} \mathrm{P}\right)$ with organic Compounds in the Gas Phase," J. Phys. Chem. Ref. Data 2, 467 (1973)

Huie, R. E., and Herron, J. T., "Reactions of Atomic Oxygen $\left(\mathrm{O}^{3} \mathrm{P}\right)$ with Organic Compounds," Prog. React. Kinetics 8 , 1 (1975)

Johnston, H. S., "Gas Phase Reaction Rate Theory," (Ronald Press, New York, 1966)

Johnston, H., and Birks, J., "Activation Energies for the Dissociation of Diatomic Molecules Are Less than the Bond Dissociation Energies," Accounts Chem. Res. 5, 327 (1972)

Johnston, H. S., and Parr, C., "Activation Energies from Bond Energies. I. Hydrogen Transfer Reactions," T. Amer. Chem. Soc. 85, 2544 (1963) 
Kagiya, T., Sumicia, Y., Inoue, T., and Dyachkovskii, F. S.,

"Evaluation of the Activation Energies of Radical

Substitution Reactions in the Gaseous Phase. I. An

Empirical Method Employing the Morse Function," Bull.

Chem. Soc. Japan 42, 1812 (1969)

Kagiya, T., Sumida, Y., and Inoue, T., "Evaluation of the Activation Energies of Radical Substitution Reactions in the Gaseous Phase. II. An Approximate Formula with Two Constants," Bull. Chem. Sco. Japan 42, 2422 (1969)

Kerr, J.A., and Parsonage, M. J., "Evaluated Kinetic Data on Gas Phase Addition Reactions: Reactions of Atoms and Radicals with Alkenes, Alkynes and Aromatic Compounds," (Butterworths, 1972)

Koch, J.G., "Chemical Kinetics Tables, Data Evaluations and Bibliographies. A Guide to the Literature,"

U.S. National Bureau of Standards NBS LP 73 (Revised) November 1974

Maltman, K. R., Tschuikow-Roux, E., and Jung, K.-H., "A Modifled Semi-Ion-Pair Model for the Evaluation of Activation Energies of Four-Center Addition Reactions of Hydrogen Halldes to Olefins," J. Phys. Chem. 78, 1035 (1974)

Mayer, S. W., "Estimation of Activation Energies for Nitrous Oxide, Carbon Dioxide, Nitrogen Dioxide, N1tric Oxide, Oxygen, and Nitrogen Reactions by a Bond-Energy Method," J. Phys. Chem. 73, 3941 (1969)

Mayer, S. W., and Schieler, L., "Computed Activation Energies and Rate Constants for Forward and Reverse Transfers of Hydrogen Atoms," J. Phys. Chem. 72, 236 (1968)

Mayer, S. W., Schieler, L., and Johnston, H. S., "Computation of High-Temperature Rate Constants for Bimolecular Reactions of Combustion Products," Symp. Combust. 1lth (Combustion Institute, Pittsburgh, 1967) 837

Marcus, R. A., "Theoretical Relations Among Rate Constants, Barrlers, and Bronsted Slopes of Chemical Reactions," J. Phys. Chem. 12, 891 (1968)

Mo1n, F. B., "Calculation of the Activation Energy of Chemical Reactions on the Basis of the Additivity Principle," Russ. Chem. Rev1ews 36, 511 (1967) 
O'Neal, H. D., and Benson, S. W., "Thermochemistry of Free Radicals," in "Free Radicals," editor Jay K. Koch1

(John Wiley and Sons, New York, 1973) volume?, 2.7!

Peeters, J., and Mahnen, G., "Reaction Mechanisins and Rate Constants of Elementary Steps in Methane-Oxygen Flames," Symp. Combust. 14th (Combustion Institute, Pittsburgh, 1973) 133

Semenov, N. N., "Some Problems in Chemical Kinetics and Reactivity," Volume 1, translated by Michel Boudart (Princeton University Press, 1958) pp. 29-49

Shteinman, A. A., "Correlation Analysis of the Reactivity of $\mathrm{C}-\mathrm{H}$ Bonds in Homolytic Reactions," Kinet. Catalysis 15, $745(1974)$

Spirin, Yu. L., "The Activation Energy of Radical Reactions," Russ. J. Phys. Chem. 36, 636 (1962)

Szabo, Z. G., "The Transition State and the Arrhenius" Parameters. I. Classification of Homogeneous Gas Reactions," Zeit. Physik. Chem. N.F., 55, I (1967)

Szabo, Z. G., and Bérces, T., "The Transition State and the Arrhenius' Parameters. II. Evaluation of Activation Energy," Ze1t. Physik. Chem. N.F., 57, 113 (1968)

Szabo, Z. G., and Bérces, T., "The Transition State and the Arrhenius' Parameters. III. Evaluation of Preexponential Factor on the Activation of Homogeneous Gas Reactions," Zeit. Physik. Chem. N.F., 57, 123 (1968)

Szabo, Z. G., and Konkoly Thege, I., "The Transition State and Arrhenius' Parameters. IV. On the 'Constants' of the Polányi-Evans Equation," Zeit. Physik. Chem. N.F., 84, 62 (1973)

Tsang, W., "Thermal Decomposition of 3,4-Dimethylpentene-1 2,3,3-Trimethylpentane, 3,3-Dimethylpentane, and Isobutylbenzene in a Single Pulse Shock Tube," Intern. J. Chem. Kinet. 1, 245 (1969)

Tsang, W., "Thermal Decomposition of Some Alkyl Halides by a Shock Tube Method," J. Chem. Phys. 41, 2487 (1964) 
Tsang, W., "Comparisons between Experimental and Calculated Rate Constants for Dissociation and Combination Reactions Involving Small Polyatomic Molecules," Intern. J. Chem. Kinet. 5, 947 (1973)

Tschuikow-Roux, E., and Maltman, K. R., "Application of the Modified Semi-Ion Pair Model for the Evaluation of Activation Energies for $\mathrm{HX}(\mathrm{X}=\mathrm{F}, \mathrm{Cl}, \mathrm{Br}, \mathrm{I}, \mathrm{OH})$ Addition to Olefins," Intern. J. Chem. Kinet. I, 363 (1975)

Ulitskii, V. A., and Stepukhovich, A. D., "Steric Factors and Rate Constants for Recombination Reactions of Alkyl Radicals," Russ. J. Phys. Chem. 37, 359 (1963)

Wilson, W. E., Jr., "A Critical Review of the Cas-Phase Reaction Kinetics of the Hydroxyl Radical," J. Phys. Chem.. Ref. Data 1, 535 (1972)

Wilson, W. E., and Westenberg, A. A., "Study of the Reaction of Hydroxyl Radical with Methane by Quantitative ESR," Symp. Combust. Ilth (Combustion Institute, Pittsburgh, 1967) 1143

Zavitsas, A. A., "Activation Energy Requirements in Hydrogen Abstractions. Quantitative Description of the Causes in Terms of Bond Energies and Infrared Frequencies," J. Amer. Chem. Soc. 94, 2779 (1972)

Zavitsas, A. A., and Melikian, A. A., "Hydrogen Abstractions by Free Radicals. Factors Controlling Reactivity," J. Amer. Chem. Soc. 97, 2757 (1975) 
7.1 The preceding sections have developed a picture of the information that is required for the useful modeling of combustion phenomena and of the behavior of combustion devices. These are rate data on pyrolysis of stable compounds and free radicals, rate data and mechanisms for oxidation reactions, and rate data on free radical reactions, all at high temperatures. A large body of information exists on such processes but much of it is not usable by modelers, because the data are fragmentary, unevaluated and often not applicable at high temperatures, as well as not being assembled into a form usable by modelers. This situation is the basis for our recommendation of a technical program proceeding along three parallel lines:

(a) An activity leading to the development of a printed, published, up-to-date body of pertinent data for the user community. This would be periodically up-dated and refined on the basis of latest available information.

(b) An activity concerned with the measurement of rates and mechanisms of oxidation processes in the appropriate high temperature regime, leading to specific information currently lacking and also directed at development of prediction schemes for additional information.

(c) An activity concerned with the measurement of rates and mechanisms of pyrolysis and hydrogen atom reactions in the appropriate high temperature regime with similar objectives.

Although an activity concerned with pollutant aspects is also desirable, we feel that the initial emphasis should be directed to the primary combustion aspects. Specific recommendations for pollutant kinetics studies could be readily formulated. 
The nature, quality, and scope of the published data base is of necessity determined by the data that is available or can be estimated as well as by the extent to which specific data needs are defined by the users. The needs as outlined above are general. They are only an approximation, albeit a good one. This activity will proceed in an iterative fashion, leading to a succession of output documents of increasing quality, scope and appropriateness.

The evolution and tactics of the experimental subprograms will be determined by the data needs and the availability of appropriate experimental techniques. Whereas there are significant data needs in all classes of processes described above, the reactions of hydrogen atoms and hydroxyl radicals at high temperatures represent areas of greatest ignorance.

There are three types of experimental techniques, all developed at NBS, which can be brought to bear on these measurement problems. One of these, the single pulse shock tube technique is already suited to obtain information on certain rates and mechanisms at the appropriate high temperatures. The two other techniques, kinetics mass spectrometry and flash photolysis resonance fluorescence will require modification to permit high temperature measurements. With these modifications, a systematic program of measurements can be undertaken. One important feature of this set of capabilities is that in a number of instances the same measurement problem can be attacked by several different types of experiments. This will be extremely useful in minimizing the possibility of systematic errors in the measurements.

More detailed description of the technical program is given in the following sections under the three categories of technical activities given above. The apparent duplication of selected experimental objectives 
is intentional and is meant to indicate where a measurement problem could be solved by a variety of experimental approaches. In selected instances, this should in fact be done for reasons discussed above. An equally close coordination is also required between the activity aimed at providing a data base and the true experimental activities in order to ensure the most rapid and effective improvement of the quality of the data base and to make available additional expert opinion for the critical evaluation of selected data.

7.2 Construction of a Combustion Kinetics Data Base

7.2.1 Introduction and Design

A plan is given in this section for providing the designer of equipment and the modeler of combustion phenomena with the chemical kinetics data needed in his solution of his particular problem.

This data base will consist of entries for elementary gas phase reactions.

Each entry will contain:

(a) The chemical reaction.

(b) It rate constant as a function of temperature, and, where necessary, also as a function of pressure.

(c) As estimate of the reliability of the rate constant, where possible.

(d) Comments as needed.

(e) References.

\subsubsection{Objectives}

(a) To provide tables of chemical kinetics data oriented toward the solution of combustion problems. They are to include reactions of major importance for every conversion, for pollutant control and for the explanation of characteristic phenomena of flames. They are also to include less important reactions about which information is needed for 
screening purposes, 1.e. setting the minimum chemical mechanism needed for the study of a particular problem.

(b) To distribute these tables periodically to engineers, designers and other students of combustion systems and high temperature industria1 processes.

\subsubsection{Detailed Plan}

The steps described here emphasize the rapid development of a kinetics data base useful for current problems. They also allow for refinement of the data base and expansion to include new problem areas. First Round (steps a through g)

(a) Analyze the current problems of interest in terms of the chemistry contained in them.

The early stages of this phase are displayed in other sections of this report.

(b) Develop a catalog of elementary chemical reactions for which rate data should be provided.

Some examples are given elsewhere in this report. But the catalog should be expanded and refined working together with the ultimate users of the data.

(c) Compile the evaluated rate data available in current tables, data reviews and monographs.

(d) Annotate the catalog mentioned above to show the reliability of the data and its suitability for use in combustion studies.

This is an analysis to be made by kineticists.

(e) Provide estimates, using one or another of the schemes described in Section 6 , for rate data for reactions that

(1) are not covered in a satisfactory manner in current evaluations, 
(2) have not been studied,

(3) are judged not to be important,

or,

(4) are needed only for screening purposes.

(f) Start a chemical kinetics measurement program that

emphasizes.

(1) reactions of major importance for which accurate data are mandatory,

(2) gaps in the data base, extension and refinement of predictive schemes and correlations.

(g) Publish and distribute the tables of data and the catalog of reactions of interest.

Second and subsequent rounds

(h) Reanalyze the field to determine new problems of interest. This is to be done working with selected users of the data.

(i) Expand the catalog of reactions and annotate it to indicate those reactions for which the data are in reasonable shape and those for which new measurements are needed.

(j) Compile and evaluate measurements for important reactions not satisfactorily treated in the earlier rounds.

(k) Make new measurements as needed for major reactions, to fill gaps and improve predictions.

(1) Estimate rate data for newly added, less important reactions.

(m) Publish and distribute an up-dated chemical kinetics data base and catalog of reactions.

\subsubsection{Comments}

(a) Combustion is a very broad, applied subject. It has been the subject of much research. Other sections of this report show 
the need for more combustion oriented research. This means that not all the goals addressed by the tactics described above will be reached in the near future. A combustion kinetics data base will be dynamic. It will change as new more accurate data become available, as new interpretations of older data come to light, and as new data needs are defined.

(b) Because combustion is a very large subject, it is unlikely that one laboratory could or will provide all the needed data for the many problems within a reasonable time-frame. Cooperative progress of measurement and data evaluation are desirable. The tactics described in the preceding section are a suitable guide for a funding agency in planning its overall program in the area of kinetics.

(c) Combustion is an applied subject. Measurements and data evaluation programs should have built into them feedback from the users. This will keep current work in line with current problems and those extensions likely to become important in the next few years.

(d) Experience with the development of a kinetics data base for atmospheric pollution studies showed that tables of rate data (and possibly other physical properties) were sufficient. The user group included chemists who decided what mechanisms were appropriate for particular problems. This probably is true for the field of combustion. If it is not true, it will become necessary to supplement the data base with mechanistic information.

7.3 Pyrolysis and Hydrogen Atom Chemistry

One class of experiments that is immediately applicable to the measurement of high temperature data is based on shock tube techniques. They yield comparatively accurate results and provide the easiest means of generating combustion and pyrolysis temperatures and pressures. 
Shock tubes have been used for over 75 years as a means of producing high temperatures. The basic apparatus and process can be seen in figure 7.1. The procedure consists of separating two sections of a closed tube by a diaphragm, one side of which is maintained at high pressure (driver) while the other side containing the test gas is at a lower pressure. When the diaphragm is ruptured a shock wave propagates through the test gas, bringing about a sudden increase in temperature. Upon reflection of the shock wave by the end wall a further increase in temperature can be achieved. The physical condition of the shocked gas is relatable to the shock velocity if ideal gas dynamic behavior is assumed. This is a pulse technique. The advantages are that extreme condition can be achieved without consideration of material stability. Since the reaction time is short, reactions are truly homogenous and much less sensitive to impurity effects. The course of the reaction can be followed either by kinetic spectroscopy or, through the use of a single pulse shock tube (see figure 7.2 ), by classical analytical techniques such as gas chromatography. The latter is capable of detecting only stable products. On the other hand with kinetic spectroscopy one can follow only one or two transient species simultaneously. The real need is for the meshing of both techniques. The principal problem in shock tube studies is the pulse nature of the excitation. Thus for the detection of transients one cannot use signal averaging techniques. There is also the uncertainty with regard to the calculated reaction temperature. This can be circumvented by the use of an internal standard. Such a procedure has been successfully applied to the interpretation of single pulse shock tube experiments. Finally it should be pointed out that although the discussion or shock tube techniques 
是
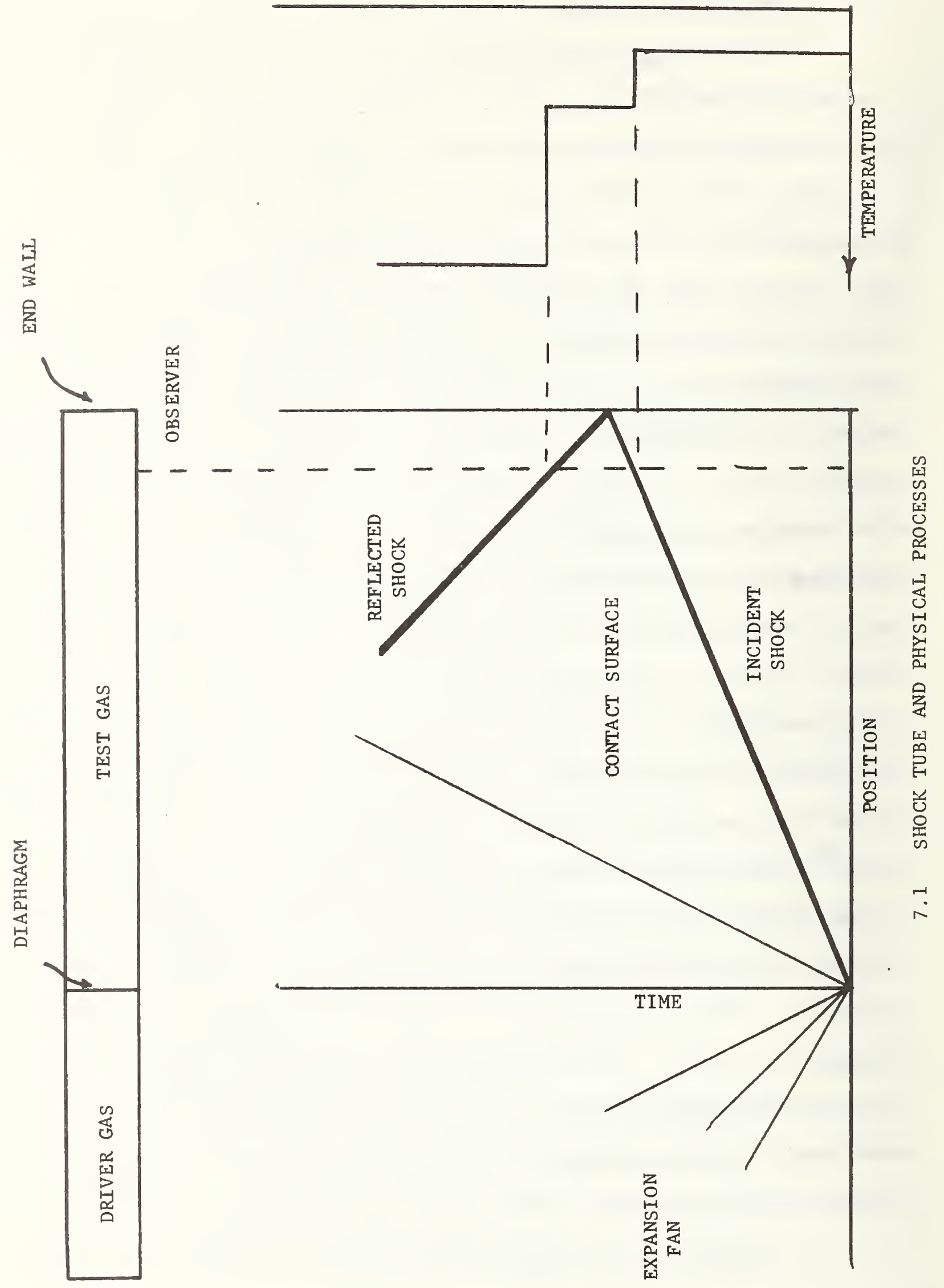


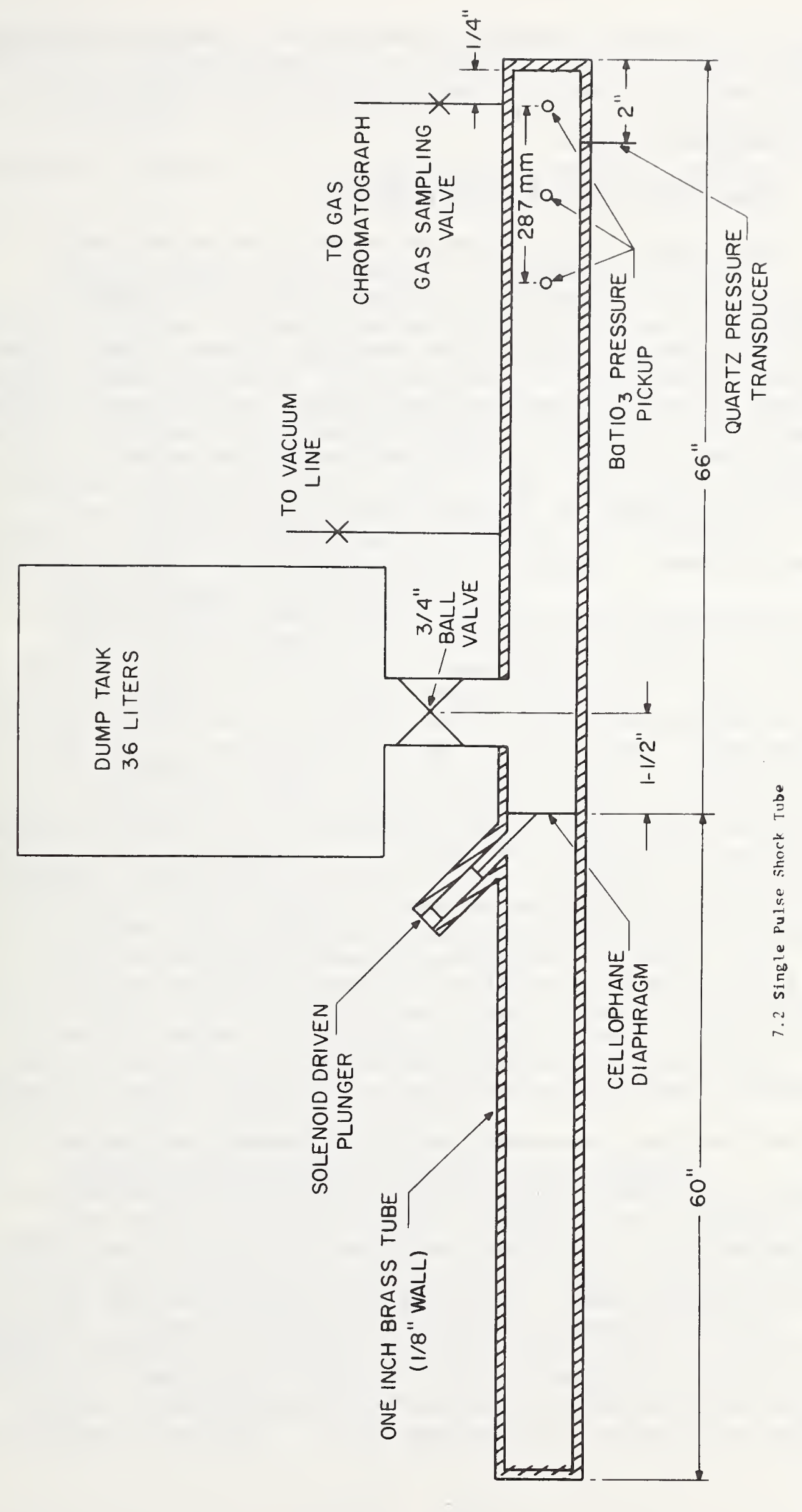


is focused on the study of pyrolytic decompositions involving hydrocarbon compounds, there is no reason why the technique cannot be applied to oxidation processes as well.

\subsubsection{Single Pulse Shock Tube Experiments}

The earlier work on the mechanism and rates of the initial steps in hydrocarbon decomposition provides a base for the study of several of the subsequent steps in the pyrolytic process. These include the reactions of hydrogen atoms with hydrocarbons and the thermal decomposition isomerization and cyclization of alkyl and unsaturated radicals. It is suspected that the former is of prime importance in pyrolytic and combustion processes. Hydrogen atoms are among the most important chain carriers in high temperature systems. This is due to their extreme reactivity. Of critical significance in the modeling of such systems is the relative importance of each of the multiplicity of reactive channels that are avaliable. The strategy will be to generate hydrogen atoms through the decomposition of a labile hydrocarbon and by proper adjustments of concentrations to enable it to react with the appropriate substrates. The aim will be to establish the order of reactivity with respect to hydrogen atom abstraction from methyl, primary, secondary, tertiary, allylic, and other resonance stabilized groups; to compare the rate of these reactions with hydrogen additions to unsaturated systems (aromatic, olefinic and acetylenic compounds) and the development and testing of appropriate correlations. With respect to unimolecular decomposition of hydrocarbon radicals, the rationale and plan of attack will be similar to that for hydrogen atoms. Once again, the processes are fast and the important factor is the identification of the important reaction channels. The radicals will, as before, be generated from appropriately labile 
hydrocarbons. Concentrations will be adjusted so that the newly formed radicals will undergo only unimolecular decompositions. Extensive gas chromatographic analysis will then pinpoint the important reaction paths.

Finally there is the necessity of completing the work on hydrocarbon pyrolyses. As mentioned before this involves the mechanism and rates of decomposition of cyclic alkenes. Although this has been neglected in the past, no serious experimental problems are anticipated. It is expected that several cyclic pentyl, hexyl, and bicyclic compounds will need to be studied before general trends can be established. 7.3.3 Heated Single Pulse Shock Tube:

The experimental program outlined above is limited to studies of the kinetic properties of volatile organic compounds. This is a serious limitation if one wishes to study the full range of substances that are of importance as fuels and feedstocks. Thus at some stage of the program it will be necessary to extend the experimental capabilities by constructing a heated shock-tube, and the analytical capabilities by the use of gas chromatographic-mass spectrographic detection. The immediate targets are the complex aromatic and heterocyclic compounds. Such a facility will be an absolute necessity for the study of the oxidation reactions of complex hydrocarbons. 7.3.4 Studies Using Shock Tube for Kinetic Spectroscopy

This facility will be needed to complement and supplement the single pulse shock tube work. The limitation of the latter is that it cannot handle reactions with small temperature dependences or slow bimolecular or termolecular reactions. This encompasses the whole range of recombination reactions. As mentioned earlier, these are the elementary 
steps in the chain reaction and there is a great need for data at combustion temperatures. Rate constants that need to be measured are recombination rates of $\mathrm{CH}_{3}+\mathrm{CH}_{3}$; resonance stabilized radicals $+\mathrm{CH}_{3}$, resonance stabilized radicals + resonance stabilized radicals, and organic radicals $+\mathrm{H}$. Another avenue of research is the reactions of organic radicals with hydrocarbon substrates. These are important chain transfer steps in thermal decomposition processes. It should be noted that kinetic spectroscopy is the traditional means of doing kinetics with a shock tube. Thus no breakthroughs in technology are involved. The only new features in this program are the application to larger molecules and the use of some of the spectrocopic and instrumental techniques that have been developed in recent years for kinetic spectroscopy.

\subsubsection{Studies of Global Kinetics}

We now turn to other pertinent application of the results of the research program outlined above. In particular we will want to join this data with appropriate kinetic models so as to simulate realistic processes. For the present purposes a particularly relevant problem is the cracking of naphtha. The industrial process involves passing the naphtha in steam through hot tubes and cracking the large organic molecules into smaller olefins and various other products. It thus lends itself admirably to bench scale experimental work. Such data can than be used to experimentally verify the prediction of appropriate models or from another point of view to "fine tune" the models. The ultimate long range aim is to define the optimum conditions for the production of desired mixtures of products as a function of initial hydrocarbon concentration. For the more immediate future the aim will 
be to begin an experimental and modeling program on the pyrolysis, first of various intermediate sized straight chained hydrocarbons such as, hexane, octane, etc. This will be followed by studies on the effect of side chains, cyclization and aromatization. At the same time the study of mixtures will be slowly phased in. It should be noted that even the study of the decomposition of individual hydrocarbons are of potential industrial significance since there have been proposals to separate the components of the naphtha prior to cracking. Finally it must be emphasized that this proposal as the others do not require any breakthrough in technology. Modeling and verification of the cracking of small compounds such as propane and butane has been carried out during the past several years. The present plan is thus a logical extension of the past work. 7.3.6 Detailed Plan

1a. Measure rates of hydrogen atom addition to saturated and unsaturated hydrocarbons using the existing shock tube facility.

1b. Measure rates of decomposition of hydrocarbon radicals with existing shock tube facility.

1c. Measure rates of decomposition of cyclic alkanes with existing shock tube faculty.

2a. Construct heated single pulse shock tube.

$2 b$. Measure rates of hydrogen atom reaction with aromatic and heterocyclic compounds.

2c. Measure rates of oxygen atom reaction with hydrocarbon substrates.

2d. Measure rates of hydroxyl radical reaction with hydrocarbon substrates.

3a. Construct shock tube for kinetic spectroscopy. 
3b. Measure rates of hydrocarbon radical recombination at elevated temperatures.

3c. Measure rates of hydrocarbon radical reactions with $\mathrm{O}_{2}$ and NO at high temperature.

4. Carry out experimental and modeling studies on hydrocarbon decomposition.

\subsection{Oxidation Processes}

In order to study reaction mechanisms and measure rate constants of oxidation processes at elevated temperatures, it is planned to adapt two successful experimental approaches for high temperature work. These are photoionization mass spectrometry, and flash photolysis resonance fluorescence.

\subsubsection{Photoionization Mass Spectrometry}

Mass spectrometry has been one of the most extensively and successfully applied methods for the study of elementary reactions. NBS has pioneered in the application of these techniques to high temperature studies, specifically as part of a long-range contribution to combustion chemistry. Recent advances in technique, including beam sampling mass spectrometers and photoionization mass spectrometers have been incorporated into the existing NBS experimental capabilities. The basic system is illustrated in Figure 7.3. As shown, it consists of a chemical reactor from which a sma11 fraction of the reacting gas flows through a "leak" into the first vacuum chamber. By means of a collimation cone, the central portion of that flow is selected and enters the second and third chambers as a molecular beam. The advantages of this method are that the reacting gases are "frozen" after passing through the leak, and the absence of wall collisions preserves the integrity of the sample. By chopping the beam mechanically and using phase sensitive detection, 


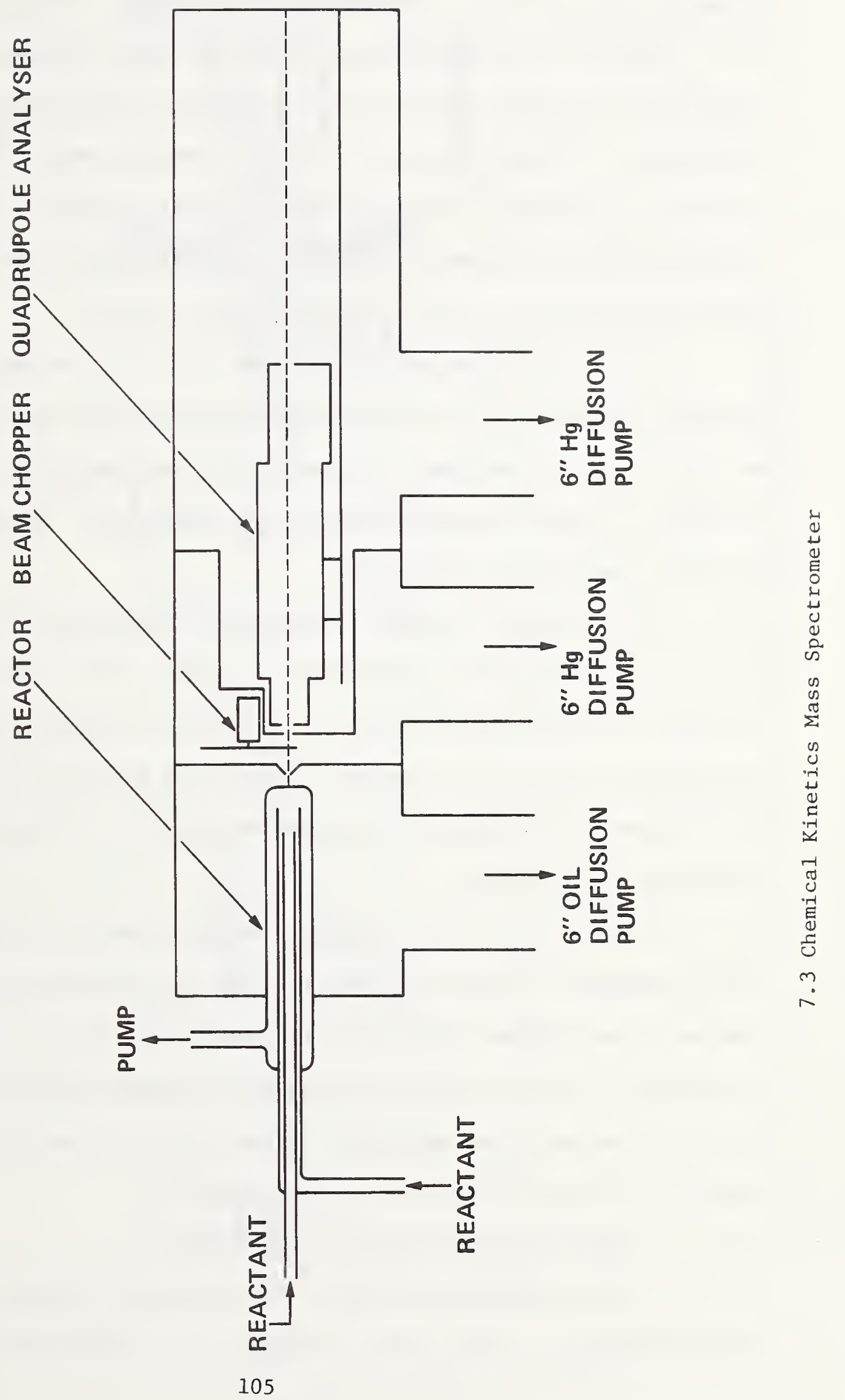


background contributions to the signal are minimized. The reactor may be of a variety of configurations. Figure 7.4 shows a temperature controlled flow reactor; Figure 7.5 a temperature controlled stoppedflow reactor. For high temperature studies reactors would be constructed of quartz and resistive electrical heating used. This will considerably extend the range of temperatures previously used in NBS studies of oxygen atom chemistry using borosilicate glass reactors.

The use of photoionization rather than electron impact ionization provides a powerful tool for the identification of free radicals, and the study of their reactions. The method has been applied by Bayes to the study of oxygen atom reactions at room temperature. Extension to very high temperatures is feasible.

In addition to studies using chemical reactors, crossed beam studies will be employed to determine the nature of the primary products in atomic and free radical reactions. The work of Gutman on oxygen atom and hydroxyl radical reactions with olefins is a beautiful demonstration of the power of the method. Here again extension to very high temperatures is feasible and desirable.

In addition to the approaches outlined here, there are several other techniques of proven reliability which can be adapted and greatly expanded in application through coupling to a photoionization mass spectrometer. These include flash photolysis, mercury photosensitized photolysis and modulated photolysis. These are a11 potentially powerful methods for studying kinetics at high temperature.

7.4.2 Flash Photolysis Resonance Fluorescence

This technique, developed at NBS, is one of the most accurate methods available for the study of atomic and free radical kinetics. A 


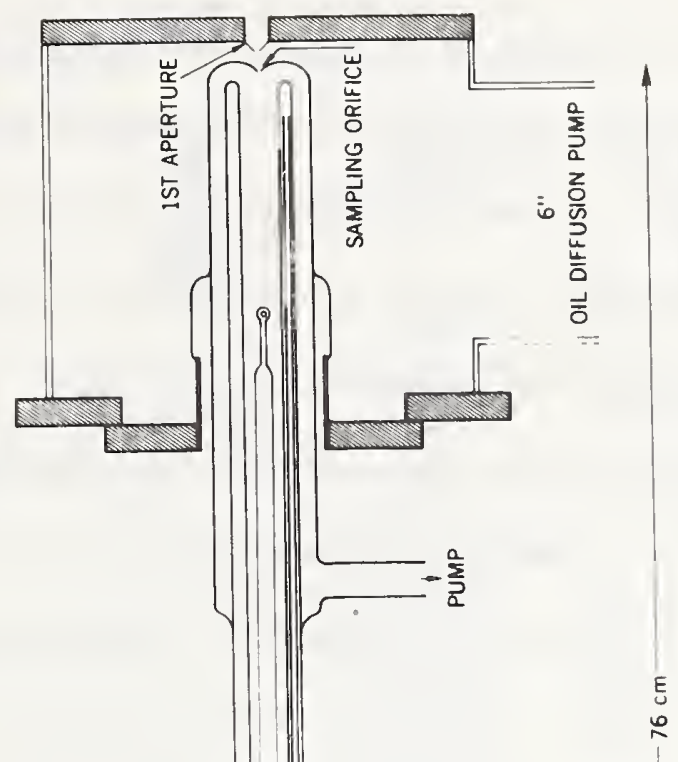

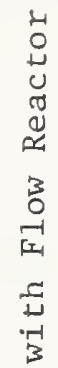

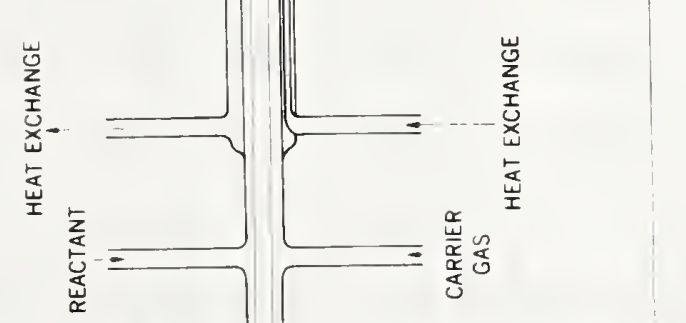

क्

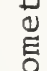

논

芩

里

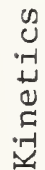

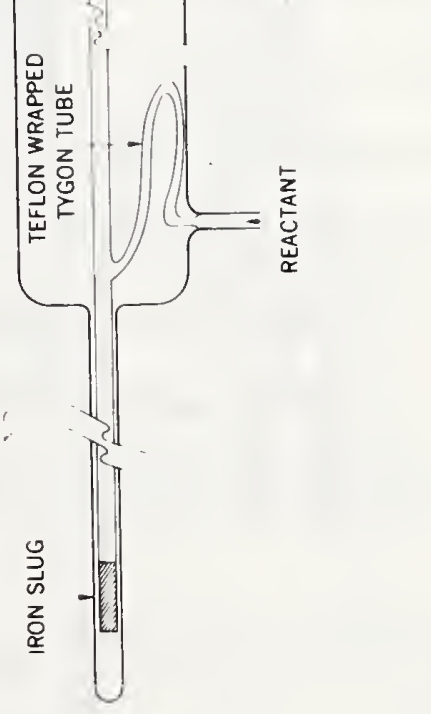

告

$\stackrel{r}{r}$ 


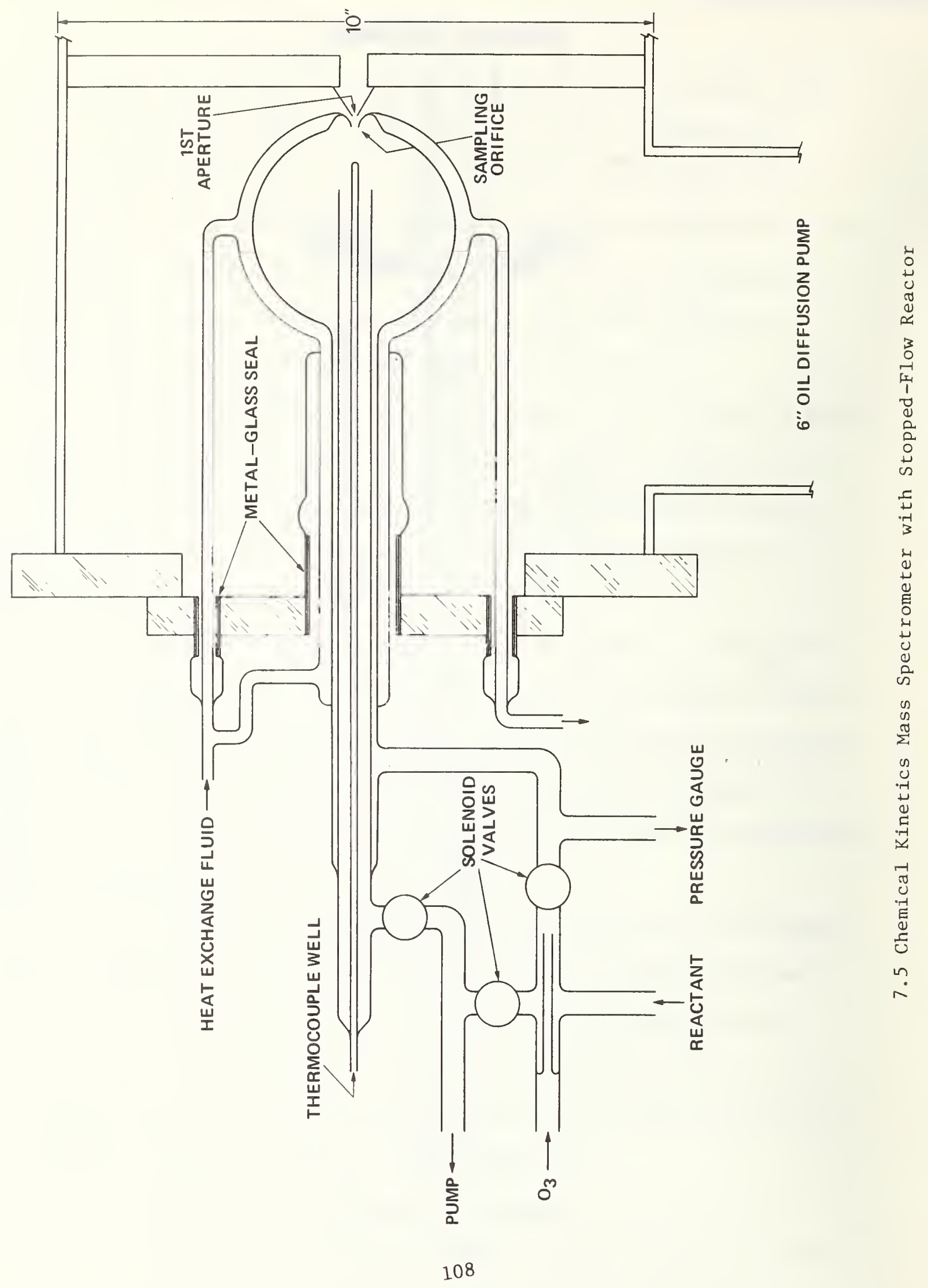


typical experimental arrangement is shown in Figure 7.6. The atom or free radical under study is produced by flash photolysis of a suitable source compound. The reaction cell is irradiated with resonance radiation which excites the reactant species into an upper state from which it fluoresces. The rate at which the fluorescence decays is a direct measure of the time dependence of the atom or radical concentration, and hence, a measure of the rate of decay of the reactant.

The maximum temperature accessible at present is about $700 \mathrm{~K}$, primarily because of limitations on the design of the optical windows of the reaction cell. Extension to much higher temperatures will require redesign of the apparatus to protect the windows from high temperature and from condensation of high temperature species. Success in this endeavor would represent a major breakthrough in high temperature chemical kinetics.

\subsubsection{Detailed P1an}

This plan consists of three lines of work which will parallel and overlap to some extent depending on level of effort.

1a. Design and construct a quartz flow reactor to be used in conjunction with the photoionization mass spectrometer.

1b. Measure the rate constant for the reactions of molecular oxygen with methy1 and other selected alky1 radicals.

2a. Design and construct a high temperature crossed nozzle beam apparatus for use in conjunction with the photoionization mass spectrometer.

2b. Study the mechanism of reaction of molecular oxygen with methyl and other selected alky1 radicals.

2c. Study the mechanism of reaction of atomic oxygen with alkanes, alkenes, and acetylene at different temperatures. 


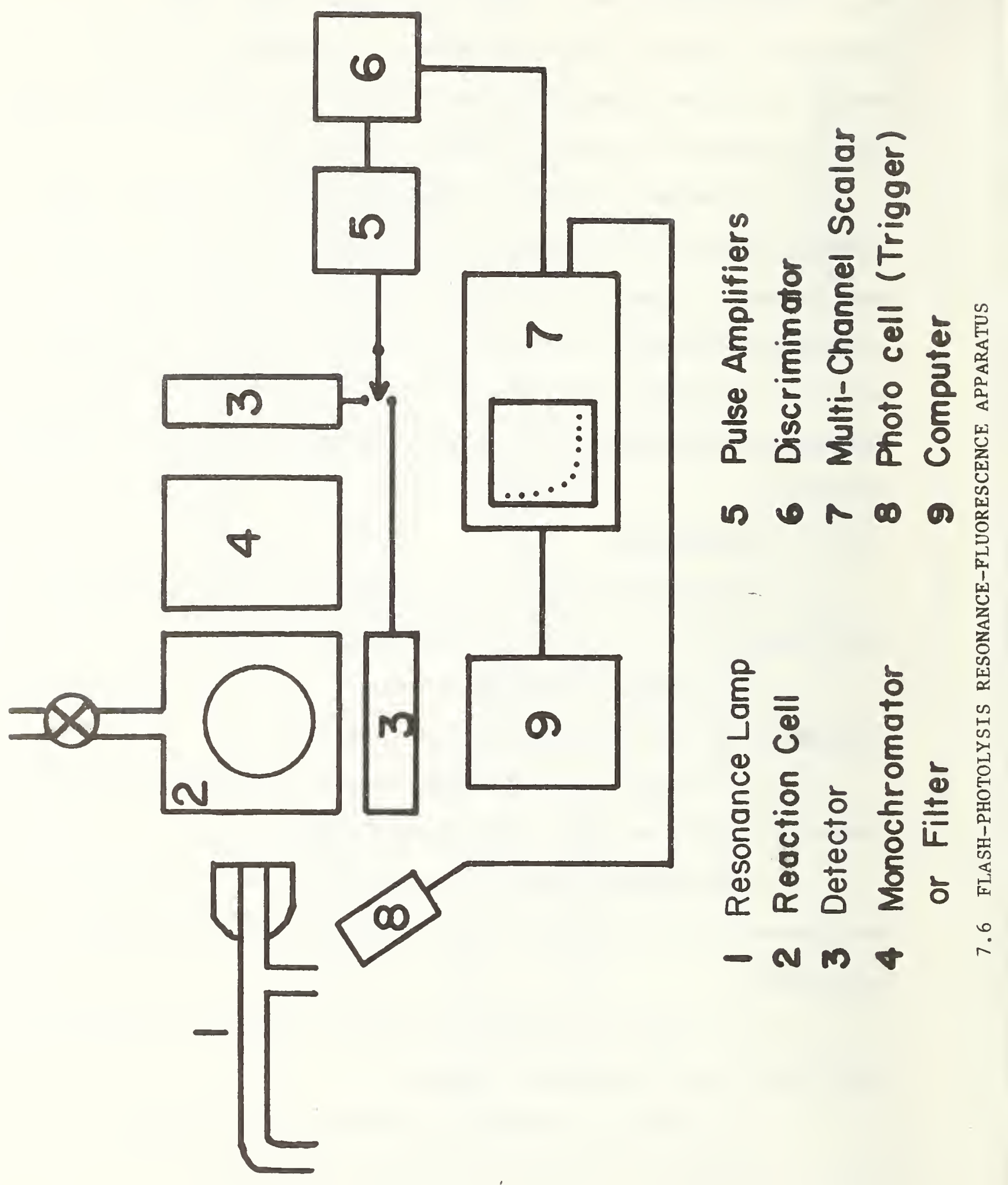


2d. Study the mechanism of reaction of hydroxyl radicals with alkanes, alkenes and acetylene at different temperatures.

3a. Design and construct high temperature photolysis cells for use in flash photolysis resonance fluorescence studies, or in conjunction with the photoionization mass spectrometer. Construct a flash photolysis resonance fluorescence apparatus.

3b. Measure the rate constants for the reactions of atomic oxygen with methane and selected alkanes.

3c. Measure the rate constants for the reactions of atomic oxygen with ethylene, acetylene, and selected alkenes.

3d. Measure the rate constants for the reactions of hydroxyl radicals with methane and selected alkanes.

3e. Measure the rate constants for the reactions of hydroxyl radicals with ethylene, acetylene, and selected alkenes.

\subsection{Pollutant Forming Processes}

The two principal classes of pollutants formed in combustion are the oxides of nitrogen and sulfur. We recommend the following program to elucidate the mechanisms whereby these oxides are formed, using experimental approaches described in 7.2 .

1. Study the mechanism of formation of nitric oxide in combustion arising both from fixation of atmospheric nitrogen, and from fuel nitrogen.

2. Study the mechanism of formation of oxides of sulfur in the combustion of sulfur containing fuels. 7.6 Scale and Scope of the Recommended Program The program of activities recommended above implies a substantial manpower commitment. An appropriate NBS manpower commitment would 
consist of 5-10 man year per year effort for up to five years. A more detailed outline of an appropriate NBS program will be submitted separately.

It should be noted that a certain amount of pertinent kinetics data will also be developed by workers outside NBS. The recommended program is so designed that the results of those activities will be incorporated into the data base in very effective fashion. Also the publication of successive editions of the body of data will be a positive force in guiding outside work towards the most effective contribution to this problem area. 


\section{Acknowledgment}

We are grateful to the Combustion Institute for permission to reproduce Table 4.2 and Figures 6.1 and 6.2 . 
List of organizations known to be carring on modeling of combustion, flames, turbines, engines, rockets, and chemical reactors.

\section{Organization}

Acurex Corp.

Aerochem Corp.

Bell Aerospace Co.

Creare Inc.

Exxon Research and Engineering Co.

Ford Motor Co.

General Applied Science Laboratories

General Electric Co.

General Motors

IKOR, Inc.

KVB Engineering Co.

Phillips Petroleum Co.

Ultrasystems Inc.

United Aircraft

Westinghouse

In addition to the companies carrying on this work, there is a comparable effort in engineering schools. It is recognized that there are strong interactions between engineering schools and industry through consulting activities.

$\underline{\text { Schools }}$

California State University, Northridge

Caltech 
Princeton

Purdue University

University of California, Berkely

University of Pennsylvania

University of HIsconsin

Washington State University

Government Laboratories and Private Research Institutions

Battelle

Bureau of Mines, Pittsburgh

Lawrence Livermore Laboratory

NBS

[In addition to the companies mentioned above, sixty-five other companies appear to be sufficiently interested in the combustion area to sponsor the 14th Annual Symposium on Combustion.]

The above listing includes only US organizations. There is a comparable number of similar organizations elsewhere.

It should be noted that there is at least a comparable number of groups carrying out experimental work on prototype systems of all types. 
NBS-114A (REV. 7.73)

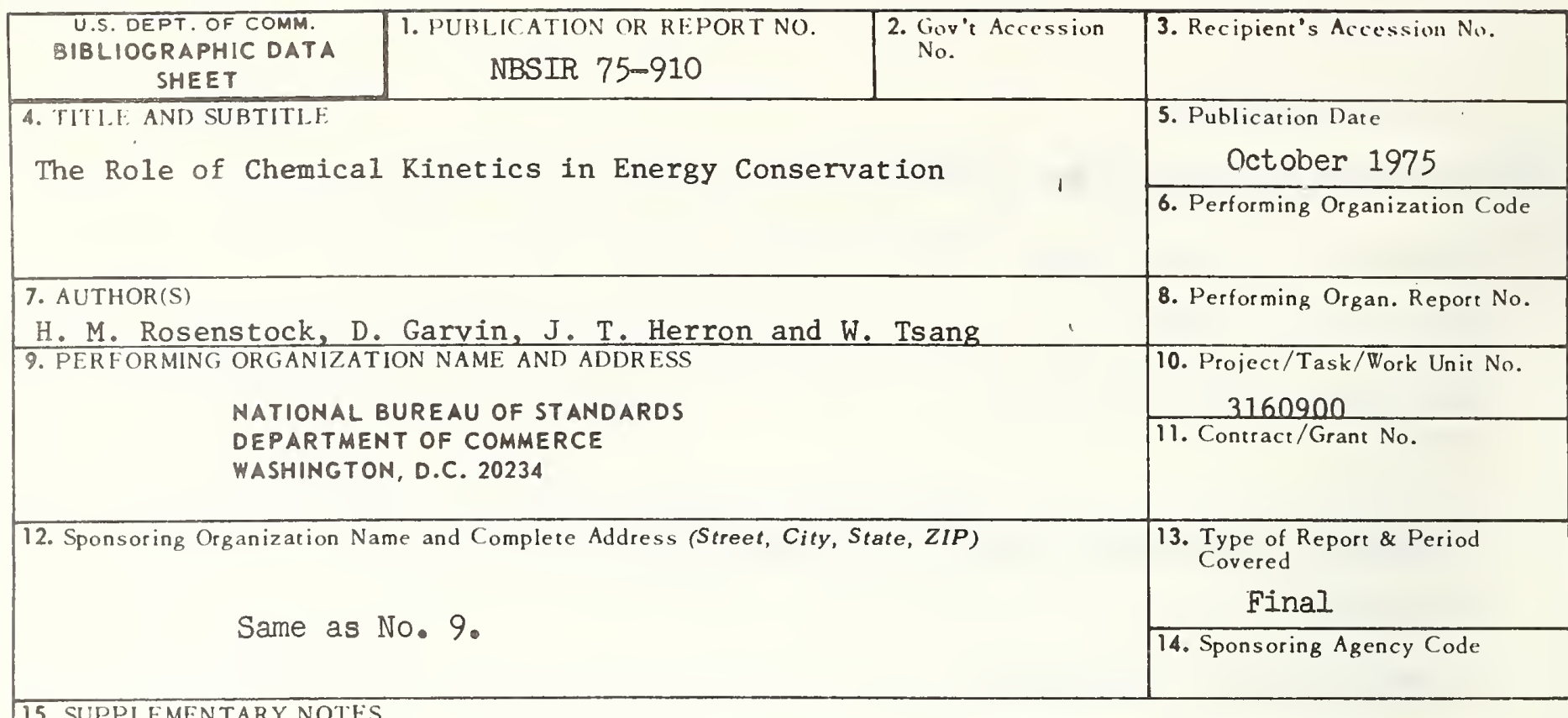

15. SUPPI.EMENTARY NOTES

16. ABSTRACT (A 200-word or less factual summary of most significant in formation. If document includes a significant bibliography ot literature survey, mention it here.)

Many of the technological areas of pertinence to energy independence involve chemical transformation of gas phase materlals at high temperatures. The design, control and optimization of such devices and processes have come to depend increasingly on mathematical modeling. Among the most important input data required for there models are information on the detalled chemical mechanisms and the rates of the individual processes. It is concluded that although many resources are avallable there does not exist at present an adequate, publicly avallable data base for the modeling of high temperature systems. A detalled program involving a combination of experimentation and compllation, evaluation and dissemination of gas kinetic data is proposed.

17. KEY WORDS (six to twelve entries; alphabetical order; capitalize only the first letter of the first key word unless a proper name; separated by semicolons)

Combustion; kinetics; pyrolysis; oxidation; data base; modeling; estimation schemes; energy conservation

18. AVAILABILITY [ Unlimited

For Official Distribution. Do Not Release to NTIS

[ Order From Sup. of Doc., U.S. Government Printing Office Washington, D.C. 20402, SD Cat. No.C13

X Order From National Technical Information Service (NTIS) Springfield, Virginia 22151

\begin{tabular}{|l|c|}
\hline $\begin{array}{l}\text { 19. SECURITY CLASS } \\
\text { (THIS REPURT) } \\
\text { UNCL ASSIFIED }\end{array}$ & 21. NO. OF PAGES \\
\hline $\begin{array}{l}\text { 20. SECURITY CLASS } \\
\text { (THIS PAGE) } \\
\text { UNCLASSIFIED) }\end{array}$ & $\begin{array}{l}22 . \text { Price } \\
\$ 5.50\end{array}$ \\
\hline
\end{tabular}



